\title{
Estudo e implementação de um método de restrições ativas para problemas de otimização em caixas
}

\author{
Jan Marcel Paiva Gentil
}

\author{
DisSERTAÇÃO APRESENTADA \\ $\mathrm{AO}$ \\ Instituto DE MATEMÁtica E EstatísticA \\ DA \\ Universidade DE SÃO PAUlo \\ PARA \\ OBTENÇÃO DO TÍTULO \\ $\mathrm{DE}$ \\ Mestre em CiênCIAS
}

Programa: Ciência da Computação Orientador: Prof. Dr. Ernesto G. Birgin

O autor recebeu apoio financeiro da FAPESP, sob o processo número 07/56645-9, para a elaboração deste trabalho.

São Paulo, agosto de 2010 


\title{
Estudo e implementação de um método de restrições ativas para problemas de otimização em caixas
}

\author{
Esta versão definitiva da dissertação \\ contém as correções e alterações sugeridas pela \\ Comissão Julgadora durante a defesa realizada \\ por Jan Marcel Paiva Gentil em 23/06/2010.
}

Comissão Julgadora:

Prof. Dr. Ernesto Julián Goldberg Birgin (Presidente) - IME-USP

Profa. Dra. Marina Andretta - ICMC-USP

Prof. Dr. José Mario Martínez Perez - UNICAMP 
À memória de meu avô Gentil, quem primeiro semeou em mim o prazer da busca pelo conhecimento. 


\section{Agradecimentos}

A meus pais, Agostinho e Janete, cujo amor inesgotável provê inabalável arrimo capaz de me escorar diante de desafios impostos. Sua grandeza de espírito e caráter notearam cada um dos passos que me trouxeram até aqui.

A meu orientador, Prof. Ernesto Birgin, que epitoma com plenitude todas as interpretações evocadas pelo conceito de mentor. Imensurável é o aprendizado com que me beneficiei em quatro anos sob sua tutelagem.

A meu estimado amigo Marcio Silva, que se mostra invarialvemente capaz de despertar minha admiração nos mais diversos âmbitos. Sinto-me mais que honrado por ser merecedor de tão valiosa amizade.

À Dra. Dilma da Silva, pesquisadora de excelência, que promoveu e orientou meu estágio na IBM RESEARCH. Os frutos proporcionados por essa ímpar experiência estão sendo colhidos até hoje em minha vida.

A meu querido amigo Daniel Cordeiro, a quem devo nada menos que o despertar para

a beleza da Ciência da Computação. É com muito orgulho que me valho de tê-lo como baliza na vida acadêmica que começo a construir.

Aos professores Carlos Eduardo Ferreira, Paulo Feofiloff e Roberto Hirata Jr., que ocuparam papel central em minha formação no IME. Não me perdoaria por perder uma oportunidade sequer de agradecê-los por suas atuações como professores, educadores e, ainda que involuntariamente, modelos em que me inspirar.

A meu inseparável amigo Christian Tjandraatmadja, com quem convivi diariamente e, mais que isso, compartilhei a maior parte das felicidades e desaventuras que se permearam por nossas vidas escolares nos últimos oito anos. Dono de inexaurível paciência, copiosa sabedoria e impressionante clareza de raciocínio, não deixa dúvidas de que sua fiel companhia tornou tais experiências ainda mais engrandecedoras. 


\section{Resumo}

Problemas de otimização em caixas são de grande importância, não só por surgirem naturalmente na formulação de problemas da vida prática, mas também por aparecerem como subproblemas de métodos de penalização ou do tipo Lagrangiano Aumentado para resolução de problemas de programação não-linear. O objetivo do trabalho é estudar um algoritmo de restrições ativas para problemas de otimização em caixas recentemente apresentado [39] chamado ASA e compará-lo à versão mais recente de GENCAN [10], que é também um método de restrições ativas. Para tanto, foi elaborada uma metodologia de testes robusta e minuciosa, que se propõe a remediar vários dos aspectos comumente criticados em trabalhos anteriores. Com isso, puderam ser extraídas conclusões que levaram à melhoria de GENCAN, conforme ficou posteriormente comprovado por meio da metodologia aqui introduzida.

Palavras-chave: programação não-linear, otimização em caixas, método de restrições ativas. 


\section{Abstract}

Box-constrained optimization problems are of great importance not only for naturally arising in several real-life problems' formulation, but also for their occurrence as subproblems in both penalty and Augmented Lagrangian methods for solving nonlinear programming problems. This work aimed at studying a recently introduced active-set method for box-constrained optimization called ASA and comparing it to the latest version of GENCAN [10], which is also an active-set method. For that purpose, we designed a robust and thorough testing methodology intended to remedy many of the widely criticised aspects of prior works. Thereby, we could draw conclusions leading to GENCAN's further development, as it later became evident by means of the same methodology herein proposed.

Keywords: nonlinear programming, box-constrained optimization, active-set methods. 


\section{Sumário}

1 Introdução 1

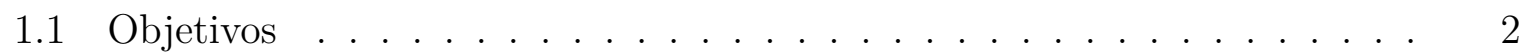

1.2 Organização da Dissertação . . . . . . . . . . . . . . . . . . 3

2 Métodos de Restrições Ativas 4

2.1 Evolução Histórica . . . . . . . . . . . . . . . . . . . . . . . 4

2.2 Conceitos Fundamentais . . . . . . . . . . . . . . . 5

2.3 Gradientes Conjugados . . . . . . . . . . . . . . . . . . . 6

3 Algoritmos Estudados $\quad 8$

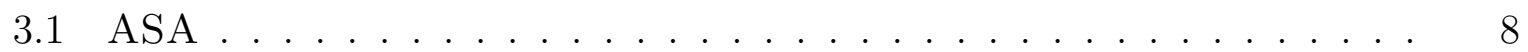

3.1.1 Algoritmo de Gradiente Projetado Não-Monótono . . . . . . . . . 8

3.1 .2 Método de Restrições Ativas . . . . . . . . . . . . . . . . . . . 10

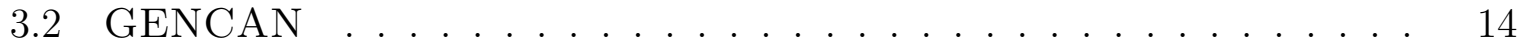

3.2.1 Algoritmo de Minimização Irrestrita . . . . . . . . . . . . . . . 14

3.2 .2 Método de Restrições Ativas . . . . . . . . . . . . . . . . . . 16

4 Metodologia de Testes $\quad 18$

4.1 Métrica de Comparação . . . . . . . . . . . . . . . . . . 18

4.2 Critérios de Parada . . . . . . . . . . . . . . . . . . . . 23

4.3 Representação de Resultados . . . . . . . . . . . . . . . . . . . . . 23 
4.4 Experimentos Numéricos Preliminares . . . . . . . . . . . . . . . 28

5 Aprimoramento de GENCAN 32

5.1 Algoritmo Empregado Internamente às Faces . . . . . . . . . . . . . . . . 32

5.2 Escalamento do Sistema Linear . . . . . . . . . . . . . . . . 37

5.3 Critérios de Parada Secundários . . . . . . . . . . . . . . 38

6 Experimentos Numéricos $\quad 40$

6.1 GENCAN versus ASA . . . . . . . . . . . . . . . . 40

6.2 GENCAN Antes versus Após Aprimoramento . . . . . . . . . . . . 43

6.3 GENCAN versus Outros Métodos . . . . . . . . . . . . . 47

$\begin{array}{lll}7 & \text { Conclusão } & 58\end{array}$

7.1 Contribuições . . . . . . . . . . . . . . . . . . 58

$\begin{array}{ll}\text { Referências Bibliográficas } & 62\end{array}$ 


\section{Lista de Figuras}

4.1 Gráficos do erro relativo de $t$ obtido para valores crescentes de $\eta$ com seis problemas de teste . . . . . . . . . . . . . . . . . 22

4.2 Gráficos de perfil de desempenho de ASA e GENCAN para diferentes critérios de convergência . . . . . . . . . . . . . . . 27

4.3 Gráficos de perfil de desempenho de ASA e GENCAN com o tempo de processamento consumido como medida de comparação empregada . . . .

5.1 Gráficos de perfil de desempenho dos possíveis algoritmos internos usados

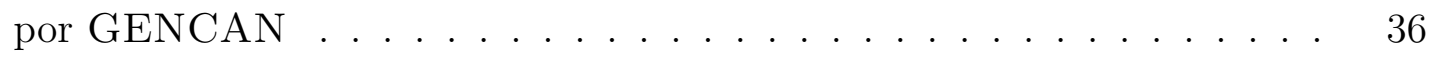

5.2 Gráfico de perfil de desempenho de duas implementações de GENCAN . 38

6.1 Gráficos de perfil de desempenho de ASA e GENCAN . . . . . . . . . . 42

6.2 Gráficos de perfil de desempenho das versões antiga e nova de GENCAN 45

6.3 Gráficos da variação de eficiência dos diversos métodos testados . . . . . 50

6.4 Gráficos da variação de robustez dos diversos métodos testados . . . . . . 52

6.5 Gráficos de perfil de desempenho dos diversos métodos testados . . . . . 57 


\section{Lista de Tabelas}

4.1 Tolerâncias utilizadas na definição de equivalência das soluções devolvidas por cada algoritmo . . . . . . . . . . . . . . . 26

4.2 Mínimo, máximo, mediana e primeiro e terceiro quartis do número de variáveis e do número de restrições de caixa dos problemas considerados em experimentos numéricos f . . . . . . . . . . . . . . . . . 28

4.3 Contagem de instâncias para as quais cada método satisfaz ao critério de convergência . . . . . . . . . . . . . . . . . . . 30

4.4 Contagem de instâncias para as quais cada método obtém uma solução ótima 31

5.1 Características de prevalência de cada possível algoritmo interno usado por GENCAN no que diz respeito ao grau de complexidade de manipulação da matriz Hessiana . . . . . . . . . . . . . . . . . . . . . . 34

6.1 Contagem de instâncias para as quais cada método satisfaz ao critério de convergência . . . . . . . . . . . . . . . . . . . . . . . . . . 42

6.2 Contagem de instâncias para as quais cada método obtém uma solução ótima 43

6.3 Contagem de instâncias para as quais a execução findou por um dado motivo 46

6.4 Contagem de instâncias para as quais cada método obtém uma solução ótima 46

6.5 Valores de eficiência e robustez dos diversos métodos testados . . . . . . 53 


\section{Lista de Algoritmos}

3.1 Algoritmo empregado por ASA na etapa de projeção do gradiente (NGPA) 9

3.2 Descrição de ASA em pseudo-código . . . . . . . . . . . . . . . . . 13

3.3 Algoritmo de minimização irrestrita empregado por GENCAN . . . . 16

3.4 Algoritmo empregrado por GENCAN para abandonar uma face (SPG) $\quad 17$ 


\section{Capítulo 1}

\section{Introdução}

O problema considerado neste trabalho é

$$
\text { minimizar } f(x) \text { sujeito a } x \in \Omega \text {, }
$$

em que

$$
\Omega=\left\{x \in \mathbb{R}^{n} \mid l \leq x \leq u\right\},
$$

com $l, u \in \mathbb{R}^{n}, l \leq u$ e $f: \mathbb{R}^{n} \rightarrow \mathbb{R}$ continuamente diferenciável.

O problema de minimizar uma função contínua com restrições em suas variáveis possui muitas aplicações práticas. Entre elas, destacam-se o problema do obstáculo [43], o problema da torção [30], a estimação de constantes óticas de filmes finos [8], problemas de inversão em propagação de ondas elásticas [6] e a análise conformacional molecular [31].

O problema (1.1) também ocorre como um subproblema de métodos do tipo Lagrangiano Aumentado ou de penalização durante a resolução de problemas de otimização mais gerais (veja [18,19,26-29,33,34,42]). Assim, o desenvolvimento de algoritmos que o resolvam com eficiência, principalmente em grandes dimensões, é importante não só sob o ponto de vista teórico, mas também sob o aplicado.

A atenção deste trabalho concentra-se em métodos de restrições ativas, cuja eficiência tem sido destacada em artigos recentes (como $[9,10,14])$. Em um método de restrições ativas, o domínio do problema é particionado em faces disjuntas. A cada iteração, um teste apropriado avalia se é conveniente ficar na face atual ou abandoná-la. Quando a decisão é por permanecer, um algoritmo de minimização irrestrita (o "algoritmo interno") é utilizado, considerando apenas as variáveis que estejam livres em tal face. Iterações do algoritmo de minimização irrestrita são executadas enquanto não for encontrado um ponto da borda ou um critério de abandonar a face não for satisfeito. 


\subsection{Objetivos}

Este trabalho foi motivado por um artigo recente de Hager e Zhang [39] em que foi introduzido um método de restrições ativas denominado ASA. Ele consiste em uma etapa de projeção de gradiente não-monótono, uma etapa de otimização irrestrita e um conjunto de regras para se alternar entre elas. No artigo foi estabelecida convergência global a um ponto estacionário e uma implementação foi apresentada utilizando um algoritmo de Barzilai-Borwein cíclico (CBB), recém desenvolvido pelos mesmos autores [21], na etapa de projeção do gradiente e o algoritmo de gradientes conjugados CG_DESCENT, também recente e de mesma autoria [35-38], para a etapa de otimização irrestrita.

GENCAN [10] é também um método de restrições ativas, que por sua vez utiliza a técnica de gradiente espectral projetado para deixar uma face e uma abordagem de Newton truncado como algoritmo interno em sua implementação proposta. Comparações numéricas realizadas pelos autores de ASA indicaram que seu método possui melhor desempenho que GENCAN, promovendo a motivação necessária à realização deste trabalho. Assim, o objetivo inicial foi estudar o método ASA, repetir os experimentos numéricos relatados (porém agora comparando-o à versão mais recente de GENCAN) e, finalmente, investigar aprimoramentos que conduzissem a uma melhoria na execução do segundo. Esperava-se também distinguir classes de problemas para as quais cada um deles se mostrasse mais eficiente que o outro e, com isso, implementar um método do tipo Lagrangiano Aumentado capaz de utilizar o mais adequado para resolução de subproblemas.

Ainda que os experimentos numéricos empreendidos no primeiro momento não apontassem na direção de uma superioridade de ASA, não se pôde deixar de levar em conta a maior taxa de satisfação a critérios de convergência apresentada por ele. As instâncias testadas nas quais apenas ASA se mostrava capaz de convergir a um minimizador local seriam a partir de então individualmente analisadas, na esperança de que GENCAN pudesse ter seu funcionamento ajustado e passasse a também atender ao critério de convergência em tais casos. Nesse momento, apresentou-se a necessidade de estipular uma metodologia de testes robusta e minuciosa, que permitisse depositar plena confiança nos resultados por meio dela coletados e, com isso, remediasse vários dos aspectos comumente criticados em trabalhos anteriores.

Uma investigação acerca dos problemas para os quais cada um dos métodos fora capaz de conduzir a melhores resultados que o outro se mostrou bastante reveladora - puderam ser implementadas modificações em GENCAN que sanassem as deficiências descobertas, conforme ficou posteriormente comprovado por meio da própria metodologia de testes introduzida. Isso posto, ganhou força o interesse pela implementação de novas abordagens 
utilizadas por GENCAN para se explorar uma face do conjunto viável, com especial atenção dada a BETRA [4], um algoritmo baseado no clássico método de regiões de confiança. Conseqüentemente, esforços foram despendidos na concepção de uma estratégia de escolha automática não mais entre as subrotinas de um método do tipo Lagrangiano Aumentado, mas sim entre os possíveis algoritmos internos usados por GENCAN, cuja nova versão pode ser usufruída por um método de Langrangianos Aumentados.

\subsection{Organização da Dissertação}

A organização da discussão de tais pontos nesta dissertação delineia-se da seguinte maneira. Por encerrarem tamanha importância ao desenvolvimento deste estudo, métodos de restrições ativas serão o assunto abordado do Capítulo 2. Um apanhado de sua evolução história será apresentado, seguido de uma análise mais precisa de seus conceitos fundamentais, com destaque ao papel ocupado por algoritmos de gradientes conjugados. O Capítulo 3 trata dos aspectos teóricos a respeito do funcionamento dos métodos ASA e GENCAN. Isso é feito com base na formalização apresentada sobre eles quando de sua publicação. Uma descrição da metodologia de testes desenvolvida e praticada consta no Capítulo 4, recebendo especial atenção os pontos que costumam ser alvo de mais questionamentos e críticas por parte da comunidade científica. Ao final desse capítulo serão expostos os resultados dos experimentos numéricos preliminares empreendidos. Seguese então, no Capítulo 5, uma minuciosa explanação das oportunidades de aprimoramento de GENCAN que se optou por explorar, bem como uma síntese de outras tentativas de melhoria praticadas. Finalmente, o Capítulo 6 concentra resultados empíricos que comprovam o ganho de desempenho obtido com a nova versão de GENCAN, não só se confrontado com sua versão anterior, mas também em relação a ASA. Ainda mais significativas são as comparações feitas com outros cinco dos mais reconhecidos e prestigiados métodos de otimização da atualidade, que encerram o capítulo. O Capítulo 7 conclui esta dissertação, sintetizando as principais contribuições deste trabalho. 


\section{Capítulo 2}

\section{Métodos de Restrições Ativas}

\subsection{Evolução Histórica}

Uma visão geral do desenvolvimento de métodos de restrições ativas é dada a seguir. Um artigo histórico é o publicado por Polyak em 1969 [44], que considera uma função de custo quadrática convexa. Um algoritmo de gradientes conjugados é empregado para explorar uma face do conjunto viável, ao passo que o método de gradiente descendente é utilizado para deixar uma face. Pelo fato de o algoritmo de Polyak adicionar ou descartar apenas uma restrição a cada iteração, Dembo e Tulowitzki propuseram [22] o método de projeção do gradiente conjugado (CGP), que poderia adicionar ou descartar várias restrições em uma mesma iteração. Posteriormente, Yang e Tolle [47] aprimoraram esse método de modo a obter parada em tempo finito, mesmo que o problema fosse degenerado em um minimizador local $x^{*}$, isto é, para algum $i, x_{i}^{*}=l_{i}$ ou $x_{i}^{*}=u_{i}$ e $\nabla f\left(x^{*}\right)_{i}=0$.

Outra variação do método CGP, para a qual há um rigorosa teoria de convergência, foi desenvolvida por Wright [46]. Moré e Toraldo [43] observam que, quando o método CGP parte de longe da solução, muitas iterações podem ser necessárias para identificar uma face apropriada em que operar. Portanto, propuseram usar o método de gradiente projetado para se identificar uma face adequada, seguido pelo método de gradientes conjugados para explorar essa face. O algoritmo apresentado, chamado GPCG, possui parada em tempo finito para problemas quadráticos não-degenerados. Mais recentemente, algoritmos adaptativos de gradientes conjugados têm sido desenvolvidos por Dostál [24,25] e Dostál, Friedlander e Santos [27] e possuem parada em tempo finito para uma função de custo estritamente convexa e quadrática mesmo que o problema seja degenerado. 


\subsection{Conceitos Fundamentais}

A idéia essencial de métodos de restrições ativas é particionar as restrições de desigualdade em dois grupos: o daquelas a serem consideradas ativas e o daquelas a serem tratadas como inativas. As restrições tidas inativas serão simplesmente ignoradas.

Considere o problema de

$$
\begin{array}{ll}
\text { minimizar } & f(x) \\
\text { sujeito a } & g(x) \leq 0,
\end{array}
$$

o qual, por simplicidade, supõe-se possuir apenas restrições de desigualdade.

As condições necessárias para solução desse problema são:

$$
\begin{aligned}
\nabla f(x)+\lambda^{T} \nabla g(x) & =0 \\
g(x) & \leq 0 \\
\lambda^{T} g(x) & =0 \\
\lambda & \geq 0 .
\end{aligned}
$$

Tais condições podem ser expressas de uma forma um tanto mais simples em termos do conjunto de restrições ativas. Seja $A$ o conjunto dos índices das restrições ativas, ou seja, $A$ é o conjunto de todos os $i$ tais que $g_{i}\left(x^{*}\right)=0$. Então as condições necessárias em (2.2) passam a ser:

$$
\begin{aligned}
\nabla f(x)+\sum_{i \in A} \lambda_{i} \nabla g_{i}(x) & =0 \\
g_{i}(x) & =0, \quad i \in A \\
g_{i}(x) & <0, \quad i \notin A \\
\lambda_{i} & \geq 0, \quad i \in A \\
\lambda_{i} & =0, \quad i \notin A .
\end{aligned}
$$

As duas primeiras linhas correspondem justamente às condições necesssárias do problema com restrições de igualdade obtido fazendo-se as restrições ativas valerem zero. Já a linha seguinte garante que as restrições de desigualdade sejam satisfeitas, enquanto que a imposição sobre o sinal dos multiplicadores de Lagrange faz com que cada restrição ativa deva estar ativa.

Fica claro que, se o conjunto das restrições ativas fosse conhecido, o problema original poderia ser substituído por seu correspondente com apenas restrições de igualdade. Alter- 
nativamente, suponha que um conjunto assim seja adivinhado e o problema com restrições de igualdade correspondente, resolvido. Então, se as outras restrições fossem satisfeitas e os multiplicadores de Langrange se mostrassem não-negativos, tal solução estaria correta.

A idéia dos métodos de restrições ativas é definir a cada passo do algoritmo um conjunto de restrições que será tratado como sendo o de restrições ativas. Esse conjunto é tomado como um subconjunto das restrições de fato ativas no ponto atual, de modo que tal ponto seja viável para o conjunto. O algoritmo, então, prossegue buscando, na face definida pelo conjunto de restrições escolhidas, por um ponto melhor. Em resumo, um método de restrições ativas consiste dos seguintes componentes: (i) determinação do conjunto atual como um subconjunto das restrições correntemente ativas, e (ii) mudança para um ponto melhor sobre a face definida pelo conjunto tomado.

Há diversos algoritmos usados para conduzir a procura por um ponto melhor na face definida. As propriedades de convergência assintótica dos métodos de restrições ativas dependem inteiramente desses algoritmos, já que próximo à solução o conjunto de restrições tomado é geralmente igual ao conjunto de restrições ativas verdadeiro, cabendo ao método simplesmente mover-se sucessivamente na face determinada por elas.

Estando evidente que o componente fundamental de métodos de restrições ativas é o algoritmo que resolve um problema com somente restrições de igualdade, um dos mais importantes métodos para isso será discutido na seção seguinte.

\subsection{Gradientes Conjugados}

Conforme descrito em [41], métodos de direções conjugadas podem ser tidos como sendo intermediários entre o método de máxima descida e o de Newton. São motivados pelo desejo de se acelerar a taxa de convergência tipicamente lenta associada ao de máxima descida, ao mesmo tempo em que evitam as necessidades advindas do cômputo, armazenamento e inversão da Hessiana (ou ao menos a resolução do sistema de equações lineares correspondente), como se faz preciso pelo método de Newton.

Métodos de direções conjugadas foram inventados e analisados para o problema puramente quadrático de

$$
\operatorname{minimizar} \frac{1}{2} x^{T} Q x-b^{T} x,
$$

sendo $Q$ uma matriz $n \times n$ simétrica e definida positiva.

As técnicas desenvolvidas para esse problema são então estendidas, por aproximação, a problemas mais gerais; isso estando entendido que, já que próximo ao ponto ótimo todo problema é aproximadamente quadrático, a taxa de convergência é similar àquela em 
cenários puramente quadráticos. De fato, métodos de direções conjugadas, especialmente de gradientes conjugados, têm se mostrado extremamente eficazes para lidar com funções objetivo gerais e são considerados uns dos melhores de uso geral disponíveis atualmente.

O método de gradientes conjugados é o método de direções conjugadas resultante de se tomarem os sucessivos vetores de direção como a versão conjugada dos sucessivos gradientes obtidos conforme o método progride. Logo, as direções não são especificadas de antemão, mas sim determinadas seqüencialmente a cada passo da iteração. No passo $k$, o vetor gradiente negativo atual é computado e somado a uma combinação linear dos vetores de direção anteriores, de modo a obter um novo vetor de direção conjugada ao longo do qual se mover.

Há três principais vantagens de tal método de escolha da direção. A primeira é que, a não ser que a solução seja alcançada em menos de $n$ passos, o vetor gradiente é sempre não-nulo e linearmente independente em relação aos vetores de direção anteriores.

Além disso, uma vantagem ainda mais importante do método de gradientes conjugados é a fórmula bastante simples usada para se determinar o novo vetor de direção. Tal simplicidade faz com que o método seja apenas levemente mais complexo que o de máxima descida.

Por fim, pelo fato de as direções serem baseadas nos gradientes, o processo exibe a cada passo um progresso uniforme em direção à solução. Apesar de um progresso uniforme não ser de grande importância para um problema puramente quadrático, é importante para generalizações de problemas não-quadráticos.

A seguir, é apresentado o algoritmo de gradientes conjugados. Partindo-se de qualquer $x_{0} \in \mathbb{R}^{n}$, seja $d_{0}=-g_{0}$ e tome ainda $g_{k}=Q x_{k}-b$ :

$$
\begin{aligned}
x_{k+1} & =x_{k}+\alpha_{k} d_{k} \\
\alpha_{k} & =-\frac{g_{k}^{T} d_{k}}{d_{k}^{T} Q d_{k}} \\
d_{k+1} & =-g_{k+1}+\beta_{k} d_{k} \\
\beta_{k} & =\frac{g_{k+1}^{T} Q d_{k}}{d_{k}^{T} Q d_{k}}
\end{aligned}
$$

No algoritmo, o primeiro passo é idêntico a um passo de máxima descida; cada passo seguinte caminha em uma direção que é combinação linear do gradiente atual e do vetor de direção anterior. O atrativo desse algoritmo são as fórmulas bastante simples $(2.7,2.8)$, para atualizar o vetor de direção. O método é de implementação apenas ligeiramente mais difícil que o de máxima descida, mas converge em um número finito de iterações. 


\section{Capítulo 3}

\section{Algoritmos Estudados}

As seções que compõem este capítulo, inteiramente fundamentadas nos trabalhos [39] e [10], respectivamente, têm sua inclusão justificada pela intenção de conferir completude ao presente texto. As contribuições originais deste trabalho, por sua vez, passam a ser consideradas a partir dos capítulos seguintes.

\subsection{ASA}

Esta seção está organizada da seguinte maneira. Inicialmente será analisado o algoritmo empregado por ASA na etapa de projeção do gradiente (NGPA). Em seguida, o método de restrições ativas será inteiramente apresentado, juntamente com as condições suficientes a serem respeitadas por todo método de otimização irrestrita que se deseje utilizar a fim de que um resultado de convergência global possa ser estabelecido. Finalmente, tal resultado será introduzido.

\subsubsection{Algoritmo de Gradiente Projetado Não-Monótono}

Considere uma generalização de (1.1) em que a caixa $\Omega$ é substituída por um conjunto convexo, fechado e não-vazio e denote por $P$ a projeção em $\Omega$ :

$$
P(x)=\arg \min _{y \in \Omega}\|x-y\| .
$$

Partindo-se do ponto atual $x_{k}$, é computado um iterado inicial $\bar{x}_{k}=x_{k}-\bar{\alpha}_{k} g_{k}$. A única restrição ao tamanho $\bar{\alpha}_{k}$ do passo inicial é que $\bar{\alpha}_{k} \in\left[\alpha_{\min }, \alpha_{\max }\right]$, sendo $\alpha_{\min }$ e $\alpha_{\max }$ constantes positivas fixadas, independentes do passo $k$. Como tal candidato a iterado pode não pertencer a $\Omega$, é calculada sua projeção $P\left(\bar{x}_{k}\right)$ nesse conjunto. Já a direção de 
busca é dada por $d_{k}=P\left(\bar{x}_{k}\right)-x_{k}$. Realizando uma busca linear não-monótona ao longo do segmento que une $x_{k}$ e $P\left(\bar{x}_{k}\right)$, obtém-se o novo iterado $x_{k+1}$.

Na descrição do NGPA feita a seguir, $f_{k}^{r}$ denota o valor de "referência" da função. Uma busca linear monótona corresponde à escolha $f_{k}^{r}=f\left(x_{k}\right)$, enquanto que a abordagem não-monótona adota $f_{k}^{r}=f_{k}^{\max }$, sendo

$$
f_{k}^{\max }=\max \left\{f\left(x_{k-i}\right): 0 \leq i \leq \min \{k, M-1\}\right\}
$$

Aqui, $M>0$ é um inteiro fixado, a memória disponível.

\section{Parâmetros}

- $\epsilon \in[0, \infty)$, erro tolerado

- $\delta \in(0,1)$, parâmetro de descida da busca Armijo

- $\eta \in(0,1)$, fator de decaimento do passo em Armijo

- $\left[\alpha_{\min }, \alpha_{\max }\right] \subset(0, \infty)$, intervalo contendo o tamanho do passo inicial

\section{Algoritmo}

Inicialize $k=0, x_{0}=$ estimador inicial e $f_{-1}^{r}=f\left(x_{0}\right)$.

Enquanto $\left\|P\left(x_{k}-g_{k}\right)-x_{k}\right\|>\epsilon$

1. Tome $\bar{\alpha}_{k} \in\left[\alpha_{\min }, \alpha_{\max }\right]$ e faça $d_{k}=P\left(x_{k}-\bar{\alpha}_{k} g_{k}\right)-x_{k}$.

2. Tome $f_{k}^{r}$ de modo que $f\left(x_{k}\right) \leq f_{k}^{r} \leq \max \left\{f_{k-1}^{r}, f_{k}^{\max }\right\}$ e $f_{k}^{r} \leq f_{k}^{\max }$.

3. Faça $f_{R}$ valer $f_{k}^{r}$ ou $\min \left\{f_{k}^{\max }, f_{k}^{r}\right\}$. Se $f\left(x_{k}+d_{k}\right) \leq f_{R}+\delta g_{k}^{T} d_{k}$, então $\alpha_{k}=1$.

4. Se $f\left(x_{k}+d_{k}\right)>f_{R}+\delta g_{k}^{T} d_{k}$, então faça $\alpha_{k}=\eta^{j}$, sendo $j>0$ o menor inteiro tal que

$$
f\left(x_{k}+\eta^{j} d_{k}\right) \leq f_{R}+\eta^{j} \delta g_{k}^{T} d_{k}
$$

5. Faça $x_{k+1}=x_{k}+\alpha_{k} d_{k}$ e $k=k+1$.

Fim

Algoritmo 3.1: Algoritmo empregado por ASA na etapa de projeção do gradiente (NGPA)

A condição $f\left(x_{k}\right) \leq f_{k}^{r}$ garante que a busca linear de Armijo no Passo 4 possa ser satisfeita. Já o requerimento de que $f_{k}^{r} \leq f_{k}^{\max }$, apesar de ser bastante fraco e poder ser satisfeito por meio de diversas estratégias distintas, é necessário à validade do teorema a seguir. 
Antes de proceder à análise de convergênica, lembre que $x^{*}$ é um ponto estacionário de (1.1) se valer a condição de otimalidade de primeira ordem:

$$
\nabla f\left(x^{*}\right)\left(x-x^{*}\right) \geq 0 \text { para todo } x \in \Omega \text {. }
$$

Esteja ainda $d^{\alpha}(x), \alpha \in \mathbb{R}$, definido em termos do gradiente $g(x)=\nabla f(x)^{T}$ como se segue:

$$
d^{\alpha}(x)=P(x-\alpha g(x))-x
$$

No NGPA, a direção de busca é $d_{k}=d^{\bar{\alpha}_{k}}\left(x_{k}\right)$. Para otimização irrestrita, $d^{\alpha}(x)$ aponta na direção do gradiente negativo em $x$ quando $\alpha>0$.

A seguir, é estabelecido um resultado de convergência para NGPA.

Teorema 1. Seja $\mathcal{L}$ o conjunto de nível definido por

$$
\mathcal{L}=\left\{x \in \Omega: f(x) \leq f\left(x_{0}\right)\right\}
$$

Suponha que valham as seguintes condições:

1. $f$ é limitada inferiormente em $\mathcal{L}$ e $d_{\max }=\sup _{k}\left\|d_{k}\right\|<\infty$.

2. Se $\overline{\mathcal{L}}$ é a coleção dos $x \in \Omega$ cuja distância a $\mathcal{L}$ é no máximo $d_{\max }$, então $\nabla f$ é Lipschitz contínua em $\overline{\mathcal{L}}$.

Então ou o algoritmo termina, para $\epsilon=0$, em um ponto estacionário após um número finito de iterações, ou tem-se

$$
\lim _{k \rightarrow \infty} \inf \left\|d^{1}\left(x_{k}\right)\right\|=0
$$

A demonstração desse resultado estende-se além do escopo pretendido e, logo, será omitida.

\subsubsection{Método de Restrições Ativas}

No que se segue, o problema (1.1) será tratado supondo-se $l=0$ e $u=\infty$. A análise feita e os resultados dela derivados, porém, continuam aplicáveis ao caso de restrições de caixa gerais.

Apesar de a abordagem de projeção do gradiente do NGPA estar associada a uma teoria de convergência global atraente, a taxa de convergência pode ser muito lenta na vizinhança de um minimizador local. Por outro lado, para otimização irrestrita, um algoritmo de gradientes conjugados geralmente apresenta convergência superlinear na 
vizinhança de minimizadores locais. Assim, ASA emprega NGPA para identificar as restrições ativas e um método de otimização irrestrita para minimizar $f$ em uma face determinada por NGPA.

A seguir será fixada alguma notação. Para todo $x \in \Omega$, sejam $\mathcal{A}(x)$ e $\mathcal{I}(x)$ os conjuntos de índices das restrições ativas e inativas, respectivamente:

$$
\begin{aligned}
& \mathcal{A}(x)=\left\{i \in[1, n]: x_{i}=0\right\}, \\
& \mathcal{I}(x)=\left\{i \in[1, n]: x_{i}>0\right\} .
\end{aligned}
$$

As restrições ativas serão subdivididas entre aquelas que satisfazem a complementaridade estrita e as degeneradas:

$$
\begin{gathered}
\mathcal{A}_{+}(x)=\left\{i \in \mathcal{A}(x): g_{i}(x)>0\right\}, \\
\mathcal{A}_{0}(x)=\left\{i \in \mathcal{A}(x): g_{i}(x)=0\right\} .
\end{gathered}
$$

Denote ainda por $g_{I}(x)$ o vetor cujas componentes associadas aos índices no conjunto $\mathcal{I}(x)$ são idênticas àquelas de $g(x)$, enquanto que as componentes correspondentes aos índices de $\mathcal{A}(x)$ valem zero:

$$
g_{I_{i}}(x)= \begin{cases}0 & \text { se } x_{i}=0 \\ g_{i}(x) & \text { se } x_{i}>0\end{cases}
$$

Uma característica importante do algoritmo desenvolvido é que busca-se distinguir entre as restrições ativas atendendo a complementaridade estrita e restrições ativas degeneradas. Dados os parâmetros fixados $\alpha \in(0,1)$ e $\beta \in(1,2)$, define-se o conjunto $\mathcal{U}$ de $x \in \Omega$ como se segue:

$$
\mathcal{U}(x)=\left\{i \in[1, n]:\left|g_{i}(x)\right| \geq\left\|d^{1}(x)\right\|^{\alpha} \text { e } x_{i} \geq\left\|d^{1}(x)\right\|^{\beta}\right\} .
$$

Para os experimentos numéricos, adotaram-se $\alpha=1 / 2$ e $\beta=3 / 2$. Na prática, $\mathcal{U}$ é quase sempre vazio na vizinhança de um minimizador e as valorações de $\alpha$ e $\beta$ não exercem qualquer efeito significativo sobre a convergência.

Os índices de $\mathcal{U}$ correspondem às componentes de $x$ para as quais a respectiva componente $g_{i}(x)$ do gradiente é relativamente grande, enquanto $x_{i}$ não está próximo de zero (no sentido de que $\left.x_{i} \geq\left\|d^{1}(x)\right\|^{\beta}\right)$. Quando o conjunto $\mathcal{U}$ de tais índices é vazio, sabe-se que os índices cuja componente do gradiente associada é grande foram quase completamente identificados. Nesse caso, opta-se por um método de otimização irrestrita.

Apesar de os experimentos numéricos terem sido realizados com a utilização de um algoritmo de gradientes conjugados específico (CG_DESCENT), uma larga classe de 
métodos de otimização irrestrita (aqui denominados UA) pode ser empregada. A seguir, são apresentadas condições suficientes a serem respeitadas pelo UA a fim de que o resultado de convergência a ser estabelecido se preserve.

1. $x_{k} \geq 0$ e $f\left(x_{k+1}\right) \leq f\left(x_{k}\right)$ para todo $k$.

2. $\mathcal{A}\left(x_{k}\right) \subset \mathcal{A}\left(x_{k+1}\right)$ para todo $k$.

3. Se $\mathcal{A}\left(x_{j+1}\right)=\mathcal{A}\left(x_{j}\right)$ para $j \geq k$, então $\lim _{j \rightarrow \infty} \inf \left\|g_{I}\left(x_{j}\right)\right\|=0$.

4. Sempre que UA for iniciado, $x_{k+1}=P\left(x_{k}-\alpha_{k} g_{I}\left(x_{k}\right)\right)$, sendo $\alpha_{k}$ tomado de modo a satisfazer a

$$
\phi\left(\alpha_{k}\right) \leq \phi(0)+\delta \alpha_{k} \phi^{\prime}(0) \quad \text { e } \quad \phi^{\prime}\left(\alpha_{k}\right) \geq \sigma \phi^{\prime}(0)
$$

com

$$
\phi(\alpha)=f\left(P\left(x_{k}-\alpha g_{I}\left(x_{k}\right)\right)\right), \quad 0<\delta<\sigma<1 .
$$

A condição (1) implica que UA seja um algoritmo monótono, de modo que a função objetivo só faça decrescer a cada iteração. A condição (2) trata de como o algoritmo se comporta quando um iterado inviável é gerado. A condição (3) descreve a convergência global de UA quando o conjunto de restrições ativas não varia. Na condição $(4), \phi^{\prime}(\alpha)$ é a derivada pelo lado direito de $\alpha ; \alpha_{k}$ existe porque $\phi$ é suave por trechos com um número finito de descontinuidades em sua derivada e $\phi^{\prime}(\alpha)$ é contínua em $\alpha=0$.

A seguir, ASA é descrito em pseudo-código.

\section{Parâmetros}

- $\epsilon \in[0, \infty)$, erro tolerado, parando-se se $\left\|d^{1}\left(x_{k}\right)\right\| \leq \epsilon$

- $\mu \in(0,1),\left\|g_{I}\left(x_{k}\right)\right\|<\mu\left\|d^{1}\left(x_{k}\right)\right\|$ implicando que o subproblema foi resolvido

- $\rho \in(0,1)$, fator de decaimento de $\mu$

- $n_{1} \in[1, n)$, número de $\mathcal{A}\left(x_{k}\right)$ repetidos até que se mude de NGPA para UA

- $n_{2} \in[1, n)$, usado na mudança de UA para NGPA

\section{Algoritmo}

1. Enquanto $\left\|d^{1}\left(x_{k}\right)\right\|>\epsilon$, execute NGPA e verifique o seguinte:

(a) $\operatorname{Se} \mathcal{U}\left(x_{k}\right)=\emptyset$, então

Se $\left\|g_{I}\left(x_{k}\right)\right\|<\mu\left\|d^{1}\left(x_{k}\right)\right\|$, então $\mu=\rho \mu$.

Senão, vá ao Passo 2. 
(b) Senão, se $\mathcal{A}\left(x_{k}\right)=\mathcal{A}\left(x_{k-1}\right)=\ldots=\mathcal{A}\left(x_{k-n_{1}}\right)$, então Se $\left\|g_{I}\left(x_{k}\right)\right\| \geq \mu\left\|d^{1}\left(x_{k}\right)\right\|$, vá ao Passo 2.

Fim

2. Enquanto $\left\|d^{1}\left(x_{k}\right)\right\|>\epsilon$, execute $\mathrm{UA}$ e verifique o seguinte:

(a) Se $\left\|g_{I}\left(x_{k}\right)\right\|<\mu\left\|d^{1}\left(x_{k}\right)\right\|$, então reinicie NGPA (Passo 1).

(b) Se $\left|\mathcal{A}\left(x_{k-1}\right)\right|<\left|\mathcal{A}\left(x_{k}\right)\right|$, então

Se $\mathcal{U}\left(x_{k}\right)=\emptyset$ ou $\left|\mathcal{A}\left(x_{k}\right)\right|>\left|\mathcal{A}\left(x_{k-1}\right)\right|+n_{2}$, reinicie UA em $x_{k}$.

Senão, reinicie NGPA.

Fim

Fim

Algoritmo 3.2: Descrição de ASA em pseudo-código

No primeiro passo do algoritmo, NGPA é executado até que se acredite ter identificado as restrições ativas que satisfazem a complementaridade estrita. No Passo 2, executa-se UA até que o subproblema tenha sido resolvido (Passo 2(a)). Quando novas restrições se tornam ativas no Passo 2(b), opta-se por reiniciar ou NGPA ou UA. Reiniciando o primeiro, fica implícito que $x_{0}$ em NGPA é dado pelo iterado $x_{k}$ atual. Reiniciando o segundo, sugere-se que iterados sejam gerados por UA usando o iterado inicial como ponto inicial.

Finalmente, é estabelecido um resultado de convergência global para ASA.

Teorema 2. Seja $\mathcal{L}$ o conjunto de nível definido por

$$
\mathcal{L}=\left\{x \in \Omega: f(x) \leq f\left(x_{0}\right)\right\}
$$

Suponha que valham as seguintes condições:

1. $f$ é limitada inferiormente em $\mathcal{L}$ e $d_{\max }=\sup _{k}\left\|d_{k}\right\|<\infty$.

2. Se $\overline{\mathcal{L}}$ é a coleção dos $x \in \Omega$ cuja distância a $\mathcal{L}$ é no máximo $d_{\max }$, então $\nabla f$ é Lipschitz contínua em $\overline{\mathcal{L}}$.

3. UA satisfaz às condições (1) a (3).

Então ou ASA, para $\epsilon=0$, termina em um ponto estacionário após um número finito de iterações, ou tem-se

$$
\lim _{k \rightarrow \infty} \inf \left\|d^{1}\left(x_{k}\right)\right\|=0
$$




\subsection{GENCAN}

Nesta seção, descreve-se primeiramente o algoritmo para minimização irrestrita em caixas empregado pelo método. Graças à técnica de busca linear em que se baseia, um resultado de convergência para esse algoritmo pode ser obtido e é apresentado. Na subseção seguinte, o método de restrições ativas propriamente dito é introduzido, bem como a técnica de gradiente projetado utilizada para se abandonar uma face.

\subsubsection{Algoritmo de Minimização Irrestrita}

No que se segue, suponha que $f: \mathbb{R}^{\bar{n}} \rightarrow \mathbb{R}, f \in C^{1}\left(\mathbb{R}^{n}\right)$ e

$$
\mathcal{B}=\left\{x \in \mathbb{R}^{\bar{n}}: \bar{l} \leq x \leq \bar{u}\right\}
$$

O conjunto $\mathcal{B}$ denotará cada uma das faces fechadas de $\Omega$ na próxima seção. A dimensão $\bar{n}$ é a dimensão do subespaço reduzido, e o gradiente nesta seção é composto pela derivadas com respeito às variáveis livres na seção seguinte.

O objetivo é definir um algoritmo iterativo que se inicie no interior de $\mathcal{B}$ e então ou convirja a um ponto estacionário irrestrito ou termine em uma fronteira de $\mathcal{B}$ após ter descrescido o valor da função. Tal método baseia-se em buscas lineares com condições de Armijo e extrapolação. Dado o ponto atual $x_{k}$ e uma direção de descida $d_{k}$, a busca linear é interrompida se $x_{k}+d_{k}$ satisfizer a um critério de descida suficiente e se a derivada direcional for suficientemente maior que $\left\langle g\left(x_{k}\right), d_{k}\right\rangle$. Se o critério suficiente de descida não for atendido, procede-se com backtracking. Já se o critério se aplicar, mas o aumento da derivada direcional não for o bastante, a extrapolação pode ser tentada.

Para todo $z \in \mathbb{R}^{n}$, a projeção Euclidiana de $z$ sobre um conjunto convexo $S$ será denotada por $P_{S}(z)$. Ainda, $P(y)=P_{\mathcal{B}}(y)$ e $\|\cdot\|$ representa a norma Euclidiana.

\section{Parâmetros}

- $\gamma \in(0,1 / 2), \beta \in(0,1)$

- $\theta \in(0,1), N>1$

- $0<\sigma_{1}<\sigma_{2}<1$

- $\epsilon_{\mathrm{abs}}, \epsilon_{\mathrm{rel}}>0$

\section{Algoritmo}

1. Inicialize $k=0$ e $x_{0} \in \operatorname{Int}(\mathcal{B})$, ponto inicial. 
2. Cômputo da direção de busca:

(a) Se $\left\|g_{k}\right\|=0$, pare.

(b) Compute $d_{k} \in \mathbb{R}^{n}$ tal que $\left\langle g_{k}, d_{k}\right\rangle \leq-\theta\left\|g_{k}\right\|\left\|d_{k}\right\|$.

3. Decisões quanto à busca linear:

(a) Compute $\alpha_{\max }=\max \left\{\alpha \geq 0:\left[x_{k}, x_{k}+\alpha d_{k}\right] \subset \mathcal{B}\right\}$ e faça $\alpha=\min \left\{\alpha_{\max }, 1\right\}$. Se $\left(\alpha_{\max }>1\right.$, então $\left.x_{k}+d_{k} \in \operatorname{Int}(\mathcal{B})\right)$, vá ao Passo 2(b). Senão, vá ao Passo 2(c).

(b) (Neste ponto, vale $x_{k}+d_{k} \in \operatorname{Int}(\mathcal{B})$.)

Se $\left(f\left(x_{k}+d_{k}\right) \leq f\left(x_{k}\right)+\gamma\left\langle g_{k}, d_{k}\right\rangle\right)$, então

Se $\left(\left\langle d_{k}, g\left(x_{k}+d_{k}\right)\right\rangle \geq \beta\left\langle g_{k}, d_{k}\right\rangle\right)$, tome $\alpha_{k}=1$ e $x_{k+1}=x_{k}+d_{k}$ e vá ao Passo 5.

Senão, vá ao Passo 3.

Senão, vá ao Passo 4.

(c) (Neste ponto, tem-se $x_{k}+d_{k} \notin \operatorname{Int}(\mathcal{B})$.)

Se $\left(f\left(x_{k}+\alpha_{\max } d_{k}\right)<f\left(x_{k}\right)\right)$, então

Tome $\alpha_{k} \geq \alpha_{\max }$ e $x_{k+1}=P\left(x_{k}+\alpha_{k} d_{k}\right) \in \mathcal{B} \backslash \operatorname{Int}(\mathcal{B})$

tal que $f\left(x_{k+1}\right) \leq f\left(x_{k}+\alpha_{\max } d_{k}\right)$ e vá ao Passo 5 .

Senão, vá ao Passo 4.

4. Extrapolação:

(a) Se $\left(\alpha<\alpha_{\max }\right.$ e $\left.N \alpha>\alpha_{\max }\right)$, faça $\alpha_{\text {trial }}=\alpha_{\max }$. Senão, faça $\alpha_{\text {trial }}=N \alpha$.

(b) Se $\left(\alpha \geq \alpha_{\max }\right.$ e $\left\|P\left(x_{k}+\alpha_{\text {trial }} d_{k}\right)-P\left(x_{k}+\alpha d_{k}\right)\right\|_{\infty}<\max \left\{\epsilon_{\text {abs }}, \epsilon_{\text {rel }} \| P\left(x_{k}+\right.\right.$ $\left.\left.\left.\alpha d_{k}\right) \|_{\infty}\right\}\right)$, tome $\alpha_{k}=\alpha$ e $x_{k+1}=P\left(x_{k}+\alpha d_{k}\right)$ e interrompa a execução.

(c) Se $\left(f\left(P\left(x_{k}+\alpha_{\text {trial }} d_{k}\right)\right) \geq f\left(P\left(x_{k}+\alpha d_{k}\right)\right)\right)$, então

Tome $\alpha_{k}=\alpha, x_{k+1}=P\left(x_{k}+\alpha d_{k}\right)$ e vá ao Passo 5 .

Senão, faça $\alpha=\alpha_{\text {trial }}$ e vá ao Passo 3(a).

5. Backtracking:

(a) Compute $\alpha_{\text {new }} \in\left[\sigma_{1} \alpha, \sigma_{2} \alpha\right]$ e faça $\alpha=\alpha_{\text {new }}$.

(b) Se $\left(f\left(x_{k}+\alpha d_{k}\right) \leq f\left(x_{k}\right)+\gamma \alpha\left\langle g_{k}, d_{k}\right\rangle\right)$, então

Tome $\alpha_{k}=\alpha, x_{k+1}=x_{k}+\alpha d_{k}$ e vá ao Passo 5 .

Senão, vá ao Passo 4(a). 
6. Se $\alpha_{k} \geq \alpha_{\max }$, interrompa a execução. Senão, faça $k=k+1$ e vá ao Passo 1.

Algoritmo 3.3: Algoritmo de minimização irrestrita empregado por GENCAN

O resultado a seguir mostra que toda seqüência gerada pelo algoritmo anterior ou converge a um ponto estacionário irrestrito ou termina em uma fronteira de $\mathcal{B}$ ou ainda, no limite, produz pontos estacionários irrestritos.

Teorema 3. O algoritmo acima descrito está bem definido e gera pontos com valores de função estritamente decrescentes. Se $\left\{x_{k}\right\}$ for uma seqüência por ele produzida, então vale uma das seguintes opções:

1. A seqüência termina em $x_{k}$, com $g\left(x_{k}\right)=0$.

2. A seqüência termina em $x_{k} \in \mathcal{B} \backslash \operatorname{Int}(\mathcal{B})$ e $f\left(x_{k}\right)<f\left(x_{k-1}\right)<\ldots<f\left(x_{0}\right)$.

3. A seqüência é infinita, possui ao menos um ponto limite e todo ponto limite $x_{*}$ satisfaz a $g\left(x_{*}\right)=0$.

\subsubsection{Método de Restrições Ativas}

O problema tratado nesta seção volta a ser o dado por (1.1). Divide-se o conjunto viável $\Omega$ em faces disjuntas abertas da seguinte forma. Para todo $I \subset\{1,2, \ldots, n, n+1, n+$ $2, \ldots, 2 n\}$, defina

$$
F_{I}=\left\{x \in \Omega: x_{i}=l_{i} \text { se } i \in I, x_{i}=u_{i} \text { se } n+i \in I, l_{i}<x_{i}<u_{i} \text { caso contrário }\right\} .
$$

Defina também $V_{I}$ como sendo o menor subespaço afim que contém $F_{I}$ e $S_{I}$ como subespaço linear paralelo a $V_{I}$. O gradiente projetado em $x \in \Omega$ é definido como

$$
g_{P}(x)=P_{\Omega}(x-g(x))-x
$$

Para cada $x \in F_{I}$, defina ainda

$$
g_{I}(x)=P_{S_{I}}\left[g_{P}(x)\right]
$$

O método de restrições ativas propriamente dito é descrito a seguir. Suponha que $x_{0} \in \Omega$ seja um ponto inicial arbitrário, $\eta \in(0,1)$ e $0<\sigma_{\min } \leq \sigma_{\max }<\infty$. Seja $F_{I}$ a face que contém o iterado atual $x_{k}$. Suponha que $g_{P}\left(x_{k}\right) \neq 0$ (caso contrário, o algoritmo termina). Na iteração principal do método, é testada a desigualdade

$$
\left\|g_{I}\left(x_{k}\right)\right\| \geq \eta\left\|g_{P}\left(x_{k}\right)\right\|
$$


Se (3.11) valer, é conveniente que o novo iterado pertença a $\bar{F}_{I}$ (fecho de $F_{I}$ ) e, assim, computa-se $x_{k+1}$ por meio de uma iteração do algoritmo apresentado na seção anterior com o conjunto de variáveis restrito ao das variáveis livres em $F_{I}$. Logo, o conjunto $\mathcal{B}$ da seção anterior equivale a $\bar{F}_{I}$.

Caso contrário, opta-se por abandonar algumas das restrições e, portanto, o novo iterado $x_{k+1}$ é obtido a partir de uma iteração do método SPG descrito ao final desta seção. Nesse caso, antes do cômputo de $x_{k+1}$, é calculado o coeficiente $\sigma_{k}$ do gradiente espectral projetado da seguinte maneira. Se $k=0$ ou $\left\langle\left(x_{k}-x_{k-1}\right),\left(g\left(x_{k}\right)-g\left(x_{k-1}\right)\right\rangle \leq 0\right.$, então

$$
\sigma_{k}=\max \left\{1,\left\|x_{k}\right\| /\left\|g_{P}\left(x_{k}\right)\right\|\right\}
$$

Caso contrário, defina

$$
\sigma_{k}^{\prime}=\frac{\left\langle\left(x_{k}-x_{k-1}\right),\left(g\left(x_{k}\right)-g\left(x_{k-1}\right)\right)\right\rangle}{\left\|x_{k}-x_{k-1}\right\|^{2}}
$$

$\mathrm{e}$

$$
\sigma_{k}=\min \left\{\sigma_{\max }, \max \left\{\sigma_{\min }, \sigma_{k}^{\prime}\right\}\right\}
$$

O algoritmo seguinte é empregado quando se faz necessário abandonar a face corrente, segundo critério estipulado no teste (3.11).

SPG Compute $x_{k+1}$ como o próximo iterado de uma iteração do SPG monótono $[11,12]$ com passo espectral $\sigma_{k}$. Mais especificamente, defina a direção de busca $d_{k}$ como

$$
d_{k}=P_{\Omega}\left(x_{k}-\sigma_{k} g\left(x_{k}\right)\right)-x_{k}
$$

e calcule $x_{k+1}=x_{k}+\alpha_{k} d_{k}$ de modo que

$$
f\left(x_{k+1}\right) \leq f\left(x_{k}\right)+\gamma \alpha_{k}\left\langle g\left(x_{k}\right), d_{k}\right\rangle,
$$

partindo-se de $\alpha_{k}=1$ e, se necessário, reduzindo o coeficiente por meio de um procedimento de interpolação quadrática.

Algoritmo 3.4: Algoritmo empregrado por GENCAN para abandonar uma face (SPG) 


\section{Capítulo 4}

\section{Metodologia de Testes}

A fim de se aferirem e de se compararem a eficiência e a robustez de ASA e GENCAN, foram despendidos muitos esforços na concepção de uma metodologia de testes que remediasse vários dos aspectos comumente criticados em trabalhos anteriores. Os mais relevantes desses serão tratados separadamente nas seções que seguem.

\subsection{Métrica de Comparação}

Como medida de desempenho dos métodos foi adotado o tempo transcorrido até o término da execução para cada instância testada. É importante ressaltar, no entanto, que apenas o tempo em que a CPU ficou efetivamente ocupada pelo processamento das operações pertinentes ao algoritmo foi contabilizado (i.e. CPU time). Em outras palavras, operações mais onerosas, como acesso ao disco para leitura e escrita, não impactam significativamente o tempo de CPU consumido pelo método.

Além do tempo, outras grandezas chegaram a ser cogitadas para servir a esse fim, como o número de avaliações de função e o total de operações do tipo ponto flutuante efetuadas. Contudo, foram preteridas por, respectivamente, não traduzir apropriadamente a noção intuitiva de eficiência ou não gozar da disponibilidade de um instrumento de medição bem estabelecido e aceito.

Uma vez escolhido o tempo como métrica de desempenho, passou-se à investigação por melhores formas de mensurá-lo. Isso porque as ferramentas tradicionalmente empregadas não asseguram precisão superior a um centésimo de segundo [32], insuficiente à obtenção dos resultados almejados neste trabalho.

Visando a atingir medições de maior acurácia, passou-se a tomar o tempo transcorrido não após uma única execução dos métodos, mas sim depois de o problema testado ter 
sido ininterrupta e sucessivamente resolvido um número suficientemente grande de vezes. Desse modo, o resultado da divisão do tempo total medido $T$ pelo número de repetições realizadas $\eta$ constituirá uma melhor aproximação do valor buscado.

Uma pergunta que inevitavelmente se coloca é a de como determinar um valor de $\eta$ suficientemente grande a esse propósito. Para respondê-la, realizaram-se experimentos numéricos nos quais um conjunto de seis problemas, extraídos da coleção CuTEr [13] (a saber, BQP1VAR, CAMEL6, HIELOW, MOREBV, NONDIA e STRATEC), foram submetidos a resolução pelos métodos para valores crescentes de $\eta$. A escolha desses problemas se deu de forma arbirtrária e objetivou compor uma amostra representativa dos demais que seriam posteriormente utilizados. Os tempos totais $T$ foram coletados e o quociente $t=T / \eta$, computado em cada caso. Denotando por $t^{*}$ aquele correspondente ao maior $\eta$ testado (simbolizado por $\eta_{\max }$ ) e supondo ser esse o valor que mais se aproxima do verdadeiro, calculou-se o erro relativo

$$
\varepsilon(t)=\frac{t-t^{*}}{t^{*}}
$$

sendo

$$
t^{*}=\frac{T_{\max }}{\eta_{\max }} .
$$

Note que a suposição de ser $t^{*}$ o valor que melhor estima o tempo de processamento efetivamente consumido por uma única execução do problema pode ser traduzida no entendimento de que quaisquer imprecisões intrínsecas à medição (sabidas serem da ordem de 0,01 s) exercerão menor influência sobre o tempo total aferido $T$ quanto maior ele for.

Tais resultados encontram-se representados pelos gráficos reunidos na Figura 4.1. Neles, o eixo das ordenadas traz os valores de $\varepsilon(t)$, ao passo que no das abcissas estão representados os de $\eta$, apenas dados por seu logaritmo em base 2 com a finalidade de facilitar a visualização. Os gráficos da direita, cada um construído a partir dos mesmos dados que o a sua esquerda, trazem uma ampliação da região situada após a linha vermelha.

Por meio deles, buscou-se identificar o menor valor de $T$ a partir do qual o erro relativo obtido não fosse superior a $2 \%$ em qualquer dos problemas testados. Foi possível constatar que $T=10$ s satisfazia a essa condição em todos os casos, levando à escolha desse como o menor intervalo de tempo de processamento durante o qual cada instância deve ser computada. Claramente, a valoração de $\eta$ que leva a um $T$ maior ou igual a 10 s varia conforme a dificuldade do problema e a eficiência do método e, logo, precisou ser empiricamente descoberta para cada par deles. As linhas tracejadas nos gráficos da Figura 4.1 indicam o primeiro $\eta$ a partir do qual $T \geq 10 \mathrm{~s}$. 


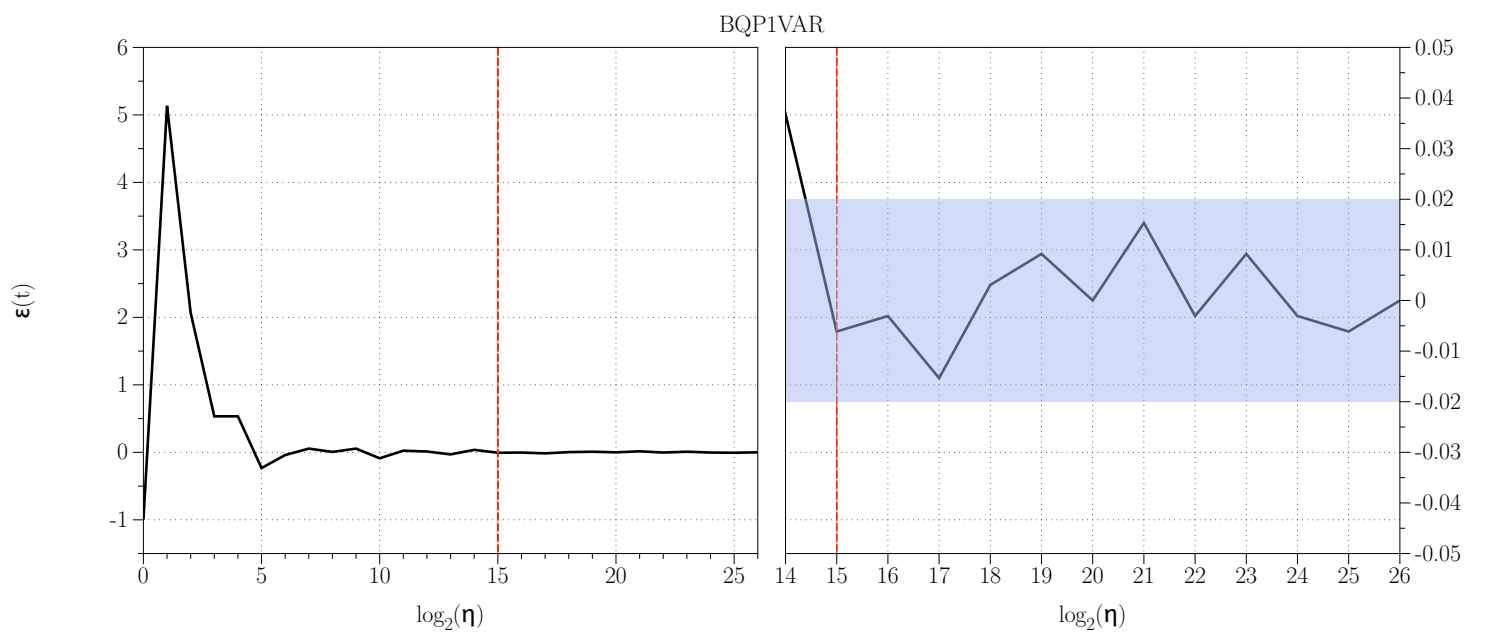

(a)

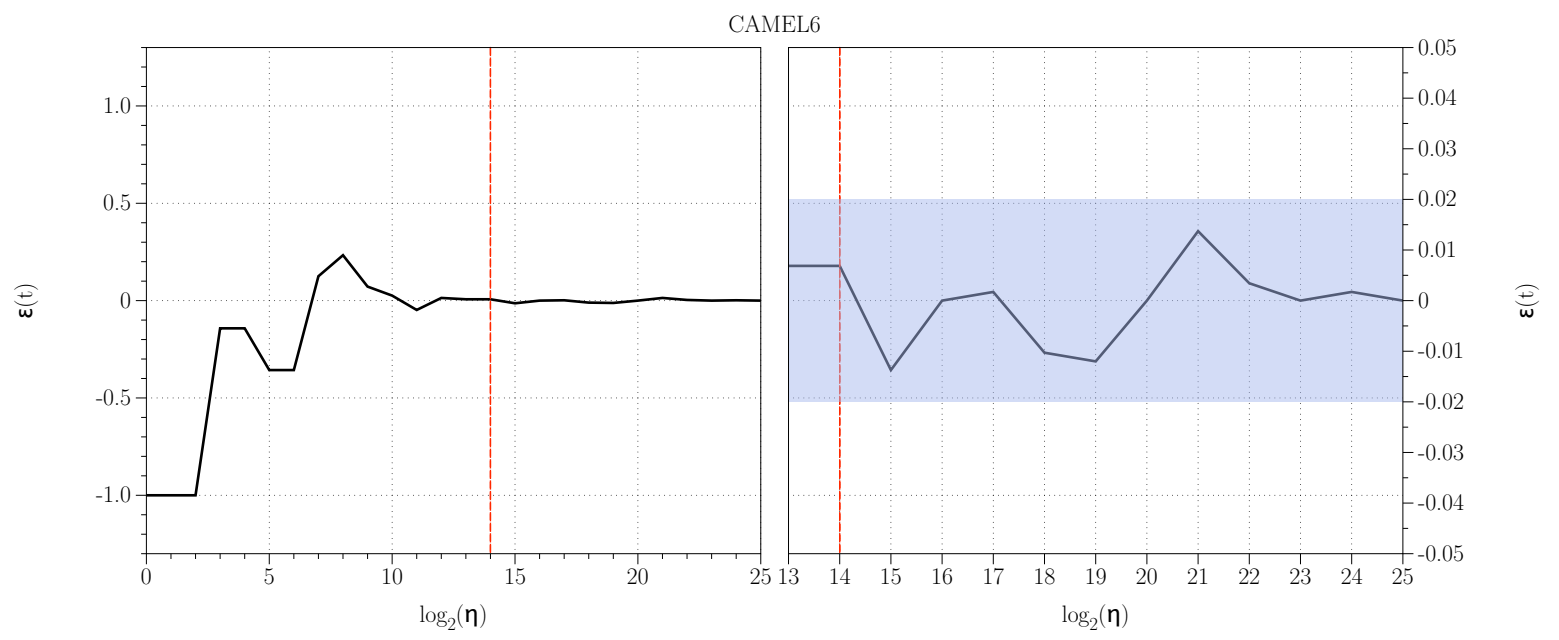

(b)

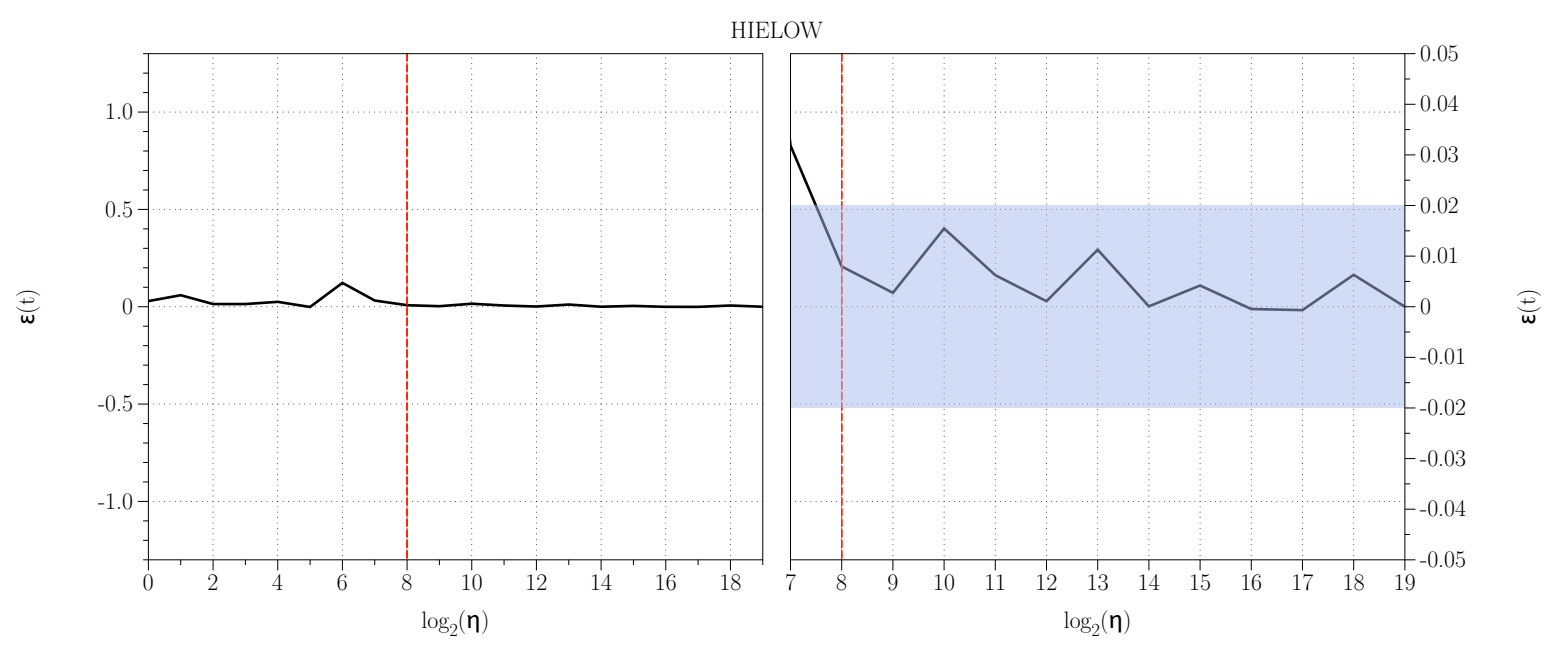

(c) 


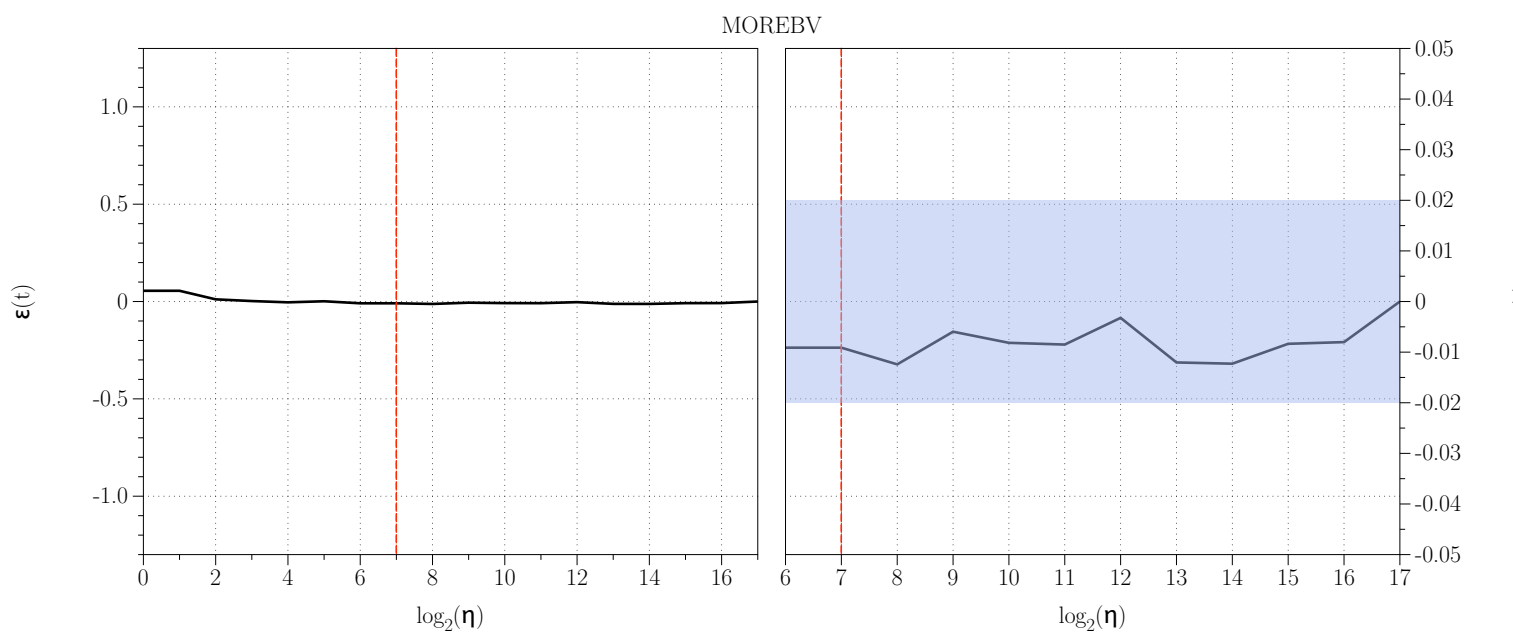

(d)

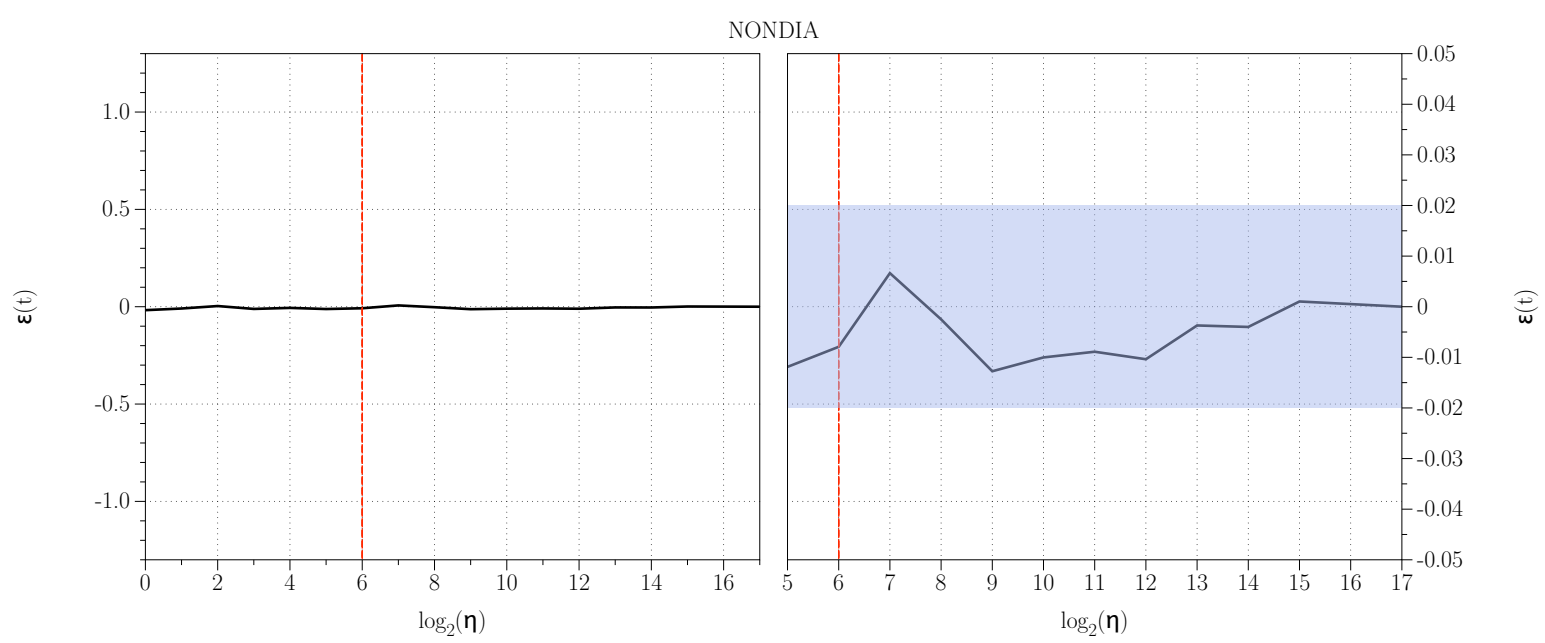

(e) 


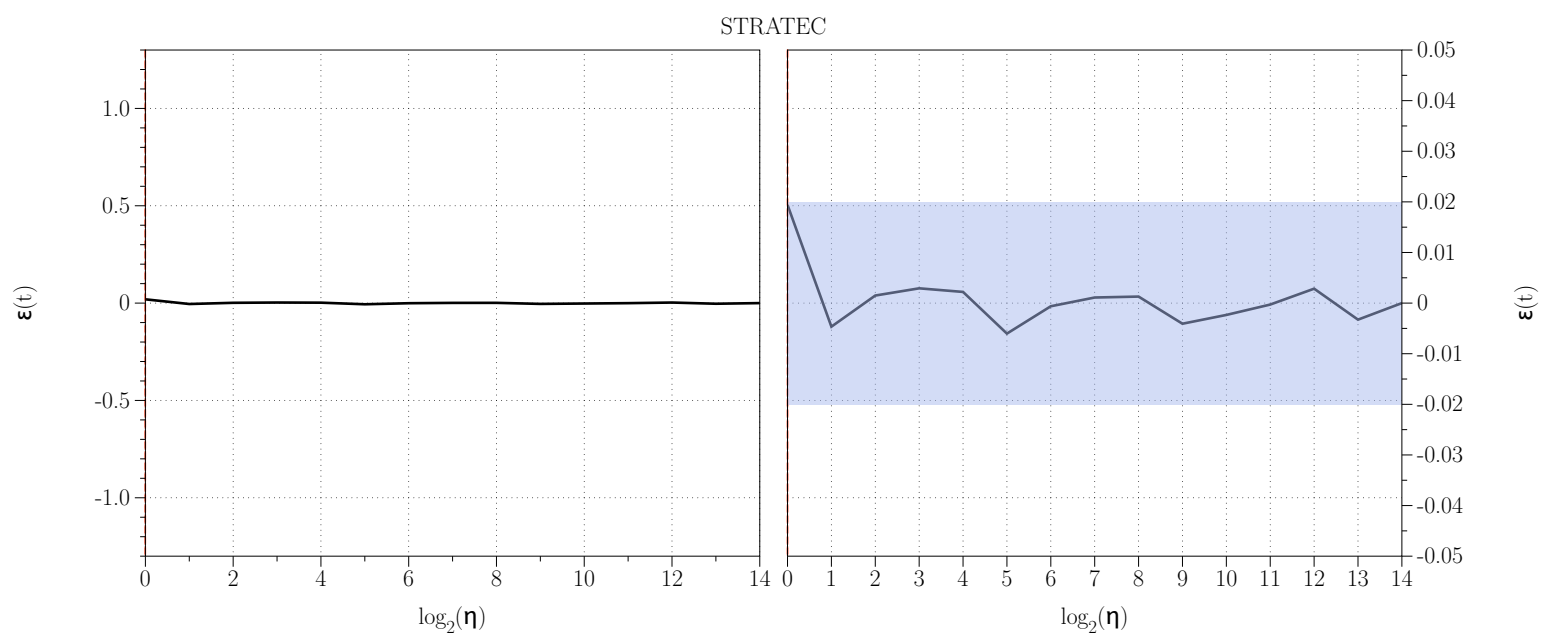

(f)

Figura 4.1: Gráficos do erro relativo de $t$ obtido para valores crescentes de $\eta$ com seis problemas de teste. O eixo das ordenadas traz os valores de $\varepsilon(t)$, ao passo que no das abcissas estão representados os de $\eta$, apenas dados por seu logaritmo em base 2 com a finalidade de facilitar a visualização. A linha em vermelho indica o primeiro $\eta$ a partir do qual $T \geq 10 \mathrm{~s}$. Os gráficos da direita, cada um construído a partir dos mesmos dados que o a sua esquerda, trazem uma ampliação da região situada após a linha vermelha. Neles encontra-se em destaque a caixa determinada por $\{-0,02 \leq \varepsilon(t) \leq 0,02\}$, permitindo comprovar que, ao menos nos casos aqui apresentados, a escolha de $10 \mathrm{~s}$ atende à finalidade esperada. Finalmente, cabe observar que, nos gráficos da Figura 4.1(f), a linha tracejada situa-se sobre o eixo das ordenadas por já ser o tempo de processamento de uma única execução do problema superior a $10 \mathrm{~s}$. 


\subsection{Critérios de Parada}

A fim de dirimir conclusões equivocadas ocasionadas por possíveis interrupções prematuras dos métodos, optou-se por desabilitar quaisquer outros critérios por eles obedecidos que não o ligado à norma infinito do gradiente projetado. Por conseguinte, a única regra que indica convergência a uma solução é

$$
\left\|g_{k}\right\|_{\infty} \leq \epsilon
$$

com $\epsilon$ assumindo valores no conjunto $\left\{10^{-8}, 10^{-7}, 10^{-6}, 10^{-5}, 10^{-4}\right\}$.

Por não ser possível garantir que a desigualdade (4.2) será em algum momento satisfeita, foi introduzido um limitante superior ao tempo de CPU decorrido. Nos experimentos que levaram aos resultados apresentados nas próximas seções deste capítulo, esse teto foi fixado em $1000 \mathrm{~s}$.

\subsection{Representação de Resultados}

Por gozarem de larga aceitação na literatura de otimização em geral, gráficos de perfil de desempenho foram selecionados como forma de representação dos resultados experimentais. Formalmente descritos em [23], reúnem a informação da fração $\rho$ de problemas para as quais cada método alcança a melhor solução encontrada por todos os comparados em até um fator $\tau$ do menor dos tempos consumidos, favorecendo a comparação tanto da eficiência (dada pela margem esquerda do gráfico) quanto da robustez (estimada pela margem direita) das implementações estudadas. Cabe ressaltar que a capacidade de um dado algoritmo de prover uma solução ótima, característica essa denominada robustez, pode ser inferida a partir do valor representado por seu perfil de desempenho à margem direita do gráfico pelo fato de o tempo de execução atribuído nesses casos ser igual a $+\infty$.

Durante sua elaboração, é necessário determinar se são equivalentes as soluções devolvidas por cada algoritmo. Um critério usualmente empregado para essa finalidade (veja $[3,5,7]$ ) considera dois valores de função $f_{1}$ e $f_{2}$ equivalentes se, e somente se,

$$
\left|f_{1}-f_{2}\right| \leq \max \left\{10^{-10}, 10^{-6} \min \left\{\left|f_{1}\right|,\left|f_{2}\right|\right\}\right\}
$$

ou, ainda, se

$$
f_{1} \leq-10^{20} \text { e } \quad f_{2} \leq-10^{20} .
$$

Tal regra, ao estabelecer uma relação entre o número de algarismos significativos em 
comum entre $f_{1}$ e $f_{2}$, pode induzir conclusões equivocadas quanto à eficácia dos métodos. Em outras palavras, lançando mão da noção intuitiva de casas decimais "corretas", não raro as soluções dadas por GENCAN apresentam o dobro delas que as fornecidas por ASA. Isso pode se verificar ainda que ambos tenham convergido a pontos que satisfaçam a um mesmo critério de parada, por ser ASA um algoritmo de primeira ordem e GENCAN, de segunda.

Diante dessa constatação, buscou-se um novo critério que não experimentasse do mesmo viés. A idéia consiste em determinar um $\varepsilon>0$ que faça ser considerada ótima uma solução $f_{j}$, razoavelmente próxima da melhor resposta $f_{\min }$ produzida pelos métodos, sempre que valer

$$
\frac{f_{j}-f_{\min }}{\max \left\{1,\left|f_{\min }\right|\right\}} \leq \varepsilon
$$

com

$$
f_{\min }=\min _{j}\left\{f_{j}\right\} .
$$

O quociente acima exprime nada menos que o erro relativo entre $f_{j}$ e $f_{\text {min }}$ no caso em que a melhor solução obtida é em módulo menor ou igual a 1 e o absoluto caso contrário. Optou-se por alternar entre essas duas métricas por se acreditar que a segunda reflete mais claramente a percepção de "semelhança" entre dois valores muito próximos de zero.

É fundamental salientar que essa prática só atende aos interesses deste estudo por já ser sabido que, para uma certa tolerância quanto ao valor de função encontrado, os métodos podem ser considerados igualmente robustos. Partindo de tal suposição, pesquisou-se justamente qual seria essa tolerância mais "justa" à comparação dos valores de função na etapa de avaliação da eficiência.

Para atender a esse fim, foram desenhados gráficos de perfil de desempenho para diferentes critérios de convergência que se desejava analisar (veja Figura 4.2), já que o quão prematuramente um método cessa sua execução é fator determinante na precisão da resposta por ele provida. As curvas traçadas devem ser interpretadas como a porcentagem de soluções ótimas encontradas por uma dada implementação para cada valor assumido por $\varepsilon$ no critério (4.3).

Nelas estão explicitadas as tolerâncias que passaram a ser utilizadas na definição de equivalência das soluções devolvidas por cada algoritmo. Tal escolha deu-se pelo menor $\varepsilon$ para o qual a diferença entre os valores representados pelas curvas não fosse superior a $1 \%$.

Assim, um valor de função $f_{j}$ é considerado ótimo se, e somente se,

$$
f_{j} \leq f_{\min }+\varepsilon \max \left\{1,\left|f_{\min }\right|\right\} \quad \text { ou } \quad f_{j} \leq-10^{20}
$$




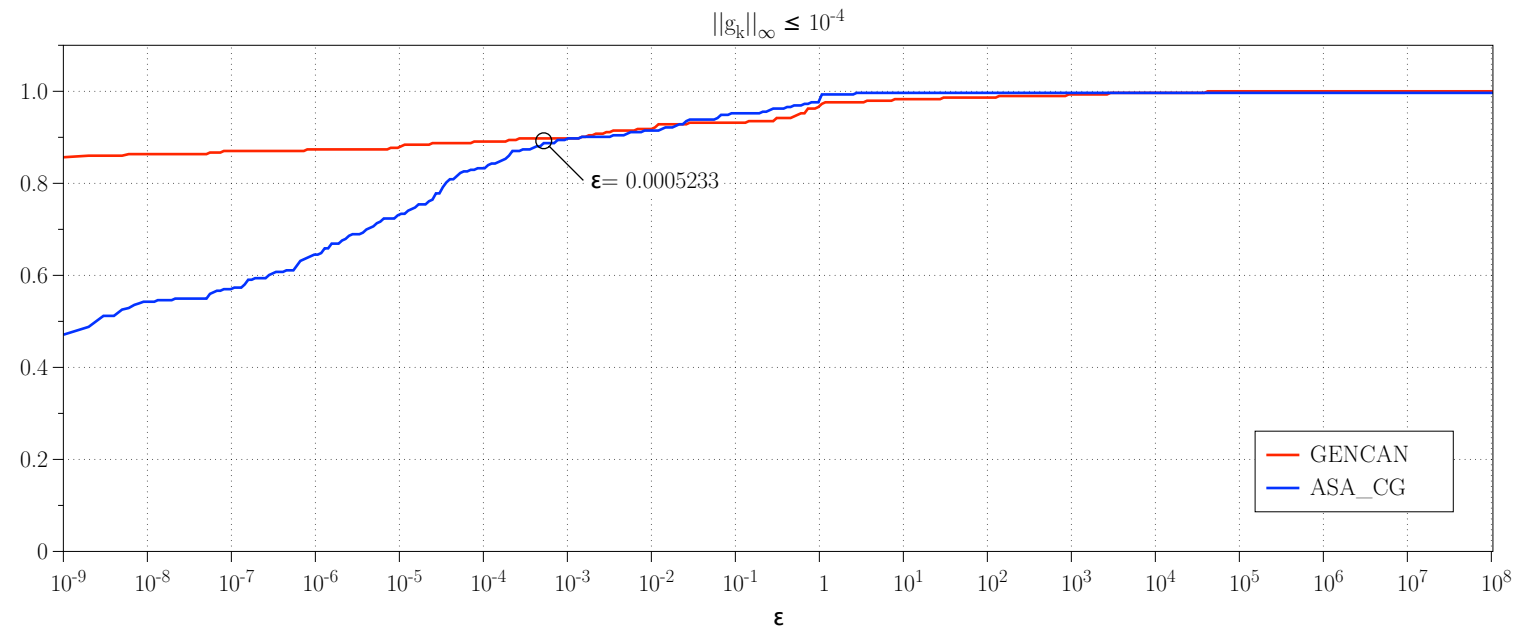

(a)

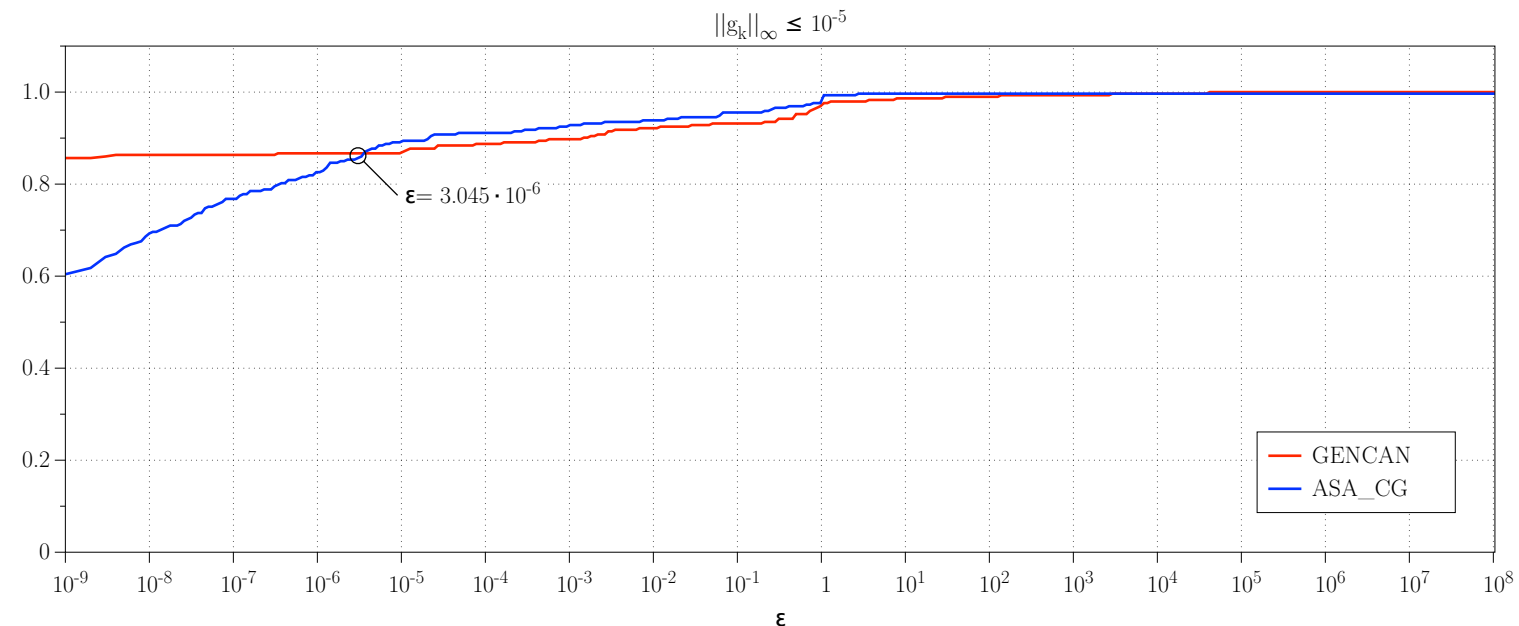

(b)

sendo $\varepsilon$ ditado pela Tabela 4.1 para diferentes critérios de convergência.

Deseja-se frisar aqui a vantagem de GENCAN no que tange à precisão das respostas obtidas, flagrante face às tolerâncias adotadas. Em um cenário em que é esse o traço mais desejável (e não o tempo demandado, por exemplo), a predileção por GENCAN é irrefutável. 


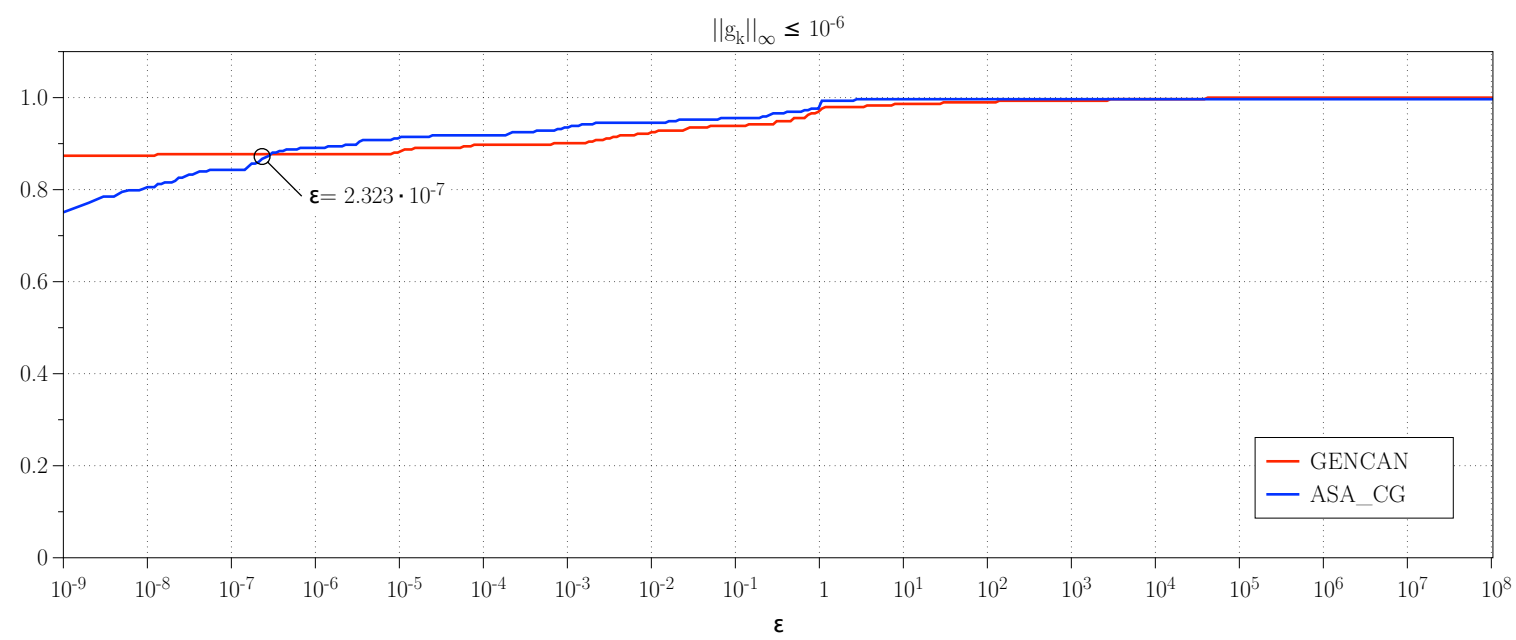

(c)

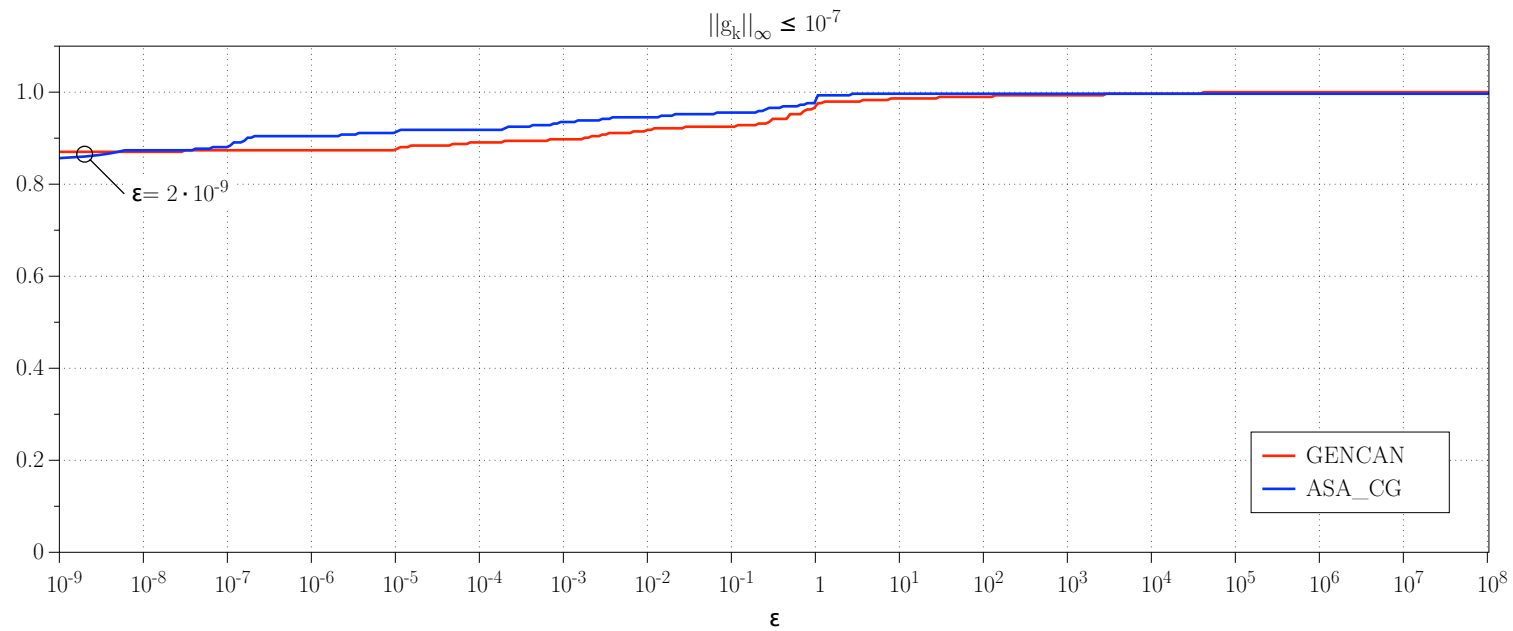

(d)

\begin{tabular}{cc}
\hline Critério de convergência & $\varepsilon$ \\
\hline$\left\|g_{k}\right\|_{\infty} \leq 10^{-4}$ & $5,233 \mathrm{E}-04$ \\
$\left\|g_{k}\right\|_{\infty} \leq 10^{-5}$ & $3,045 \mathrm{E}-06$ \\
$\left\|g_{k}\right\|_{\infty} \leq 10^{-6}$ & $2,323 \mathrm{E}-07$ \\
$\left\|g_{k}\right\|_{\infty} \leq 10^{-7}$ & $2,000 \mathrm{E}-09$ \\
$\left\|g_{k}\right\|_{\infty} \leq 10^{-8}$ & $1,000 \mathrm{E}-09$ \\
\hline
\end{tabular}

Tabela 4.1: Tolerâncias utilizadas na definição de equivalência das soluções devolvidas por cada algoritmo 


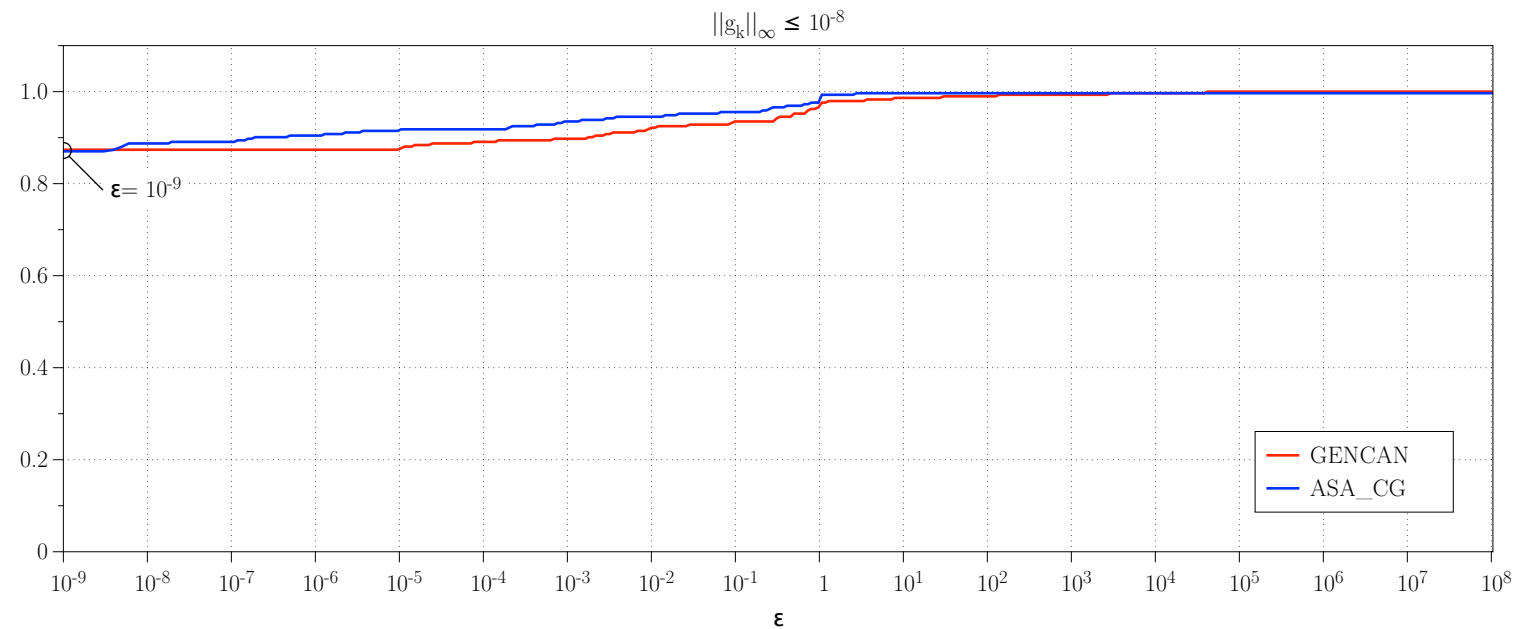

(e)

Figura 4.2: Gráficos de perfil de desempenho de ASA e GENCAN para diferentes critérios de convergência. As curvas representam a porcentagem de soluções ótimas encontradas por uma dada implementação para cada valor assumido por $\varepsilon$ no critério (4.3). Nelas estão também explicitadas as tolerâncias que passaram a ser utilizadas na definição de equivalência das soluções devolvidas por cada algoritmo. Da Figura 4.2(c), por exemplo, é possível depreender que, considerando ótima uma solução $f_{j}$ sempre que valer $\left(f_{j}-f_{\min }\right) / \max \left\{1,\left|f_{\min }\right|\right\} \leq 10^{-8}$, com $f_{\min }=\min _{j}\left\{f_{j}\right\}$, ASA a obtém em $80 \%$ das instâncias, enquanto GENCAN, em $90 \%$. 


\subsection{Experimentos Numéricos Preliminares}

Parte fundamental desta pesquisa foi a execução de experimentos numéricos que permitissem aferir e comparar a eficiência e robustez de ASA e GENCAN. Para isso, implementações de ambos os métodos foram submetidas à resolução tanto de problemas de otimização em caixas como também irrestritos pertencentes à coleção CUTEr [13]. A escolha de tal repositório foi motivada não só por sua vasta popularidade perante a comunidade de otimização mundial, mas principalmente por ter sido a mesma base de problemas empregada na comparação traçada pelos autores de [39].

Dentre todos os disponíveis, os problemas de otimização em caixas e os irrestritos totalizam, juntos, 294. Algumas estatísticas a respeito desses estão disponíveis na Tabela 4.2.

Todos os testes foram realizados em uma máquina Intel Core 2 QuAD 2, $4 \mathrm{GHz}$ com 4 GB de memória RAM e sistema operacional GNU/Linux. O código foi compilado pelo GNU ForTRAn Compiler (gfortran) 4.3 .3 com a diretiva - 04 de otimização habilitada.

Gráficos de perfil de desempenho de ASA e GENCAN com o tempo de processamento consumido como medida de comparação empregada foram gerados para todos os possíveis valores atribuídos a $\epsilon$ em (4.2) (veja Figura 4.3).

Por proverem apenas uma contagem dos problemas resolvidos por cada método, perfis de desempenho são freqüentemente criticados como único mecanismo de comparação entre rotinas. Dessa forma, a informação por eles retratada deve ser acompanhada pelas taxas de satisfação ao critério de convergência e de obtenção de uma solução ótima por cada algoritmo, detalhadas nas Tabelas 4.3 e 4.4, respectivamente.

Complementando as tabelas acima, é pertinente notar que somente uma das instâncias testadas (WALL100) não foi resolvida por nenhuma das duas implementações em razão de dificuldades de compilação da interface com CuTEr.

\begin{tabular}{ccc}
\hline Métrica & Variáveis & Caixas \\
\hline Mínimo & 1 & 0 \\
$Q_{1}$ & 4 & 0 \\
Mediana & 100 & 0 \\
$Q_{3}$ & 5000 & 12 \\
Máximo & 37311 & 20000 \\
\hline
\end{tabular}

Tabela 4.2: Mínimo, máximo, mediana e primeiro e terceiro quartis do número de variáveis e do número de restrições de caixa dos problemas considerados em experimentos numéricos 


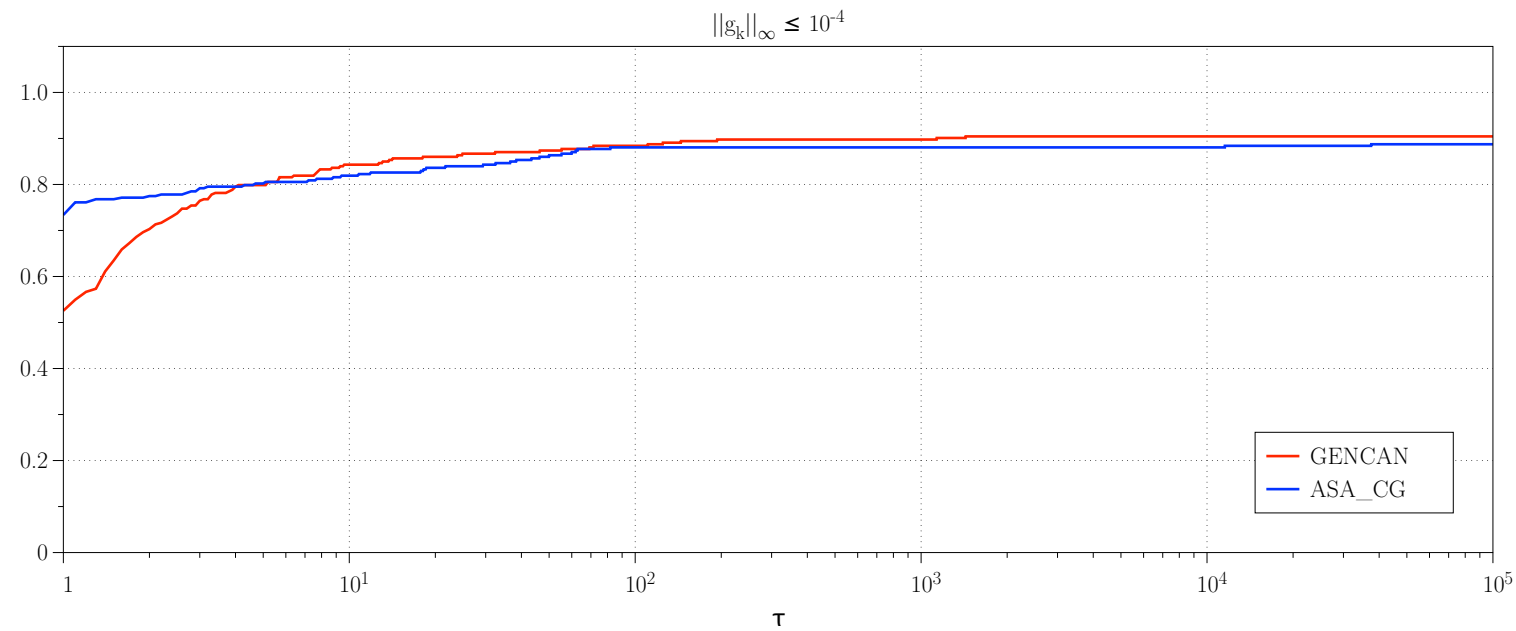

(a)

$\left\|g_{k}\right\|_{\infty} \leq 10^{-5}$

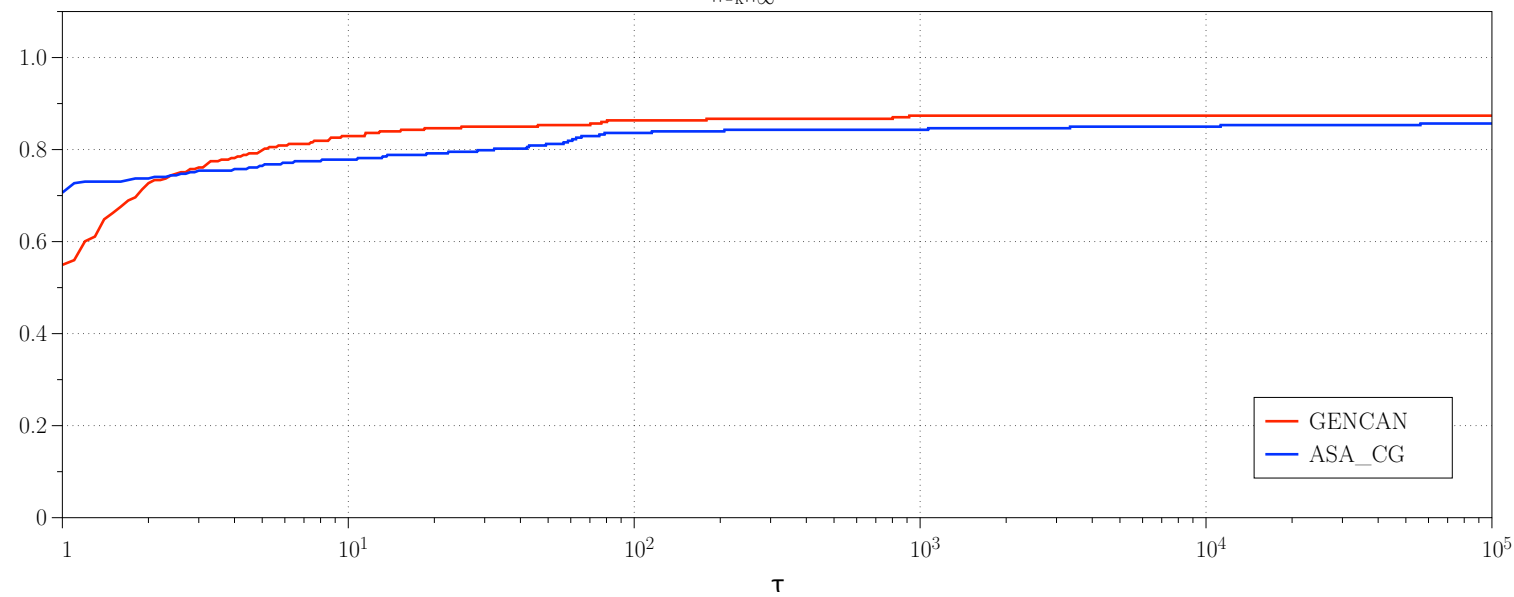

(b)

$\left\|\mathrm{g}_{\mathrm{k}}\right\|_{\infty} \leq 10^{-6}$

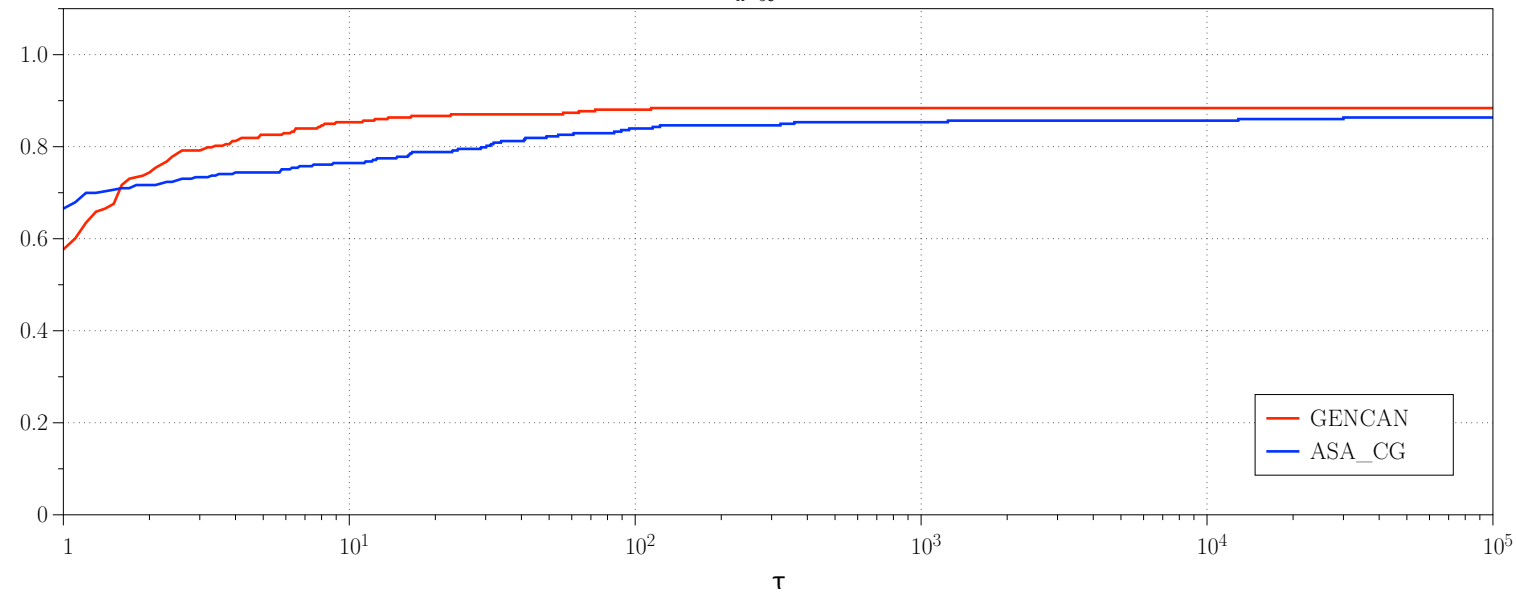

(c) 


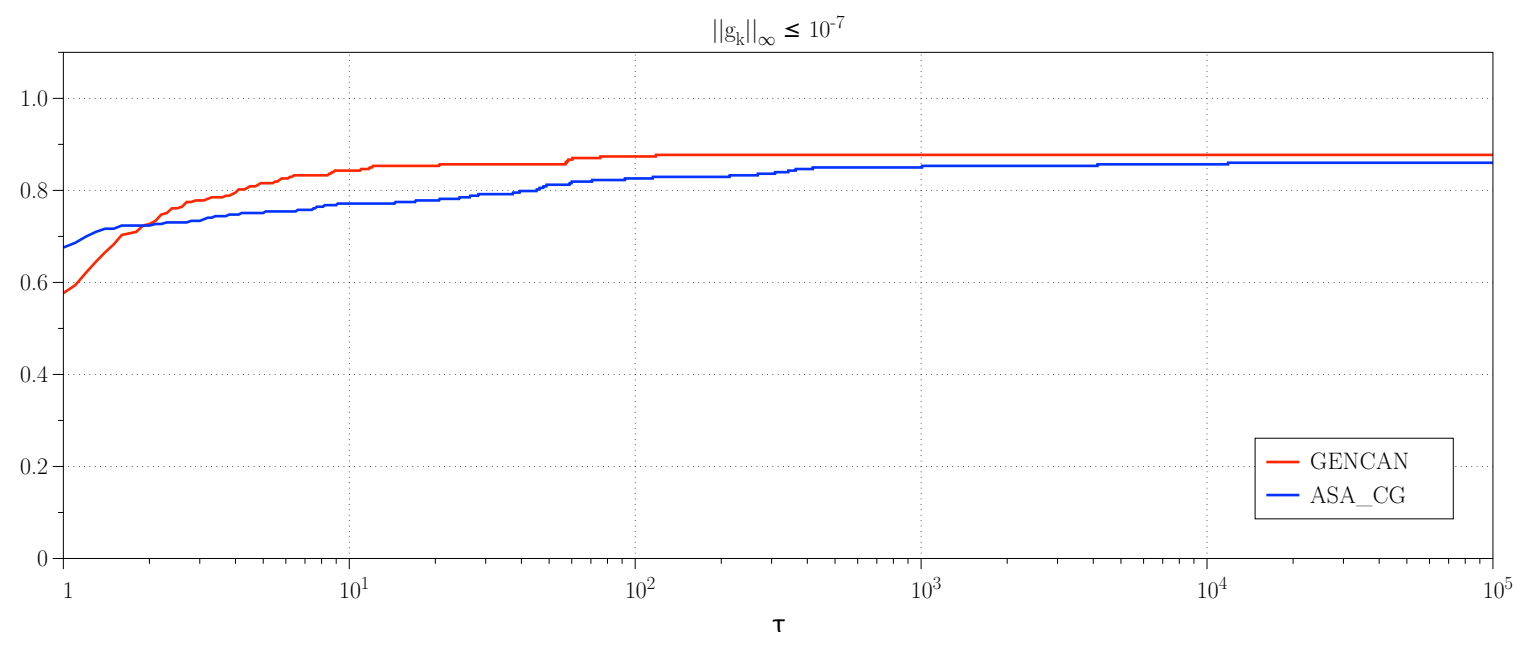

(d)

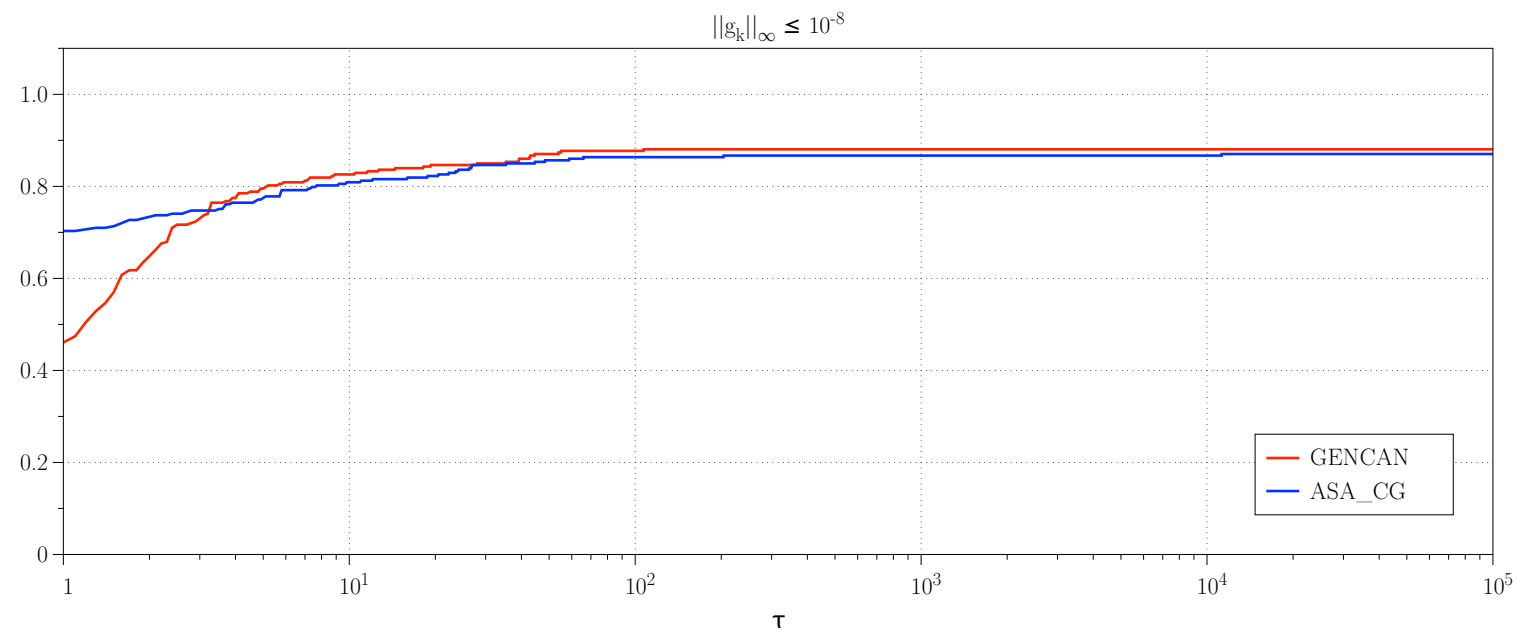

(e)

Figura 4.3: Gráficos de perfil de desempenho de ASA e GENCAN com o tempo de processamento consumido como medida de comparação empregada, gerados para todos os possíveis valores atribuídos a $\epsilon$ em (4.2)

\begin{tabular}{ccc}
\hline$\epsilon$ & GENCAN & ASA \\
\hline $10^{-4}$ & $258(88,05 \%)$ & $279(95,22 \%)$ \\
$10^{-5}$ & $255(87,03 \%)$ & $276(94,20 \%)$ \\
$10^{-6}$ & $253(86,35 \%)$ & $269(91,81 \%)$ \\
$10^{-7}$ & $248(84,64 \%)$ & $265(90,44 \%)$ \\
$10^{-8}$ & $244(83,28 \%)$ & $262(89,42 \%)$ \\
\hline
\end{tabular}

Tabela 4.3: Contagem de instâncias para as quais cada método satisfaz ao critério de convergência 


\begin{tabular}{cccc}
\hline$\epsilon$ & Apenas GENCAN & Apenas ASA & Ambos \\
\hline $10^{-4}$ & $33(11,26 \%)$ & $28(9,56 \%)$ & $232(79,18 \%)$ \\
$10^{-5}$ & $42(14,33 \%)$ & $37(12,63 \%)$ & $214(73,04 \%)$ \\
$10^{-6}$ & $40(13,65 \%)$ & $34(11,60 \%)$ & $219(74,74 \%)$ \\
$10^{-7}$ & $41(13,99 \%)$ & $36(12,29 \%)$ & $216(73,72 \%)$ \\
$10^{-8}$ & $38(12,97 \%)$ & $35(11,95 \%)$ & $220(75,09 \%)$ \\
\hline
\end{tabular}

Tabela 4.4: Contagem de instâncias para as quais cada método obtém uma solução ótima

Ao confrontar tais resultados com aqueles obtidos pelos autores de ASA, é imprescindível atentar ao fato de que, enquanto a curva dos gráficos de perfil de desempenho gerados neste trabalho indica a porcentagem de problemas para os quais um dado método foi capaz de, em um tempo de até $\tau$ vezes o consumido pelo mais rápido, obter uma solução equivalente (segundo o critério adotado) à melhor entre as devolvidas por todos os algoritmos testados, a dos gráficos por eles produzidos indica a porcentagem de instâncias para as quais cada método foi bem sucedido em convergir a um certo minimizador local naquela mesma proporção de tempo. Desse modo, tendo em vista a prevalência exibida por ASA em prover um minimizador local ao término de sua execução (veja Tabela 4.3), é possível afirmar que os resultados aqui apresentados corroboram aqueles divulgados em [39], ainda que as mesmas conclusões não se sustentem ao serem levados em conta os valores de função em tais pontos.

É interessante observar ainda que a variação dos valores atribuídos a $\epsilon$ em (4.2) não influenciou significativamente o desempenho relativo entre os métodos ou quaisquer conclusões que dele se possa deduzir. 


\section{Capítulo 5}

\section{Aprimoramento de GENCAN}

Ainda que os gráficos de perfil de desempenho levantados não sugiram uma superioridade de ASA sobre GENCAN, não se pode deixar de levar em conta a maior taxa de satisfação ao critério de convergência apresentada pelo primeiro. As instâncias testadas nas quais apenas ASAse mostrava capaz de convergir a um minimizador local foram então individualmente analisadas, revelando promissoras oportunidades de aprimoramento de GENCAN. Uma minuciosa explanação daquelas que optou-se por explorar, bem como uma síntese das tentativas de melhoria praticadas, são o conteúdo deste capítulo.

\subsection{Algoritmo Empregado Internamente às Faces}

Uma promissora via de aperfeiçoamento de GENCAN parecia estar na identificação da metodologia mais apropriada para se explorar uma face do conjunto viável. Em sua implementação originalmente proposta [10], é empregada uma abordagem de Newton truncado para o cômputo da direção de busca $d_{k}$, isto é, o sistema Newtoniano correspondente é resolvido por um algoritmo de gradientes conjugados semelhante ao apresentado na Seção 2.3 , com $Q \approx \nabla^{2} f\left(x_{k}\right)$ e $b=g\left(x_{k}\right)$. Para os produtos Hessiana-vetor que surgem ao se adotar a essa estratégia, é necessário haver uma forma de calcular a própria Hessiana, ou, alternativamente, dispor-se de uma subrotina capaz de devolver o valor desses produtos já efetuados. No que se segue, essa abordagem será referida apenas por HP.

Já quando nenhuma informação de segunda ordem é disponibilizada a GENCAN, a implementação inicialmente apresentada busca ou aproximar por meio da técnica de quocientes incrementais os produtos Hessiana-vetor cujo cômputo se faz necessário (no caso em que as restrições são todas de caixa), ou ainda uma aproximação da Hessiana pode ser empregada para se calcularem tais produtos (no caso de restrições gerais). A 
essa outra metodologia de cômputo da direção de Newton interna à face será dado o nome nesta seção de IQ.

Uma abordagem de exploração das faces do conjunto viável incorporada recentemente é a utilização de BETRA [4], um algoritmo baseado no clássico método de regiões de confiança. Porém, sua disponibilidade não vinha sendo aproveitada por GENCAN por falta de um critério de como essa nova opção seria melhor empregada. Tal estratégia será aqui denotada por TR.

Finalmente, durante o desenrolar deste trabalho, vislumbrou-se a possibilidade de implementar uma abordagem baseada em busca linear, que confiaria a um método direto (LU) o cômputo da direção de Newton. Isso então foi feito por meio das rotinas MA27 ou MA57 da HSL Mathematical Software Library [40], sendo que a segunda é preferida por GENCAN quando ambas estão disponíveis no sistema. A esse último algoritmo interno será dado o nome de NW.

Conhecendo os aspectos teóricos de cada uma das opções acima apresentadas, é razoável inferir que a escolha daquela mais apropriada para se explorar uma dada face identificada pelo método de restrições ativas está intimamente relacionada ao grau de esparsidade da matriz Hessiana. Isso porque é justamente essa a noção que determina o custo computacional de suas operações de fatoração e multiplicação por vetor, cuja necessidade diverge entre as estratégias possíveis.

No entanto, é impraticável trabalhar com a noção de esparsidade da matriz Hessiana, já que dados confiáveis para estimá-la raramente estão disponíveis. Por outro lado, ainda que a natureza do problema permitisse antevê-la, pouco poderia ser afirmado sobre a esparsidade de sua forma fatorada, como diversos casos práticos têm evidenciado.

De muito mais fácil determinação, contudo, é o número de variáveis livres, ou seja, a dimensão da face atual, da qual se pode depreender com razoável grau de confiança uma estimativa do tamanho da matriz Hessiana com que o método irá operar. Mais ainda, experimentos numéricos permitiram averiguar que a própria dimensão do problema já carrega informação suficientemente confiável para essa tomada de decisão, não se justificando reavaliar a metodologia de minimização irrestrita a ser empregada a cada iteração.

Por essas razões, resta recorrer ao número de variáveis do problema a fim de se determinar a estratégia a ser empregada por GENCAN como seu algoritmo interno. O critério desenvolvido e adotado por este estudo para tal fim encontra-se sintetizado na Tabela 5.1.

A fim de se determinar a valoração da tripla $\left(n_{0}, n_{1}, n_{2}\right)$ que levaria aos maiores ganhos 


\begin{tabular}{cccc}
\hline Dimensão do prob. & Fatoração da Hessiana & Produto por vetor & Estratégia adotada \\
\hline$n \leq n_{0}$ & eficiente & indiferente & TR \\
$n_{0}<n \leq n_{1}$ & praticável & indiferente & NW \\
$n_{1}<n \leq n_{2}$ & praticável & eficiente & HP \\
$n_{2}<n$ & inviável & inviável & IQ \\
\hline
\end{tabular}

Tabela 5.1: Características de prevalência de cada possível algoritmo interno usado por GENCAN no que diz respeito ao grau de complexidade de manipulação da matriz Hessiana. A informação contida em cada linha da tabela deve ser interpretada da seguinte forma: em problemas cuja dimensão é dada pela primeira coluna, os custos médios observados para as operações de interesse com a matriz Hessiana são os dados pela segunda e terceira colunas; assim, é adotada a estratégia dada pela quarta coluna.

de desempenho, praticaram-se diversos experimentos ditados pela intuição, os quais foram posteriormente implementados, testados, e os resultados representados em gráficos de perfil de desempenho (Figura 5.1). Neles foram confrontados os quatro possíveis algoritmos internos usados por GENCAN (TR, NW, HP e IQ) juntamente à doravante denominada "versão combinada" (COMB), que os escolhe dinamicamente com base na dimensão do problema de acordo com o critério dado pela Tabela 5.1.

Algumas tentativas se mostraram frustradas até que se chegasse ao resultado buscado. Uma delas tinha por objetivo que a versão combinada satisfizesse ao critério de convergência (4.2) (com $\epsilon=10^{-8}$ ) o maior número de vezes. Isso pode ser conseguido adotando-se, por exemplo, $\left(n_{0}, n_{1}, n_{2}\right):=(500,5000,5500)$. Tal escolha, porém, não conduz a um método mais eficiente, como torna claro o gráfico de perfil de desempenho da Figura 5.1(a).

Outra tentativa visava à maximização do número de problemas nos quais a versão combinada satisfez ao mesmo critério de convergência, porém desta vez em um intervalo de tempo menor que o despendido por cada algoritmo interno individualmente, o que se obtém com a valoração $\left(n_{0}, n_{1}, n_{2}\right):=(2000,10000,20000)$. Uma vez mais, tal decisão não se refletiu em uma ampla melhoria de desempenho de GENCAN, conforme permite concluir o gráfico de perfil de desempenho da Figura 5.1(b).

O resultado mais satisfatório foi alcançado quando se procurou determinar uma versão combinada dos algoritmos internos de GENCAN que, a exemplo do que se busca medir por meio de gráficos de perfil de desempenho, fosse capaz de maximizar a porcentagem de soluções ótimas encontradas por uma implementação em uma certa proporção (maior ou igual a 1) do tempo necessário ao método que mais rapidamente chegou àquela solução. A tripla que melhor exibe essa característica é $(500,10000,20000)$, o que fica patente com a ajuda da Figura 5.1(c). 
COMBINED1

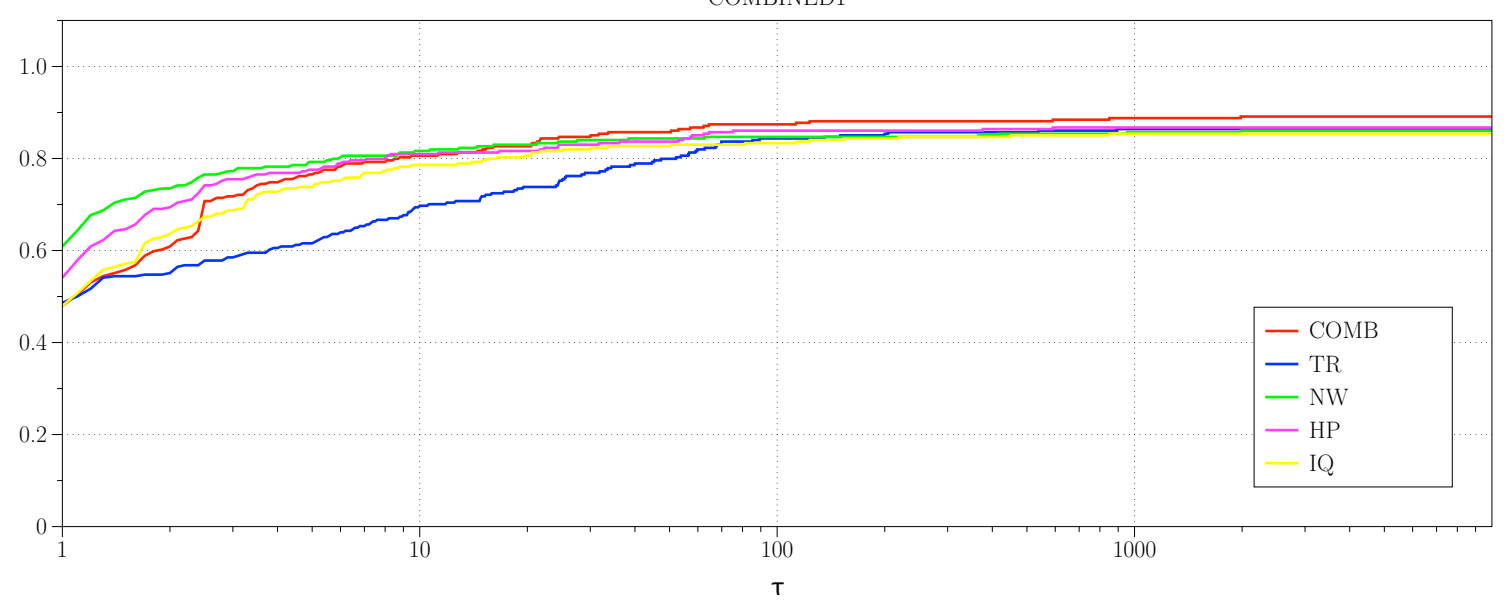

(a)

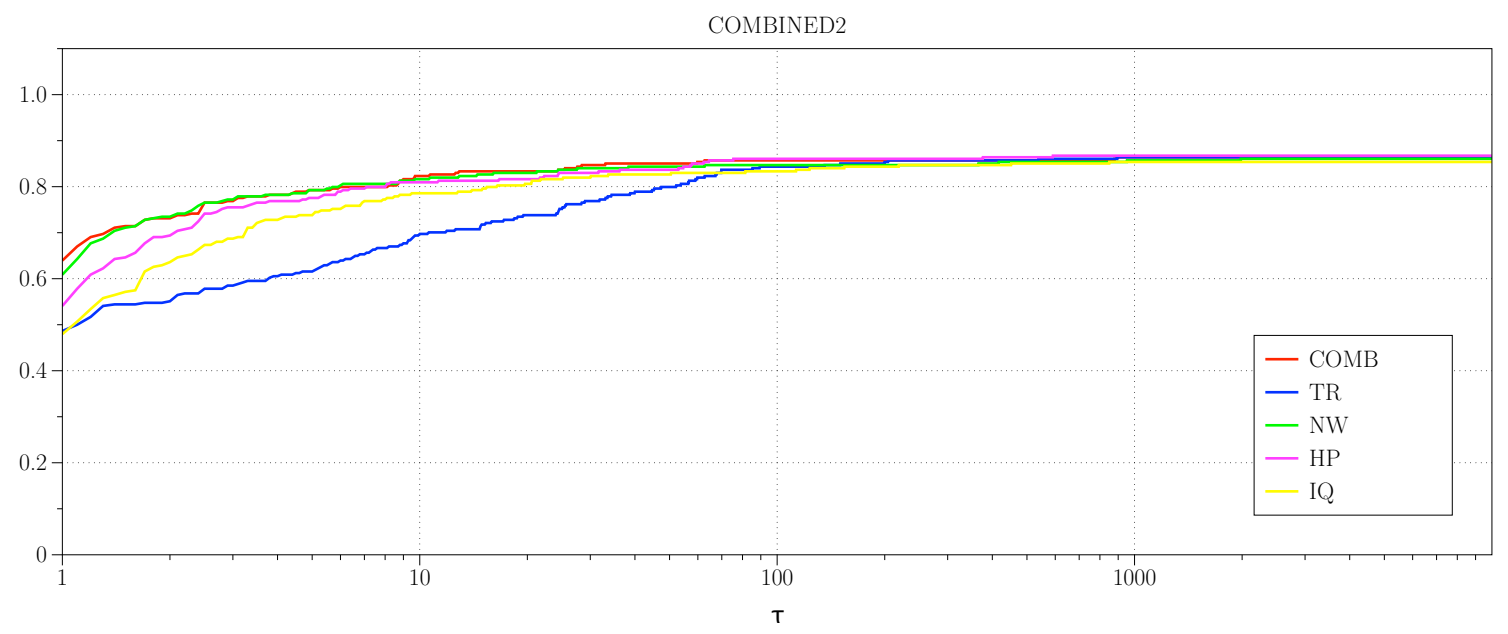

(b) 


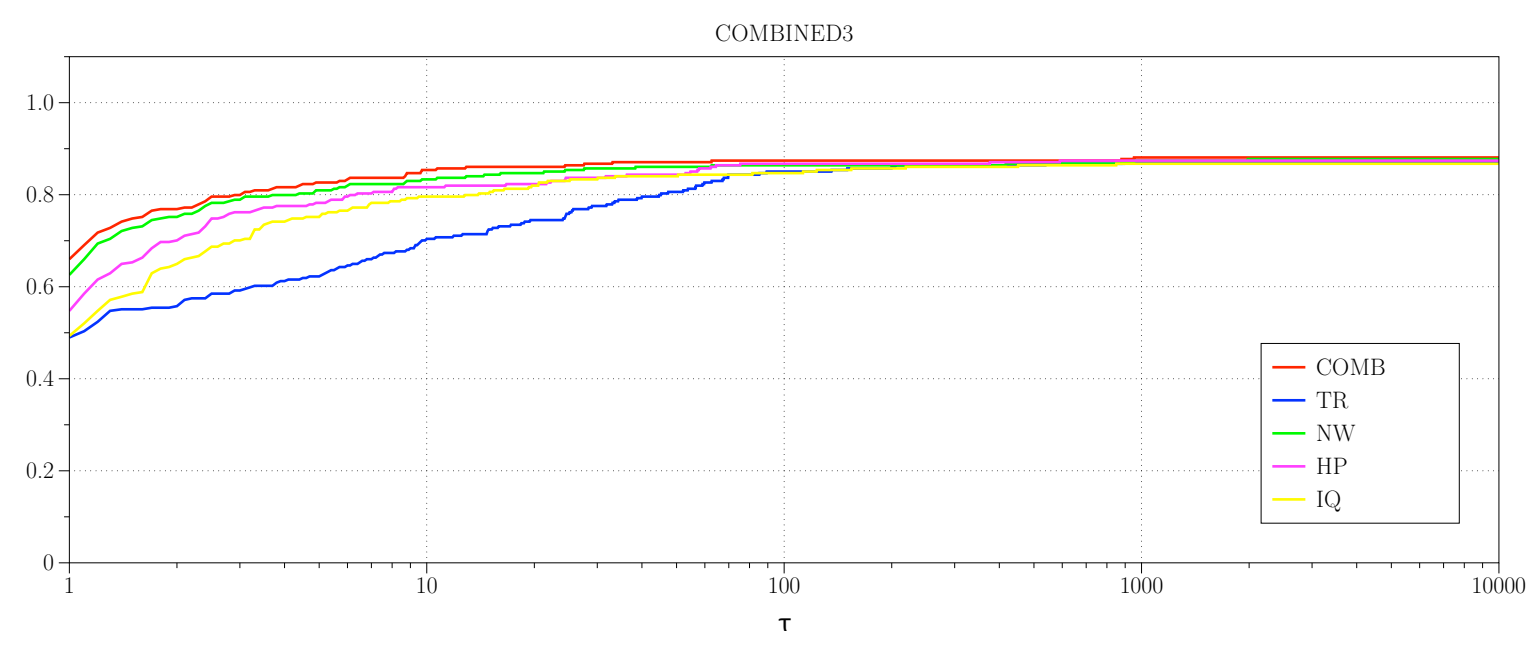

(c)

Figura 5.1: Gráficos de perfil de desempenho dos possíveis algoritmos internos usados por GENCAN (TR, NW, HP e IQ) e a versão que os escolhe dinamicamente (COMB) com o tempo de processamento consumido como medida de comparação empregada, gerados para diferentes valores assumidos por $\left(n_{0}, n_{1}, n_{2}\right)$ no critério dado pela Tabela 5.1. Na Figura 5.1(a), a versão combinada é tal que maximize o número de instâncias para as quais o critério de convergência (4.2) é satisfeito e resulta da atribuição $\left(n_{0}, n_{1}, n_{2}\right):=$ (500,5000,5500). Já na Figura 5.1(b), o objetivo buscado foi a maximização do número de problemas nos quais a versão combinada satisfez ao mesmo critério de convergência, porém desta vez em um intervalo de tempo menor que o despendido cada algoritmo interno individualmente, o que se obtém com a valoração $\left(n_{0}, n_{1}, n_{2}\right):=(2000,10000,20000)$. A Figura 5.1(c), por sua vez, retrata uma nítida melhoria de desempenho alcançada pela versão combinada resultante da tripla $(500,10000,20000)$, que pode ser interpretada como aquela capaz de maximizar a porcentagem de soluções ótimas encontradas por uma implementação em uma certa proporção (maior ou igual a 1) do tempo necessário ao método que mais rapidamente chegou àquela solução. 
Uma segunda oportunidade de melhoria relacionada ao algoritmo empregado internamente às faces pôde ser percebida estudando-se o comportamento de GENCAN para alguns problemas mal condicionados. O fênomeno detectado acontece quando o algoritmo interno empregado é o de busca linear, que calcula a direção de descida por meio da resolução efetiva do sistema Newtoniano. Sabendo-se que a matriz Hessiana ser definida positiva é uma condição suficiente ao fato de que a direção de Newton seja de descida e, por conseguinte, à convergência do método de Newton globalizado, na implementação proposta de GENCAN é somada uma quantia à diagonal da Hessiana sempre que tal condição não se verifica. Entretanto, se muito for somado a ponto de os elementos da diagonal se tornarem demasiadamente grandes em relação aos demais, corre-se o risco de a Hessiana se assemelhar a um múltiplo (também grande) da matriz identidade, fazendo com que a direção computada se resuma a um múltiplo pequeno do gradiente negativo, ao longo do qual o método não é capaz de convergir. Nesse caso, alterando-se a forma de cômputo da direção para um método de gradientes conjugados, em razão da forma como GENCAN o implementa, será obtida uma nova direção de descida que permitirá ao método deixar o ponto atual. Assim, foi adicionada uma simples verificação de se o valor somado à diagonal da Hessiana é superior à maior entrada da matriz, o que troca o algoritmo interno unicamente para a iteração seguinte.

\subsection{Escalamento do Sistema Linear}

Para as estratégias TR e NW, decidiu-se investigar se seria vantajoso adotar o escalamento (i.e. scaling) do sistema linear por padrão, sempre que uma rotina da HSL capaz de fazê-lo estivesse disponível ao método (em ordem de preferência, MA57, MC77 ou MC30). Para isso, procedeu-se à execução de GENCAN para os dois possíveis cenários, que foram comparados via perfil de desempenho. Observando o gráfico da Figura 5.2, não restam dúvidas de que a realização de scaling do sistema deve se tornar a política padrão, caracterizando essa como mais uma das melhorias implementadas. 


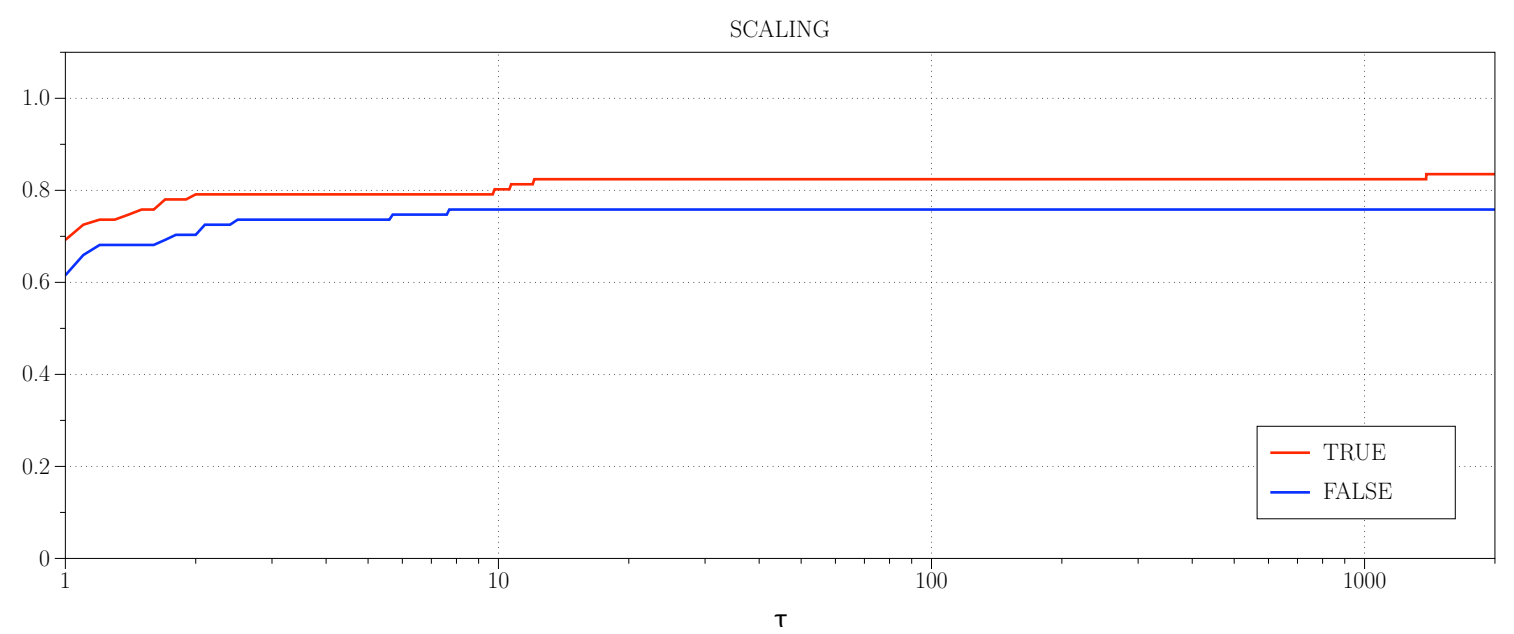

Figura 5.2: Gráfico de perfil de desempenho de duas implementações de GENCAN, com (TRUE) e sem (FALSE) escalamento do sistema linear para as estratégias TR e NW.

\subsection{Critérios de Parada Secundários}

Lembrando que todos os critérios de parada não relacionados à convergência do método foram desativados para a realização dos experimentos numéricos preliminares, coube a este trabalho a tarefa de reavaliar sua influência ao funcionamento geral do método.

Ao reintroduzi-los, ficou evidente sua influência negativa às taxas de satisfação ao critério de convergência de GENCAN. Foi possível observar, por exemplo, que os critérios que isoladamente aferiam a falta de progresso pelo algoritmo quer do valor da função objetivo, quer da norma do gradiente projetado, quer do ponto atual, quase sempre intervinham prematuramente, não permitindo que o critério (4.2) chegasse a ser atendido. Dessa forma, procedeu-se a uma análise individual das instâncias testadas nas quais GENCAN se mostrava incapaz de convergir a um minimizador local, estudo esse que culminou na concepção de um novo critério de parada secundário, mais simples e elegante, além de unificado. Para avaliá-lo, são monitorados os seguintes eventos:

1. Falta de progresso do melhor valor da função objetivo já avaliado.

2. Falta de progresso da melhor norma infinito ou da melhor norma euclidiana do gradiente projetado.

3. Falta de progresso do valor da norma infinito ou da norma euclidiana do ponto atual.

Caso todos os três ocorram por três iterações consecutivas, o método pára ainda que não tenha satisfeito ao critério de convergência. 
Os efeitos dessa reestruturação foram a prevenção de paradas prematuras em instâncias para as quais o critério de convergência, fosse prorrogada a execução do método, viria a ser satisfeito, e a economia de tempo advinda de se abortarem os casos para os quais isso não seria possível. Os resultados dos experimentos numéricos podem ser apreciados no próximo capítulo. 


\section{Capítulo 6}

\section{Experimentos Numéricos}

Já tendo sido a metodologia de testes amplamente discutida, basta observar que foi rigorosamente seguida nos experimentos numéricos cujos resultados são apresentados neste capítulo. A única providência adicional tomada foi a remoção o problema WALL100 do conjunto de instâncias testadas, já que sua compilação se mostrou problemática.

\subsection{GENCAN versus ASA}

Primeiramente, optou-se por refazer as comparações entre ASA e GENCAN para o mesmo critério de convergência anteriormente adotado:

$$
\left\|g_{k}\right\|_{\infty} \leq \epsilon
$$

com $\epsilon$ assumindo valores no conjunto $\left\{10^{-8}, 10^{-7}, 10^{-6}, 10^{-5}, 10^{-4}\right\}$.

O novo critério de parada secundário foi habilitado, bem como o limite de tempo de CPU esteve fixado em $1800 \mathrm{~s}$. As demais configurações do contexto de testes foram mantidas.

Os gráficos de perfil de desempenho produzidos podem ser encontrados na Figura 6.1, enquanto as demais métricas de comparação estão detalhadas nas Tabelas 6.1 e 6.2.

A indicação mais patente de melhoria é a taxa de satisfação ao critério de convergência, métrica na qual GENCAN supera ASA pela primeira vez desde a publicação desse. A fim de deixar ainda mais evidente o sensível ganho de desempenho sofrido por GENCAN, foram realizadas comparações entre as versões antiga e atual, cujos resultados são apresentados a seguir. 
$\left\|g_{k}\right\|_{\infty} \leq 10^{-4}$

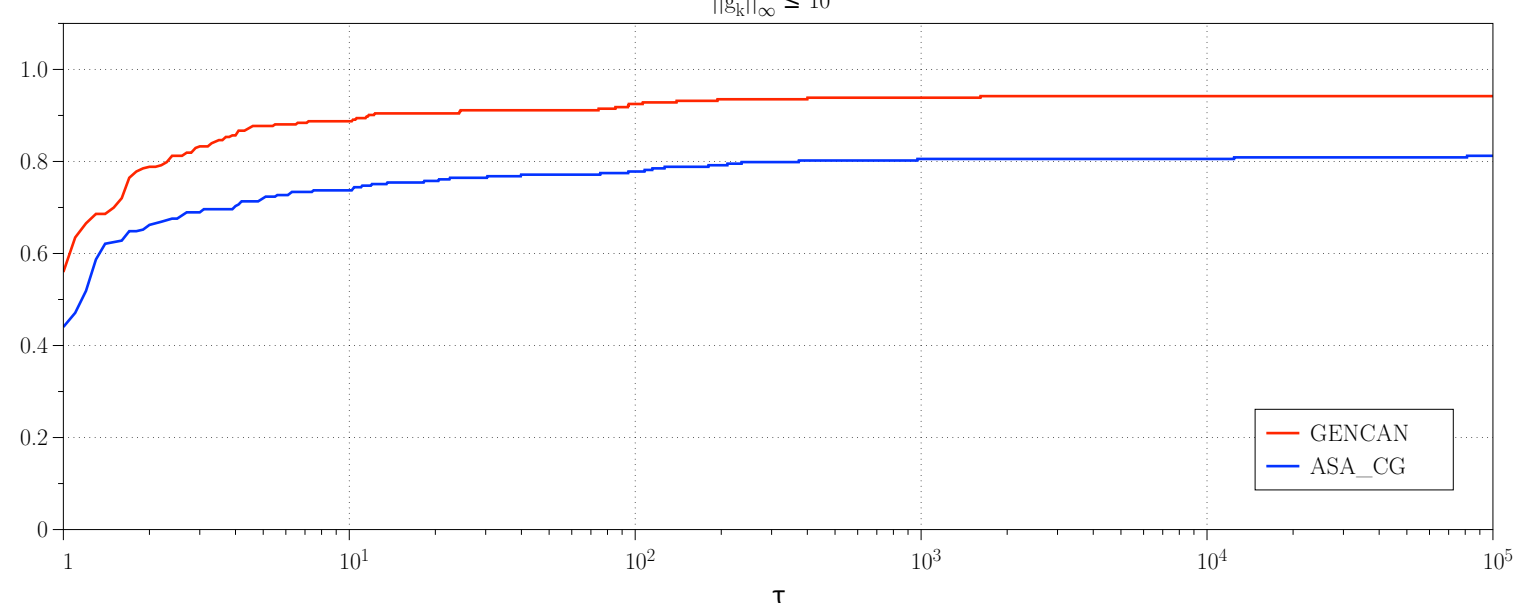

(a)

$\left\|g_{k}\right\|_{\infty} \leq 10^{-5}$

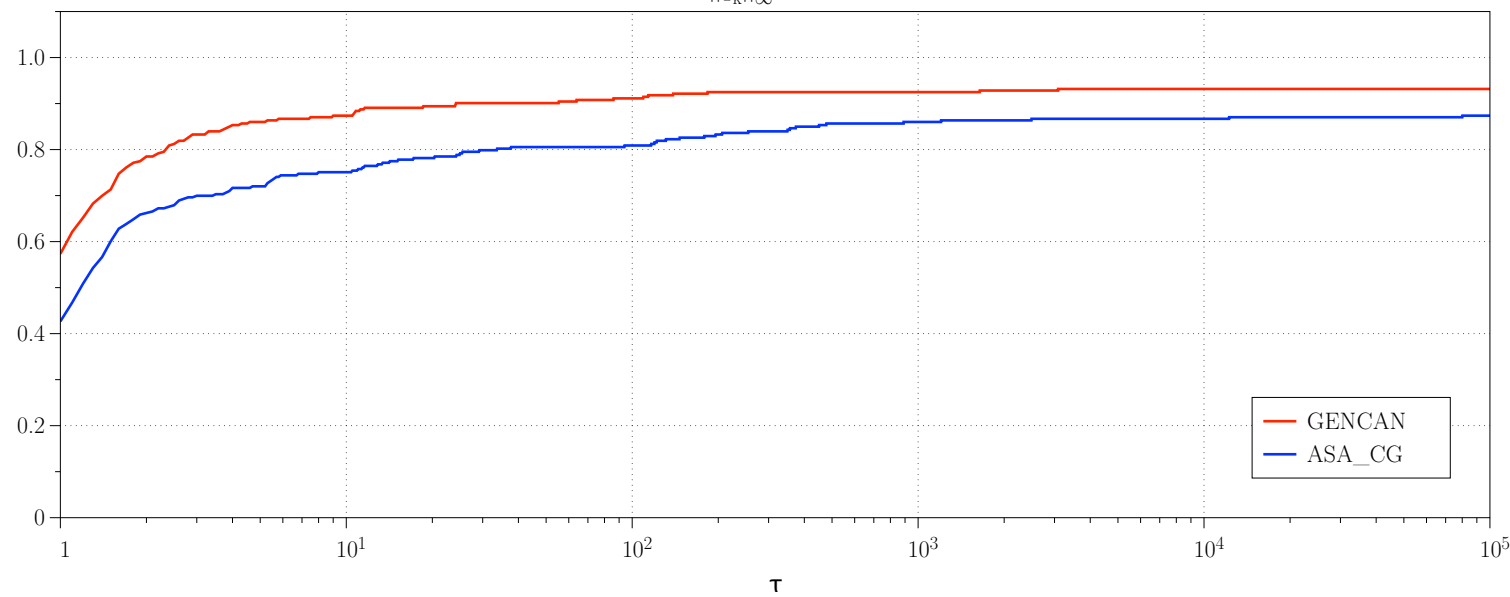

(b)

$\left\|g_{k}\right\|_{\infty} \leq 10^{-6}$

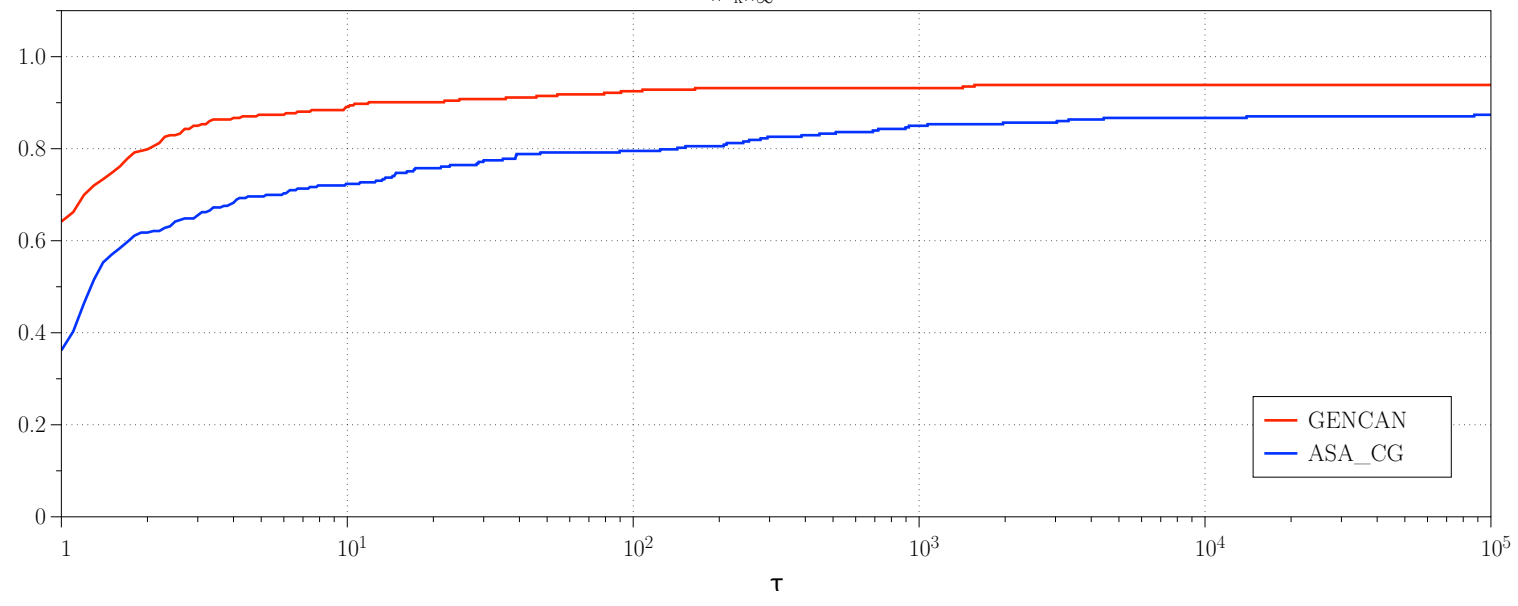

(c) 


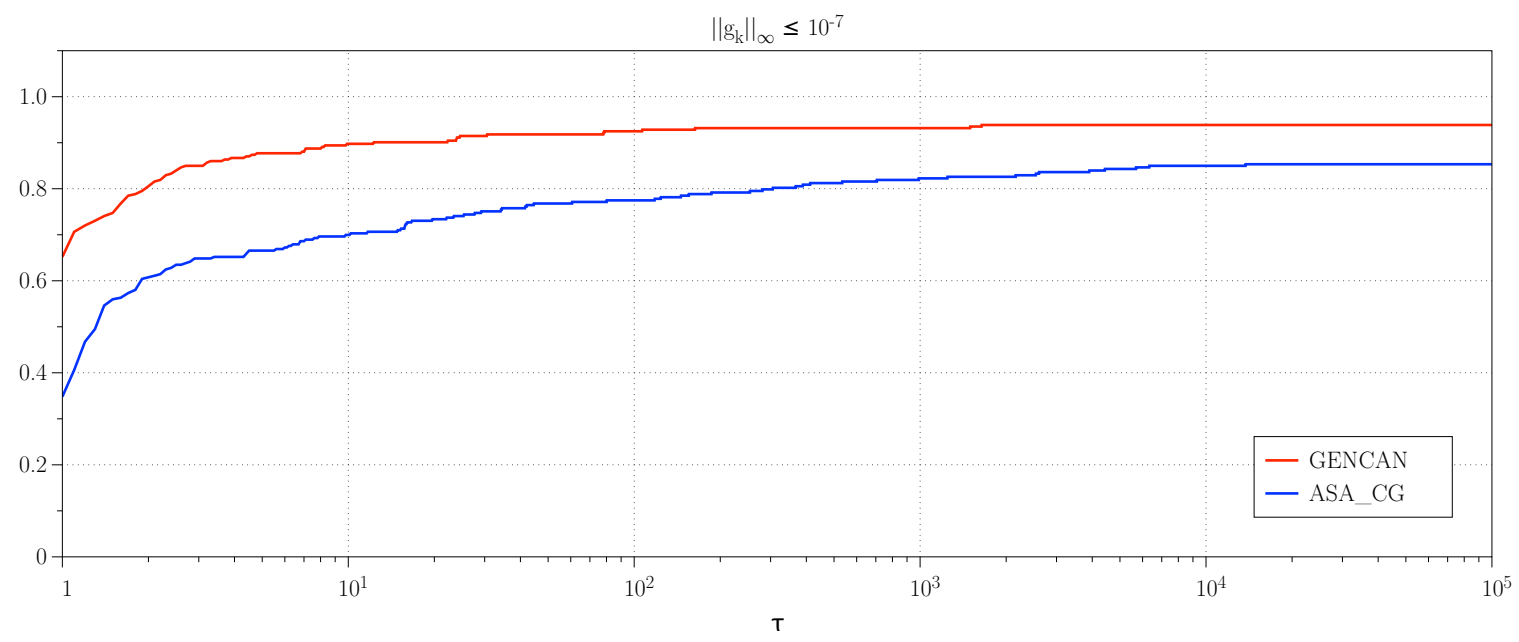

(d)

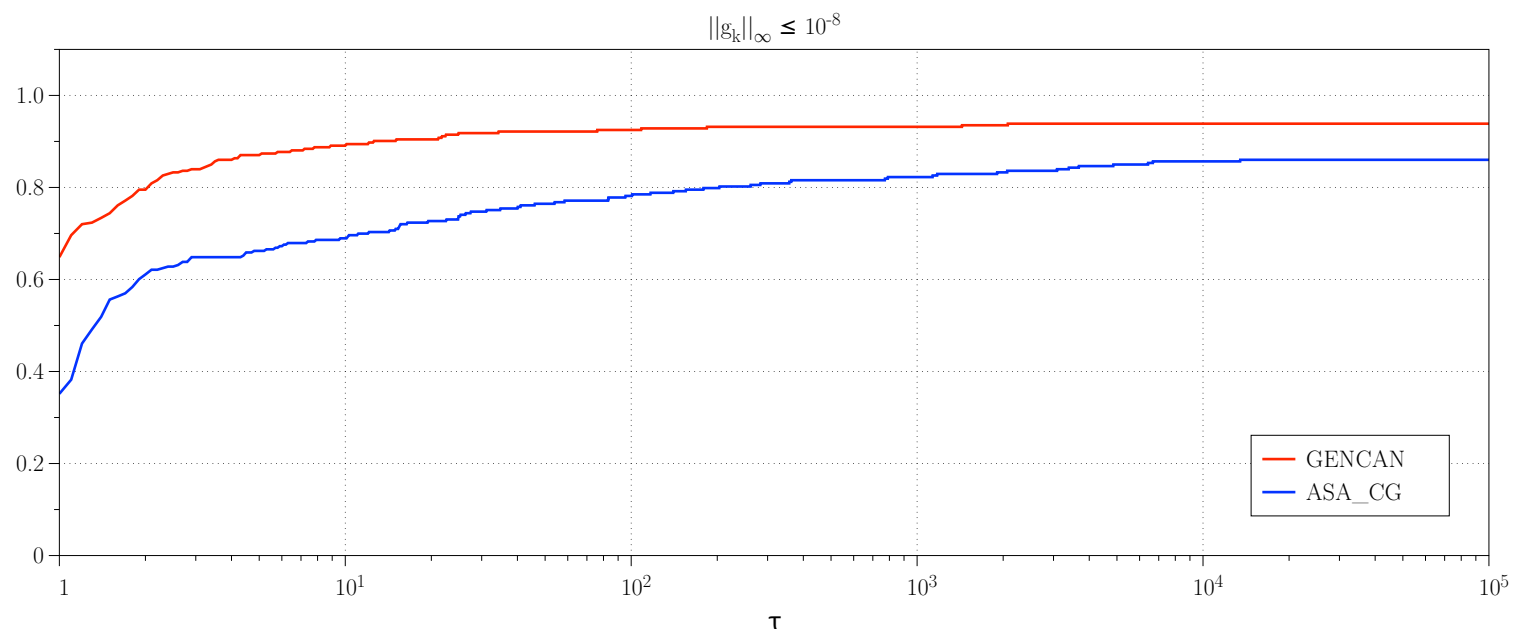

(e)

Figura 6.1: Gráficos de perfil de desempenho de ASA e GENCAN com o tempo de processamento consumido como medida de comparação empregada.

\begin{tabular}{ccc}
\hline$\epsilon$ & GENCAN & ASA \\
\hline $10^{-4}$ & $276(94,20 \%)$ & $279(95,22 \%)$ \\
$10^{-5}$ & $275(93,86 \%)$ & $276(94,20 \%)$ \\
$10^{-6}$ & $270(92,15 \%)$ & $269(91,81 \%)$ \\
$10^{-7}$ & $268(91,47 \%)$ & $265(90,44 \%)$ \\
$10^{-8}$ & $265(90,44 \%)$ & $262(89,42 \%)$ \\
\hline
\end{tabular}

Tabela 6.1: Contagem de instâncias para as quais cada método satisfaz ao critério de convergência 


\begin{tabular}{cccc}
\hline$\epsilon$ & Apenas GENCAN & Apenas ASA & Ambos \\
\hline $10^{-4}$ & $55(18,77 \%)$ & $17(5,80 \%)$ & $221(75,43 \%)$ \\
$10^{-5}$ & $37(12,63 \%)$ & $20(6,83 \%)$ & $236(80,55 \%)$ \\
$10^{-6}$ & $37(12,63 \%)$ & $18(6,14 \%)$ & $238(81,23 \%)$ \\
$10^{-7}$ & $43(14,68 \%)$ & $18(6,14 \%)$ & $232(79,18 \%)$ \\
$10^{-8}$ & $41(13,99 \%)$ & $18(6,14 \%)$ & $234(79,86 \%)$ \\
\hline
\end{tabular}

Tabela 6.2: Contagem de instâncias para as quais cada método obtém uma solução ótima

\subsection{GENCAN Antes versus Após Aprimoramento}

Nesta seção encontram-se confrontados GENCAN em sua implementação anterior aos aprimoramentos descritos no capítulo anterior (versão aqui chamada de OLD) e a atual (analogamente, NEW), amplamente beneficiada de todas as alterações propostas.

Os gráficos de perfil de desempenho concentrados na Figura 6.2 não deixam dúvidas quanto ao efeito positivo das modificações efetuadas - é flagrante o ganho não só de robustez, mas principalmente de eficiência. Além da disponibilidade de novos algoritmos internos ao método, parte dessa evolução deve ser também creditada ao refinamento do critério de parada secundário, que tem se mostrado muito eficaz em abreviar o tempo de processamento de diversos problemas. Os motivos que levaram ao término da execução em cada instância estão contabilizados na Tabela 6.3.

Completando a análise destes experimentos, a Tabela 6.4 compara as versões de GENCAN quanto à qualidade das soluções encontradas. O aumento de cerca de $5 \%$ na taxa de satisfação ao critério de convergência pela nova versão de GENCAN sem que, para isso, tenha sido necessário renunciar a nenhuma das tantas outras vantagens já exibidas pelo método caracteriza uma das mais importantes contribuições deste trabalho. 
$\left\|g_{k}\right\|_{\infty} \leq 10^{-4}$

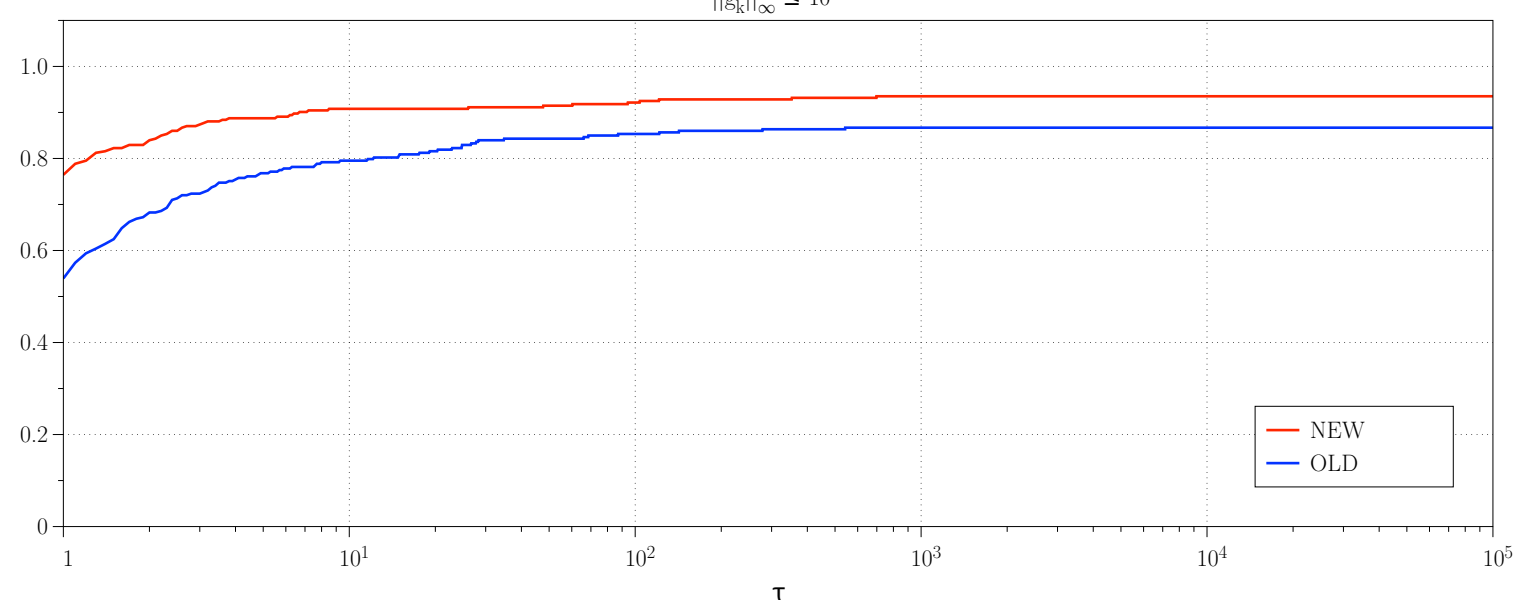

(a)

$\left\|g_{k}\right\|_{\infty} \leq 10^{-5}$

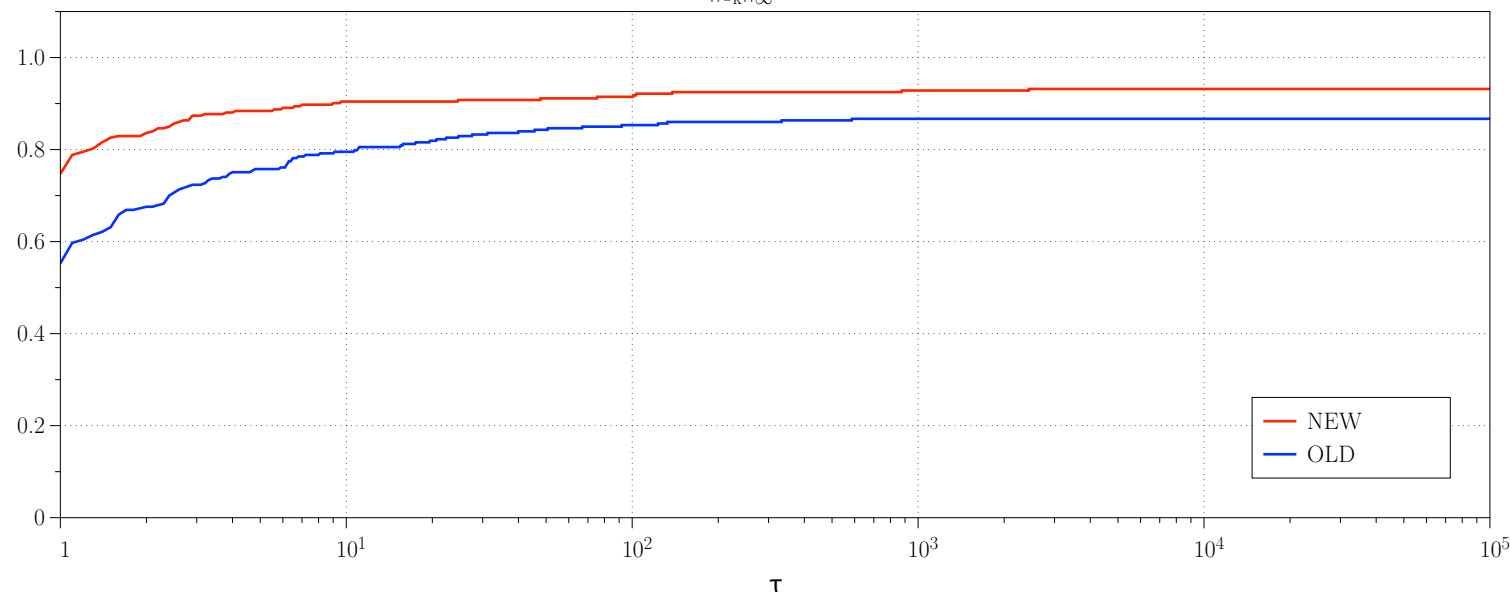

(b)

$\left\|g_{k}\right\|_{\infty} \leq 10^{-6}$

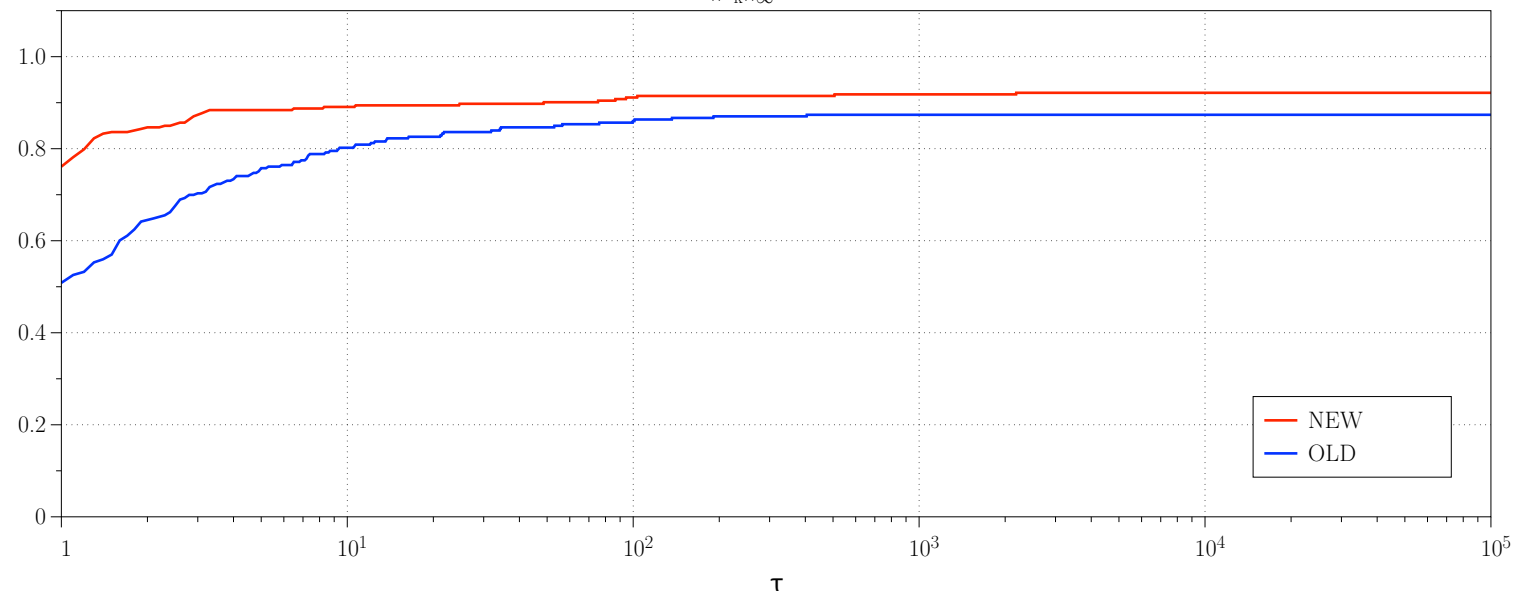

(c) 


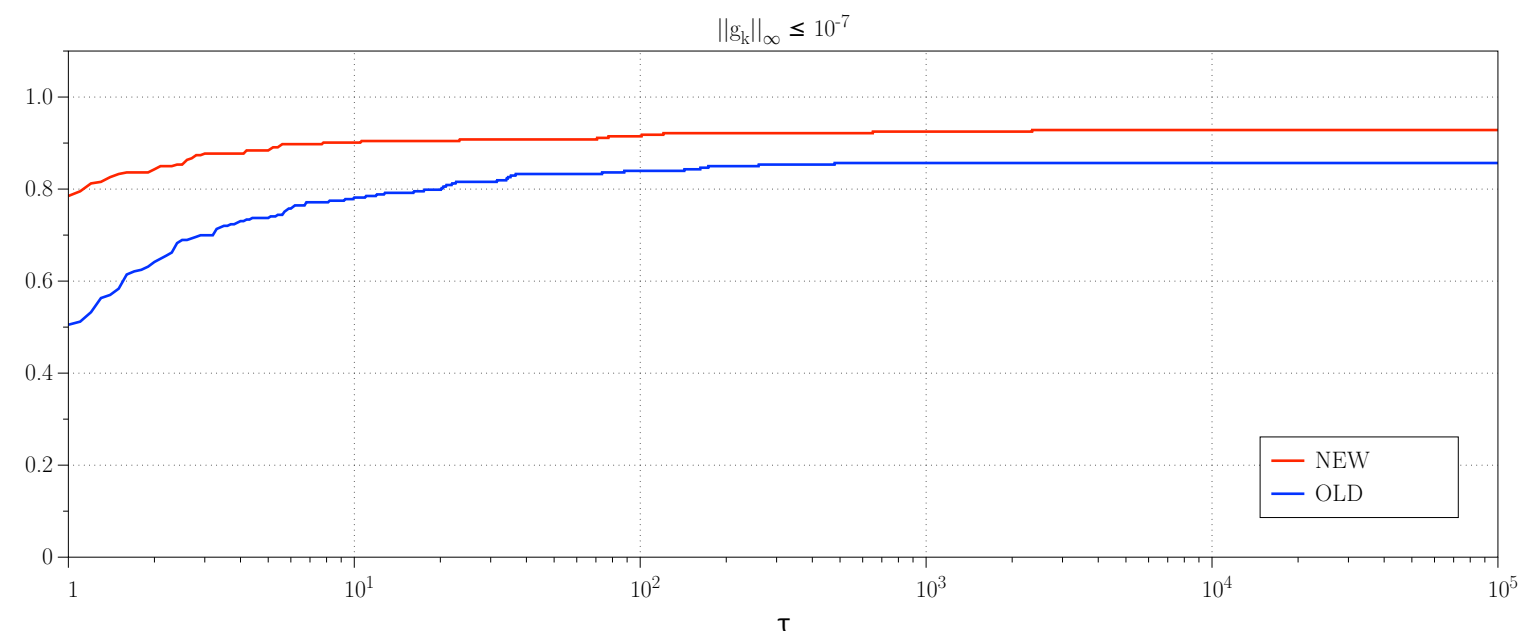

(d)

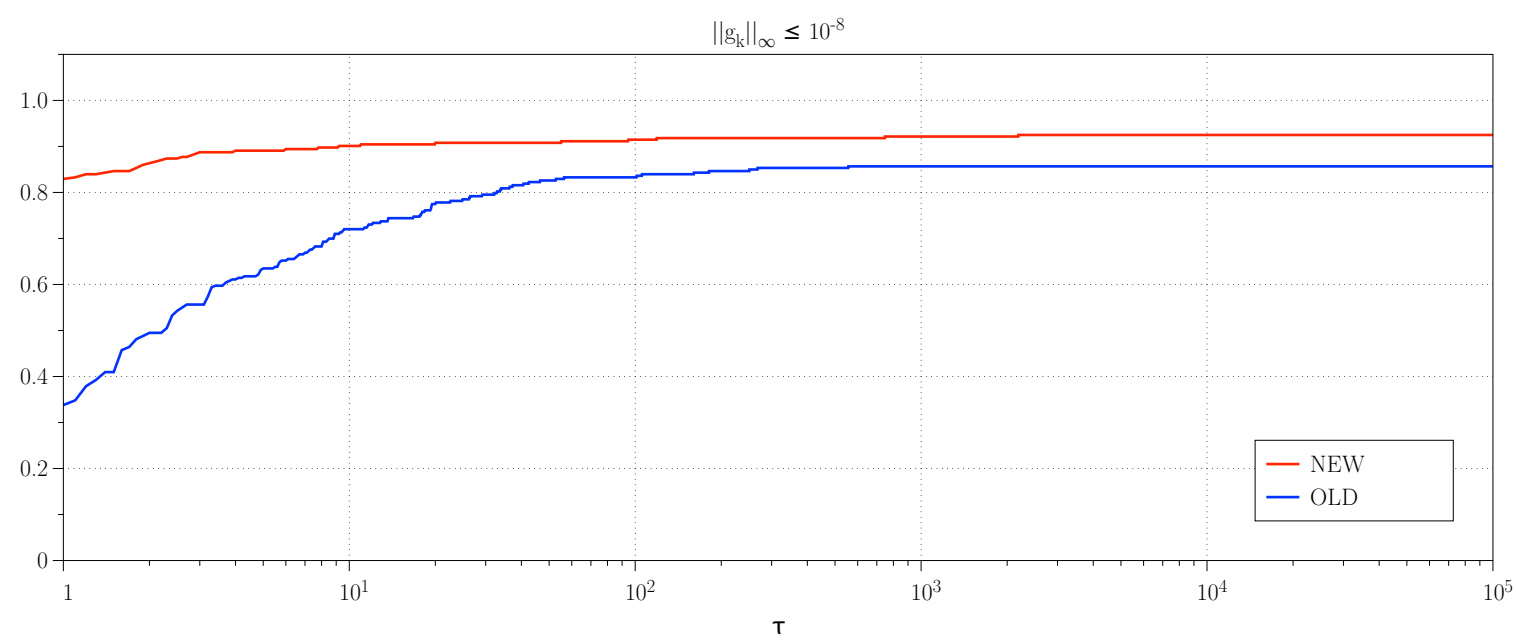

(e)

Figura 6.2: Gráficos de perfil de desempenho das versões antiga (OLD) e nova (NEW) de GENCAN com o tempo de processamento consumido como medida de comparação empregada. 


\begin{tabular}{cccccccc}
\hline & \multicolumn{2}{c}{ Sucesso } & & Falta de progresso & & \multicolumn{2}{c}{ Limite de tempo } \\
\cline { 2 - 3 } \cline { 7 - 8 }$\epsilon$ & NEW & OLD & & NEW & & NEW & OLD \\
\hline $10^{-4}$ & $276(94,20 \%)$ & $269(91,81 \%)$ & & $8(2,73 \%)$ & & $9(3,07 \%)$ & $24(8,19 \%)$ \\
$10^{-5}$ & $275(93,86 \%)$ & $265(90,44 \%)$ & & $9(3,07 \%)$ & & $9(3,07 \%)$ & $28(9,56 \%)$ \\
$10^{-6}$ & $270(92,15 \%)$ & $262(89,42 \%)$ & & $12(4,10 \%)$ & & $11(3,75 \%)$ & $31(10,58 \%)$ \\
$10^{-7}$ & $268(91,47 \%)$ & $258(88,05 \%)$ & & $14(4,78 \%)$ & & $11(3,75 \%)$ & $35(11,95 \%)$ \\
$10^{-8}$ & $265(90,44 \%)$ & $254(86,69 \%)$ & & $18(6,14 \%)$ & & $10(3,41 \%)$ & $39(13,31 \%)$ \\
\hline
\end{tabular}

Tabela 6.3: Contagem de instâncias para as quais a execução findou por um dado motivo. Como "Sucesso" foram contabilizados tanto os problemas para os quais o critério de convergência foi satisfeito quanto aqueles que o método detectou serem irrestritos. Já "Falta de progresso" engloba toda interrupção provocada pelo critério secundário (v. Seção 5.3), ao passo que "Limite de tempo" encerra os casos em que o algoritmo ainda estava sendo executado quando o tempo máximo de CPU foi atingido. A inexistência de ocorrências de parada por "Falta de progresso" na primeira versão de GENCAN (OLD) deve-se ao fato de o critério por ela responsável haver sido suprimido dada sua ineficácia.

\begin{tabular}{cccc}
\hline$\epsilon$ & Apenas NEW & Apenas OLD & Ambos \\
\hline $10^{-4}$ & $39(13,31 \%)$ & $19(6,48 \%)$ & $235(80,20 \%)$ \\
$10^{-5}$ & $39(13,31 \%)$ & $20(6,83 \%)$ & $234(79,86 \%)$ \\
$10^{-6}$ & $37(12,63 \%)$ & $23(7,85 \%)$ & $233(79,52 \%)$ \\
$10^{-7}$ & $42(14,33 \%)$ & $21(7,17 \%)$ & $230(78,50 \%)$ \\
$10^{-8}$ & $42(14,33 \%)$ & $22(7,51 \%)$ & $229(78,16 \%)$ \\
\hline
\end{tabular}

Tabela 6.4: Contagem de instâncias para as quais cada método obtém uma solução ótima 


\subsection{GENCAN versus Outros Métodos}

A qualidade dos resultados obtidos motivou a realização de comparações de desempenho mais abrangentes e minuciosas. Para isso, foram selecionados os métodos mais bem estabelecidos e de código aberto que também se prestam a resolver problemas de otimização em caixas. Além do próprio ASA, o conjunto testado foi o seguinte:

IPOPT [45] Baseado em uma estratégia de pontos interiores, destina-se a tratar problemas de otimização não-linear em grande escala. Utilizou-se a versão 3.8.

L-BFGS-B [15,48] Adota um algoritmo de otimização quasi-Newton para resolver problemas de otimização em caixas sem jamais calcular explicitamente a matriz Hessiana. A versão empregada foi a 2.1.

LANCELOT B [20] Reformulação de LANCELOT, atende ao propósito de minimizar uma função objetivo sujeita a restrições não-lineares e com grande número de variáveis. Foi obtido em sua versão 2.1.

fmincon $[16,17]$ Dos diversos algoritmos disponibilizados sob uma mesma interface, o chamado "Trust Region Reflective Algorithm" é o padrão para problemas de otimização em caixas e, assim, foi empregado neste estudo. Sua utilização se deu por meio do pacote MATLAB R2008b.

SPG [11,12] Presta-se a minimizar funções suaves com restrições convexas cujo número de variáveis é potencialmente muito grande. O código obtido havia sido modificado pela última vez em 13 de abril de 2010.

Todos esses métodos foram submetidos à mesma rotina de testes já descrita. A única variação deu-se quanto à escolha do valor assumido por $\varepsilon$ no critério que define equivalência entre uma solução $f_{j}$ e a melhor resposta $f_{\text {min }}$ produzida:

$$
\frac{f_{j}-f_{\min }}{\max \left\{1,\left|f_{\min }\right|\right\}} \leq \varepsilon
$$

$\operatorname{com} f_{\min }=\min _{j}\left\{f_{j}\right\}$. Isso porque não se pode estender a métodos tão distintos em seu funcionamento e desempenho a suposição sustentada na Seção 4.3 de que, para certa tolerância $\varepsilon$ aceitável, seria possível considerá-los igualmente robustos.

A fim de investigar o efeito que essa decisão poderia ter sobre o resultado da comparação, foram traçados gráficos da eficiência e da robustez — definidas aqui simplesmente como os valores às margens esquerda e direita, respectivamente, de seu perfil de desempenho exibidas pelas implementações conforme suas respostas eram confrontadas utilizando-se 


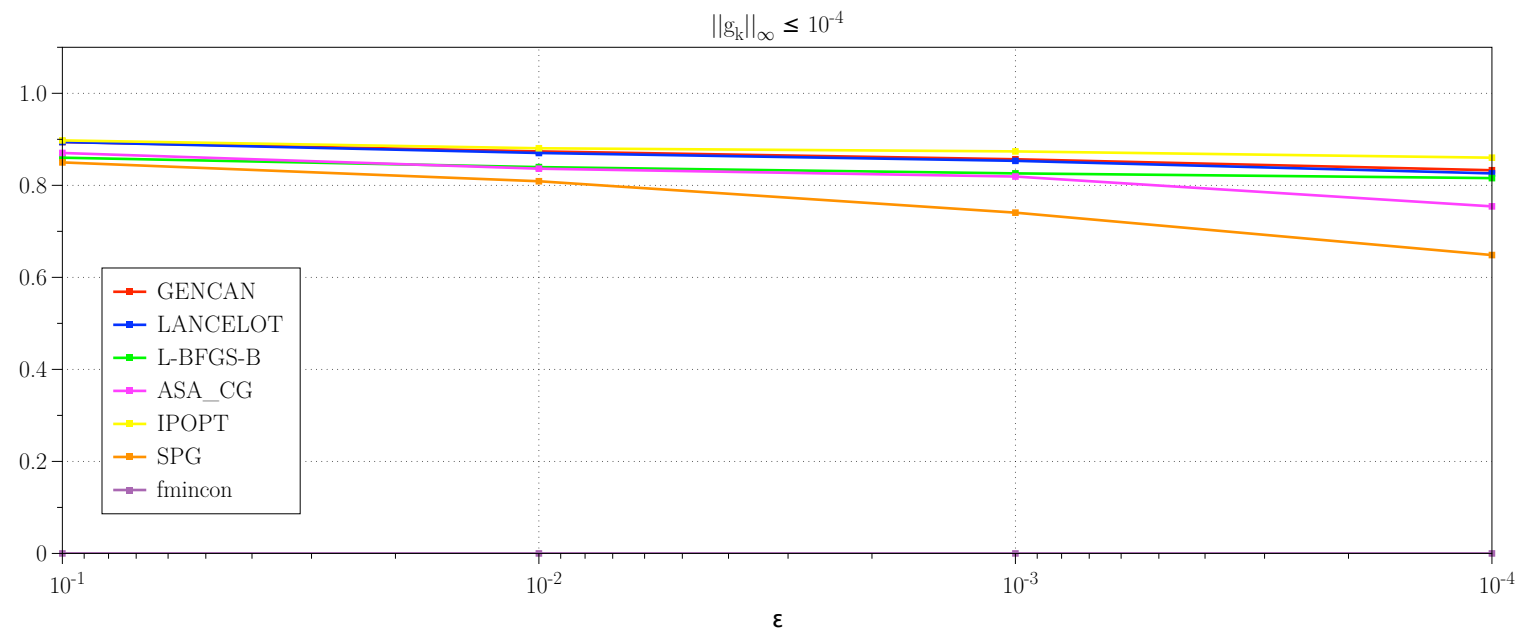

(a)

tolerâncias $\varepsilon$ cada vez mais estritas. A exemplo do que já foi feito anteriormente, construiuse um par de gráficos para cada valoração de $\epsilon$ no conjunto $\left\{10^{-8}, 10^{-7}, 10^{-6}, 10^{-5}, 10^{-4}\right\}$, em que $\epsilon$ denota a maior tolerância aceitável para a norma infinito do gradiente projetado:

$$
\left\|g_{k}\right\|_{\infty} \leq \epsilon
$$

É imprescindível observar ainda que não carregaria nenhum significado a utilização de tolerâncias do critério de equivalência entre soluções $(\varepsilon)$ mais rigorosas que a própria precisão pedida sobre a norma infinito do gradiente projetado $(\epsilon)$. Por essa razão, a seguinte desigualdade foi respeitada na prospecção dos resultados aqui reunidos:

$$
\varepsilon \geq \epsilon
$$




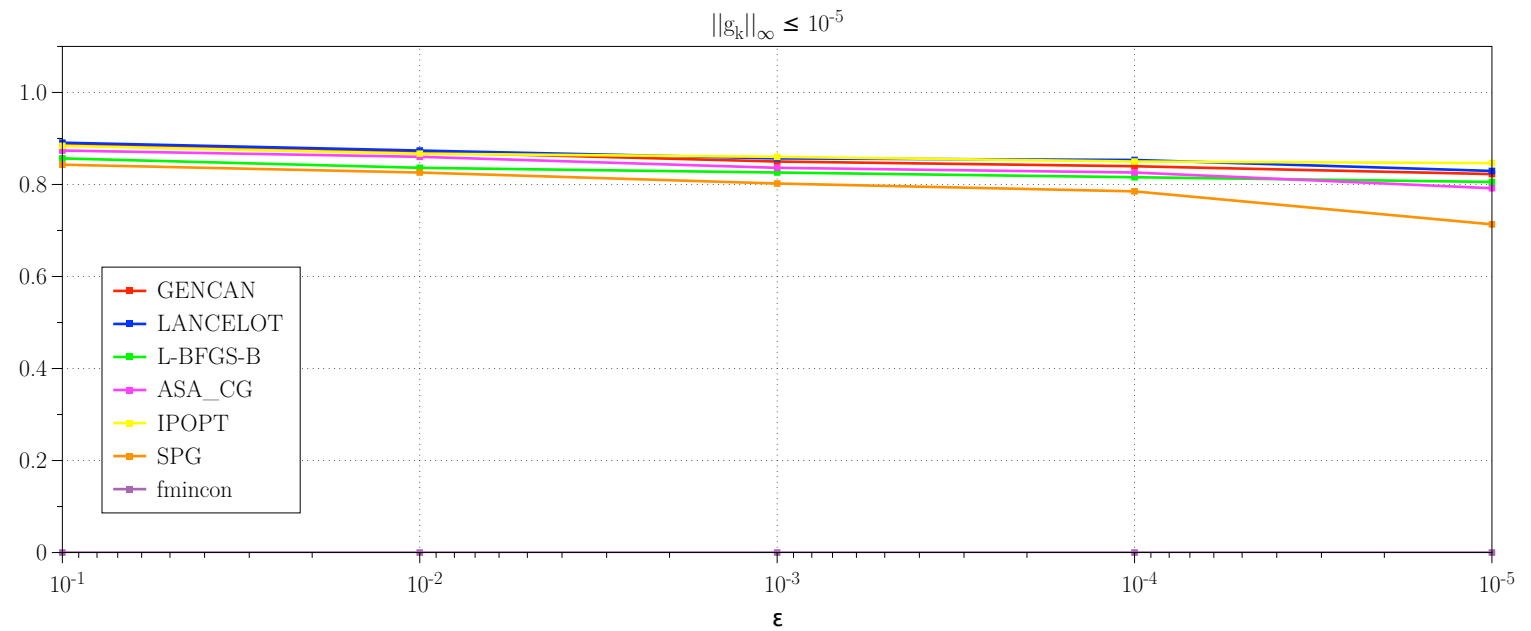

(b)

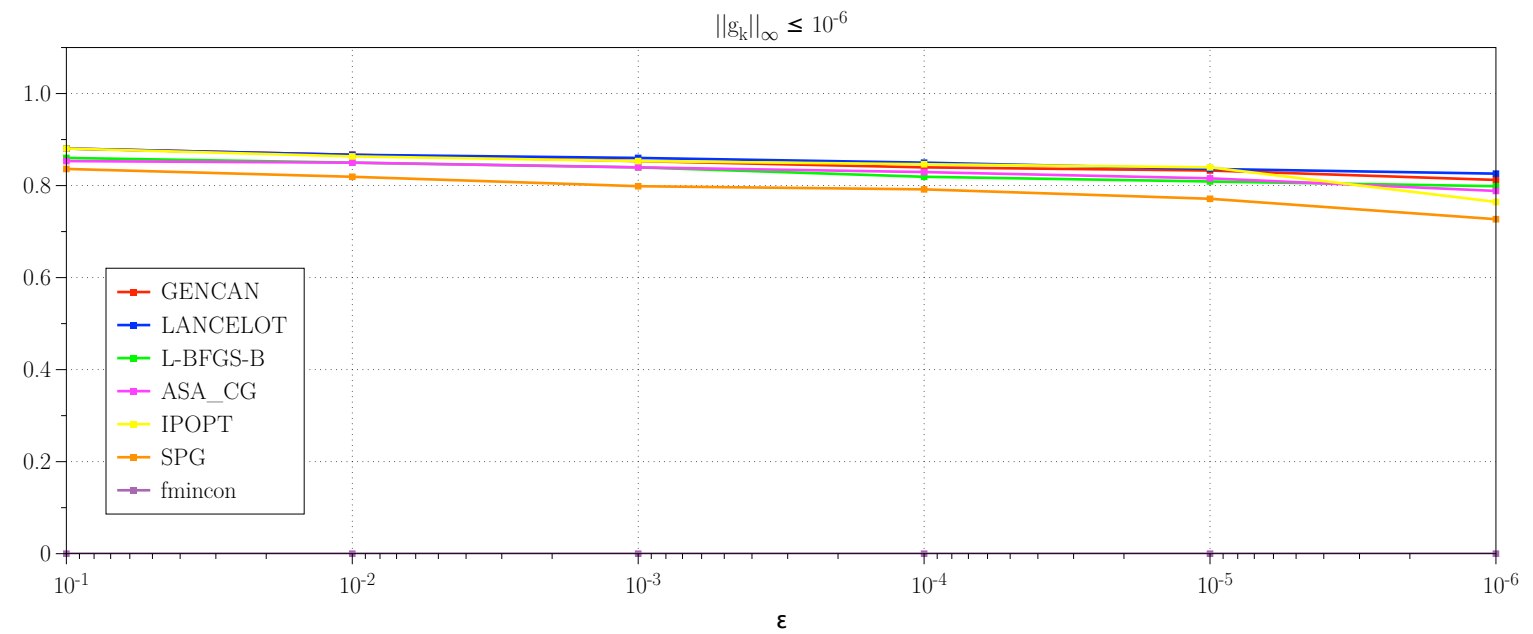

(c)

$\left\|\mathrm{g}_{\mathrm{k}}\right\|_{\infty} \leq 10^{-7}$

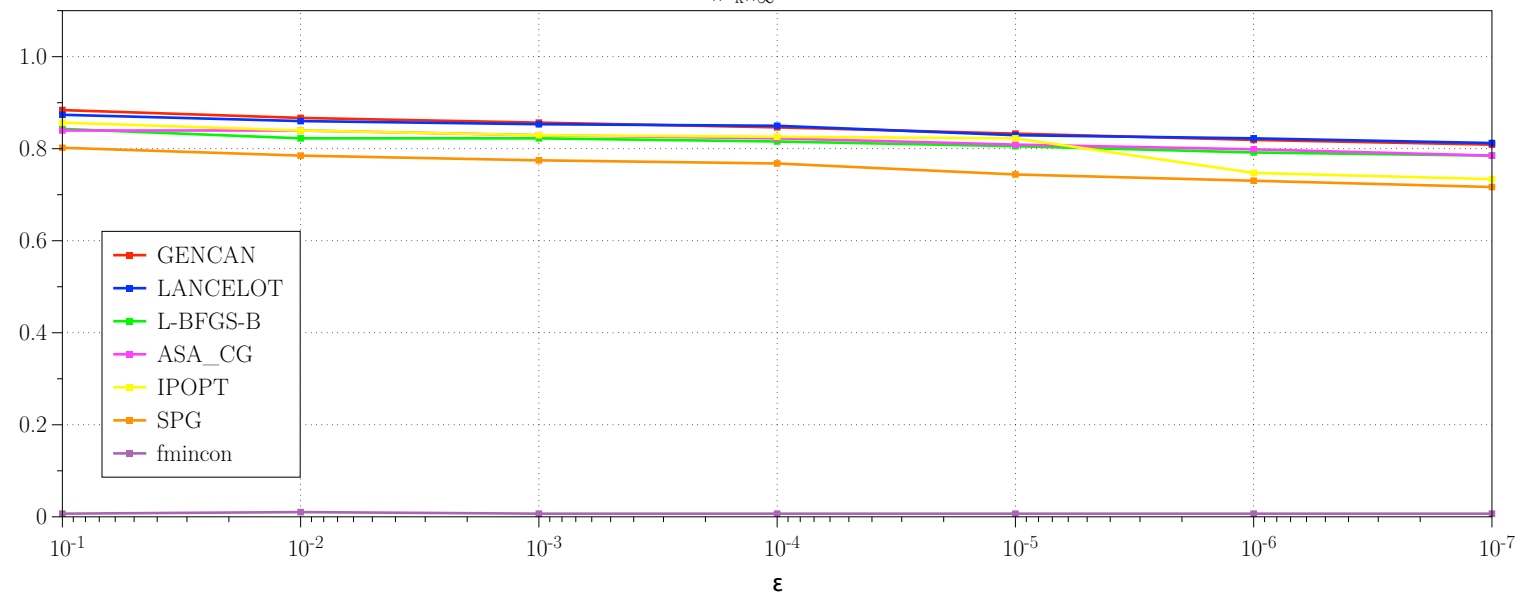

(d) 


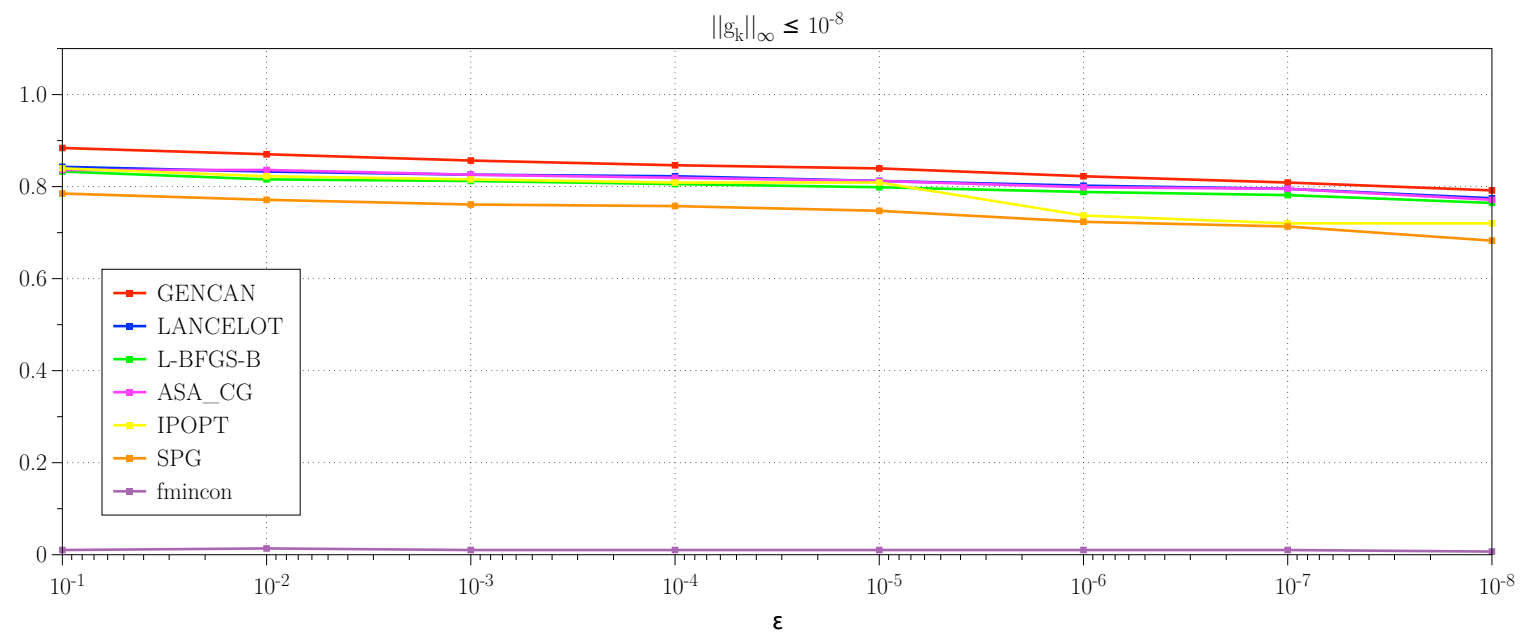

(e)

Figura 6.3: Gráficos da variação de eficiência dos diversos métodos testados segundo a tolerância adotada no critério de otimalidade e para diferentes critérios de convergência

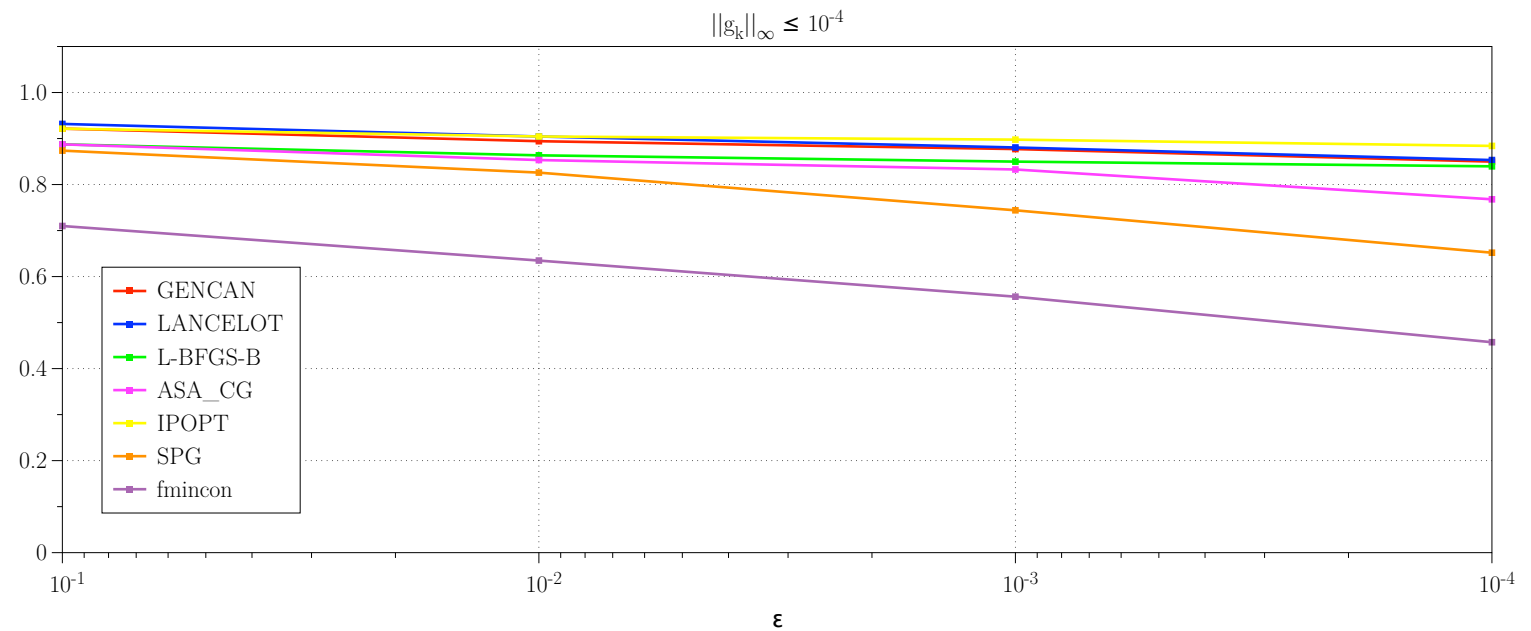

(a) 
$\left\|g_{k}\right\|_{\infty} \leq 10^{-5}$

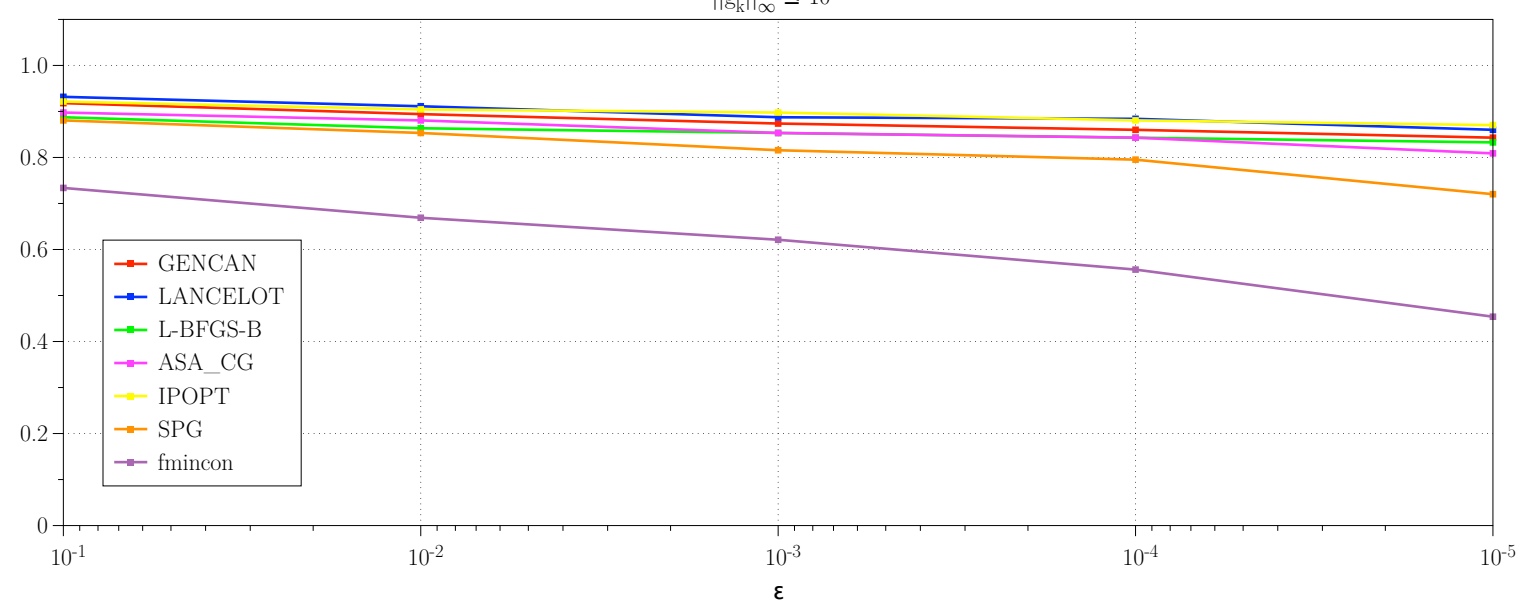

(b)

$\left\|g_{k}\right\|_{\infty} \leq 10^{-6}$

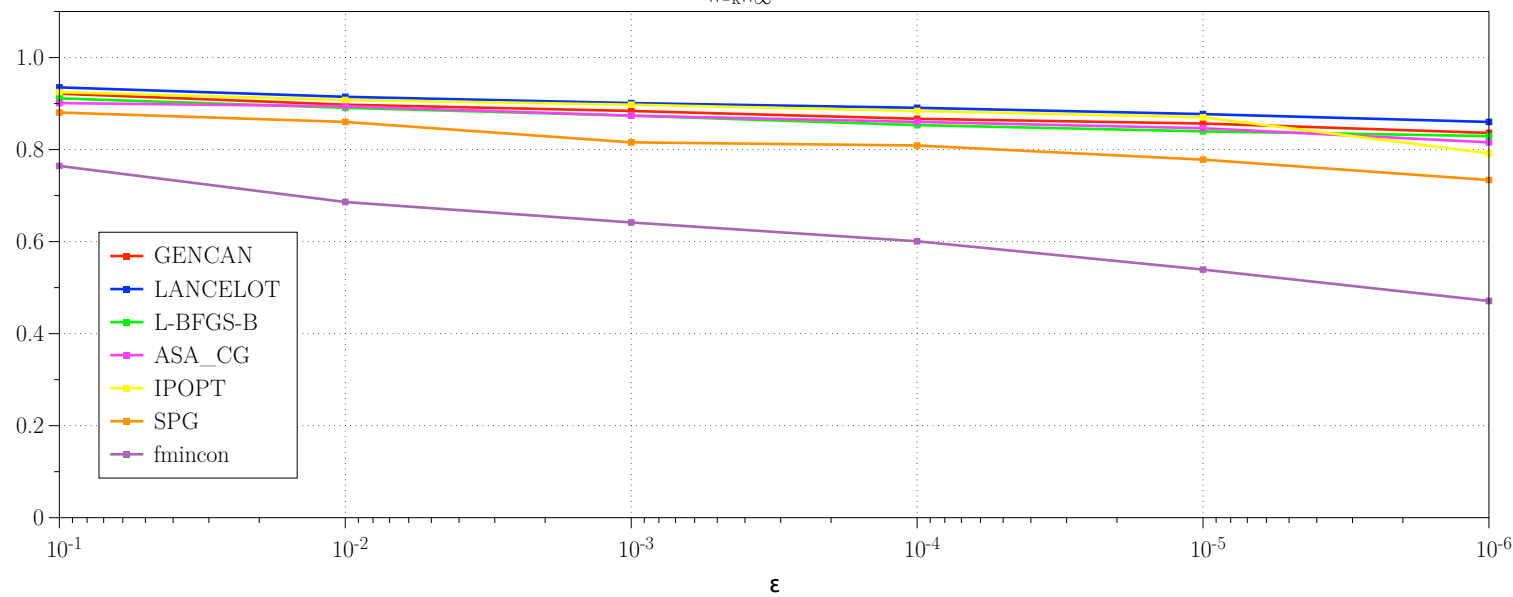

(c)

$\left\|\mathrm{g}_{\mathrm{k}}\right\|_{\infty} \leq 10^{-7}$

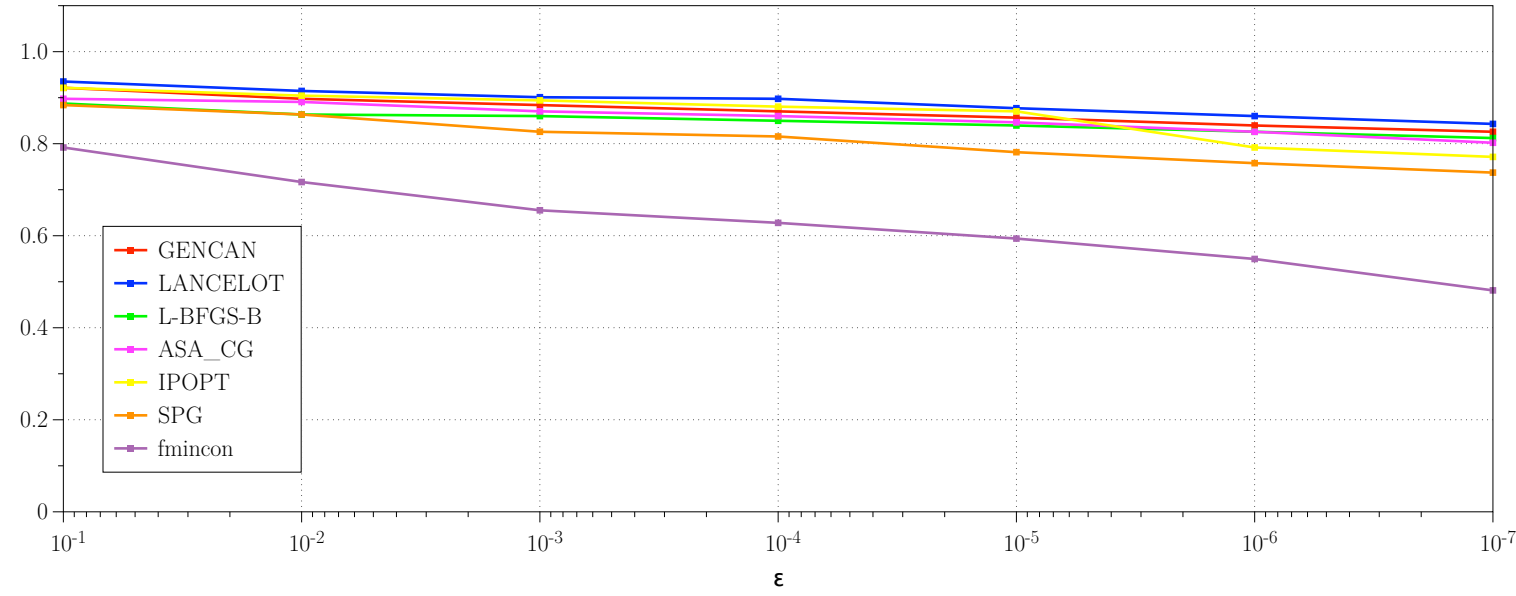

(d) 


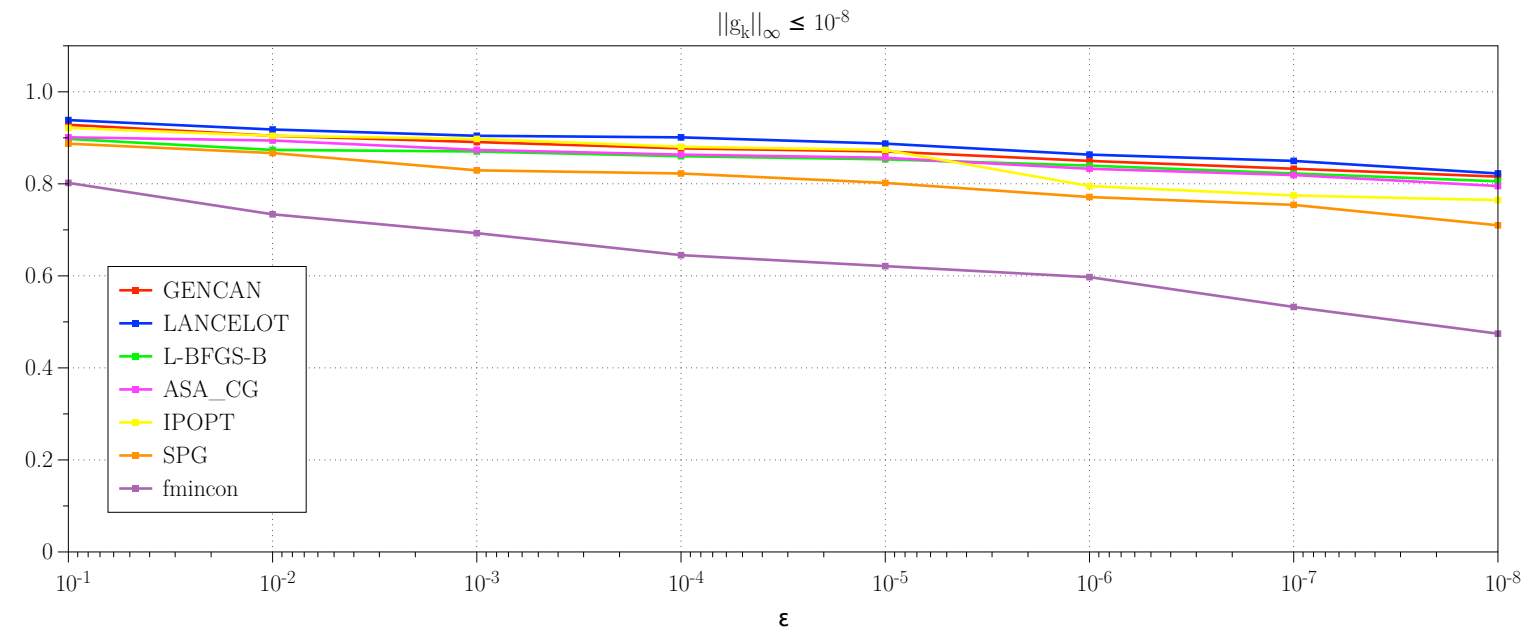

(e)

Figura 6.4: Gráficos da variação de robustez dos diversos métodos testados segundo a tolerância adotada no critério de otimalidade e para diferentes critérios de convergência 


\begin{tabular}{|c|c|c|c|c|c|c|c|c|c|c|}
\hline \multirow[b]{2}{*}{$\varepsilon=$} & \multicolumn{5}{|c|}{ Eficiência } & \multicolumn{5}{|c|}{ Robustez } \\
\hline & $10^{-4}$ & $10^{-5}$ & $10^{-6}$ & $10^{-7}$ & $10^{-8}$ & $10^{-4}$ & $10^{-5}$ & $10^{-6}$ & $10^{-7}$ & $10^{-8}$ \\
\hline \multicolumn{11}{|l|}{ GENCAN } \\
\hline$\epsilon=10^{-4}$ & 0,8328 & - & - & - & - & 0,8498 & - & - & - & - \\
\hline$\epsilon=10^{-5}$ & 0,8396 & 0,8225 & - & - & - & 0,8601 & 0,8430 & - & - & - \\
\hline$\epsilon=10^{-6}$ & 0,8396 & 0,8328 & 0,8123 & - & - & 0,8669 & 0,8567 & 0,8362 & - & - \\
\hline$\epsilon=10^{-7}$ & 0,8464 & 0,8328 & 0,8191 & 0,8089 & - & 0,8703 & 0,8567 & 0,8396 & 0,8259 & - \\
\hline$\epsilon=10^{-8}$ & 0,8464 & 0,8396 & 0,8225 & 0,8089 & 0,7918 & 0,8771 & 0,8703 & 0,8498 & 0,8328 & 0,8157 \\
\hline \multicolumn{11}{|l|}{ LANCELOT } \\
\hline$\epsilon=10^{-4}$ & 0,8259 & - & - & - & - & 0,8532 & - & - & - & - \\
\hline$\epsilon=10^{-5}$ & 0,8532 & 0,8294 & - & - & - & 0,8840 & 0,8601 & - & - & - \\
\hline$\epsilon=10^{-6}$ & 0,8498 & 0,8362 & 0,8259 & - & - & 0,8908 & 0,8771 & 0,8601 & - & - \\
\hline$\epsilon=10^{-7}$ & 0,8498 & 0,8294 & 0,8225 & 0,8123 & - & 0,8976 & 0,8771 & 0,8601 & 0,8430 & - \\
\hline$\epsilon=10^{-8}$ & 0,8225 & 0,8123 & 0,8020 & 0,7952 & 0,7747 & 0,9010 & 0,8874 & 0,8635 & 0,8498 & 0,8225 \\
\hline \multicolumn{11}{|c|}{ L-BFGS-B } \\
\hline$\epsilon=10^{-4}$ & 0,8157 & - & - & - & - & 0,8396 & - & - & - & - \\
\hline$\epsilon=10^{-5}$ & 0,8157 & 0,8055 & - & - & - & 0,8430 & 0,8328 & - & - & - \\
\hline$\epsilon=10^{-6}$ & 0,8191 & 0,8089 & 0,7986 & - & - & 0,8532 & 0,8396 & 0,8294 & - & - \\
\hline$\epsilon=10^{-7}$ & 0,8157 & 0,8055 & 0,7918 & 0,7850 & - & 0,8498 & 0,8396 & 0,8259 & 0,8123 & - \\
\hline$\epsilon=10^{-8}$ & 0,8055 & 0,7986 & 0,7884 & 0,7816 & 0,7645 & 0,8601 & 0,8532 & 0,8396 & 0,8225 & 0,8055 \\
\hline \multicolumn{11}{|l|}{ ASA } \\
\hline$\epsilon=10^{-4}$ & 0,7543 & - & - & - & - & 0,7679 & - & - & - & - \\
\hline$\epsilon=10^{-5}$ & 0,8259 & 0,7918 & - & - & - & 0,8430 & 0,8089 & - & - & - \\
\hline$\epsilon=10^{-6}$ & 0,8294 & 0,8157 & 0,7884 & - & - & 0,8601 & 0,8464 & 0,8157 & - & - \\
\hline$\epsilon=10^{-7}$ & 0,8225 & 0,8089 & 0,7986 & 0,7850 & - & 0,8601 & 0,8464 & 0,8259 & 0,8020 & - \\
\hline$\epsilon=10^{-8}$ & 0,8191 & 0,8123 & 0,7986 & 0,7952 & 0,7713 & 0,8635 & 0,8567 & 0,8328 & 0,8191 & 0,7952 \\
\hline \multicolumn{11}{|l|}{ IPOPT } \\
\hline$\epsilon=10^{-4}$ & 0,8601 & - & - & - & - & 0,8840 & - & - & - & - \\
\hline$\epsilon=10^{-5}$ & 0,8498 & 0,8464 & - & - & - & 0,8805 & 0,8703 & - & - & - \\
\hline$\epsilon=10^{-6}$ & 0,8464 & 0,8396 & 0,7645 & - & - & 0,8840 & 0,8703 & 0,7918 & - & - \\
\hline$\epsilon=10^{-7}$ & 0,8259 & 0,8225 & 0,7474 & 0,7338 & - & 0,8805 & 0,8703 & 0,7918 & 0,7713 & - \\
\hline$\epsilon=10^{-8}$ & 0,8089 & 0,8089 & 0,7372 & 0,7201 & 0,7201 & 0,8805 & 0,8737 & 0,7952 & 0,7747 & 0,7645 \\
\hline \multicolumn{11}{|c|}{ SPG } \\
\hline$\epsilon=10^{-4}$ & 0,6485 & - & - & - & - & 0,6519 & - & - & - & - \\
\hline$\epsilon=10^{-5}$ & 0,7850 & 0,7133 & - & - & - & 0,7952 & 0,7201 & - & - & - \\
\hline$\epsilon=10^{-6}$ & 0,7918 & 0,7713 & 0,7270 & - & - & 0,8089 & 0,7782 & 0,7338 & - & - \\
\hline$\epsilon=10^{-7}$ & 0,7679 & 0,7440 & 0,7304 & 0,7167 & - & 0,8157 & 0,7816 & 0,7577 & 0,7372 & - \\
\hline$\epsilon=10^{-8}$ & 0,7577 & 0,7474 & 0,7235 & 0,7133 & 0,6826 & 0,8225 & 0,8020 & 0,7713 & 0,7543 & 0,7099 \\
\hline \multicolumn{11}{|l|}{ fmincon } \\
\hline$\epsilon=10^{-4}$ & 0,0000 & - & - & - & - & 0,4573 & - & - & - & - \\
\hline$\epsilon=10^{-5}$ & 0,0000 & 0,0000 & - & - & - & 0,5563 & 0,4539 & - & - & - \\
\hline$\epsilon=10^{-6}$ & 0,0000 & 0,0000 & 0,0000 & - & - & 0,6007 & 0,5392 & 0,4710 & - & - \\
\hline$\epsilon=10^{-7}$ & 0,0068 & 0,0068 & 0,0068 & 0,0068 & - & 0,6280 & 0,5939 & 0,5495 & 0,4812 & - \\
\hline$\epsilon=10^{-8}$ & 0,0102 & 0,0102 & 0,0102 & 0,0102 & 0,0068 & 0,6451 & 0,6212 & 0,5973 & 0,5324 & 0,4744 \\
\hline
\end{tabular}

Tabela 6.5: Valores de eficiência e robustez dos diversos métodos testados segundo a tolerância adotada no critério de otimalidade e para diferentes critérios de convergência 
Da atenta análise das Figuras 6.3 e 6.4, pode-se chegar a relevantes conclusões. Primeiramente, fica claro que métodos que se valem de informações de segunda ordem, como GENCAN e LANCELOT B, beneficiam-se quanto maior for a precisão deles requerida na obtenção de um minimizador local (no sentido de tornar a norma infinito do gradiente projetado suficientemente pequena). Já algoritmos que se caracterizam por explorar apenas informações de primeria ordem do problema tratado podem se destacar ao, afrouxando-se o critério de convergência (e, naturalmente, o rigor com que suas soluções serão comparadas), proverem soluções "ótimas" (entre as obtidas) tão ou até mais rapidamente que seus concorrentes.

Esse é um traço que também pode ser muito claramente observado para IPOPT com auxílio da Tabela 6.5, que agrega os valores numéricos representados nos gráficos. Por meio dela, é possível constatar que IPOPT, para valores de $\epsilon$ e $\varepsilon$ iguais a $10^{-4}$, supera GENCAN e LANCELOT B tanto no que diz respeito à eficiência $(0,8601$ vs. 0,8328 e 0,8259 , respectivamente) quanto à robustez (0,8840 vs. 0,8498 e 0,8532 , respectivamente), ao passo que fica atrás de ambos segundo os mesmos critérios para valores de $\epsilon$ e $\varepsilon$ iguais a $10^{-8}$.

Entre os métodos que apresentam maiores eficiência e robustez, alternam-se GENCAN e LANCELOT B. A partir da análise da Tabela 6.5 para valores de $\varepsilon$ iguais a $\epsilon$, é possível afirmar que GENCAN se mostra consistentemente mais eficiente que LANCELOT B ( 0,8328 vs. 0,8259 e 0,7918 vs. 0,7747 , por exemplo), enquanto esse exibe maior robustez que aquele $(0,8532$ vs. 0,8498 ou ainda 0,8225 vs. 0,8157$)$. Entretanto, tal diferença é irrisória na tentativa de se estabelecer a superioridade de um perante o outro.

Cabe ainda tentar jogar luz sobre o desempenho de fmincon, à primeira vista bastante inferior em relação aos demais. Por meio do monitoramento de sua execução, é possível perceber que estão nele implementadas muitas verificações que buscam detectar pequenas reduções na taxa de progresso a cada iteração e, nesse caso, interromper sua execução, quase sempre em mãos de um ponto em que o valor de função será amplamente superado por seus competidores. Porém, há de se compreender que essas foram opções feitas durante a concepção do algoritmo que não podem ser intrinsecamente classificadas como positivas ou negativas, mas apenas não tornam o método vantajoso face a nossa métrica de comparação, que também é arbitrária.

Tal caráter arbitrário, inerente a qualquer comparação que se venha a realizar, fica evidenciado pelas ponderações feitas nos parágrafos anteriores. Por essa razão, e também por não ser possível notar nos gráficos das Figuras 6.3 e 6.4 nenhuma diferença patente entre o desempenho relativo dos métodos conforme se varia o valor de $\varepsilon$, todos os 


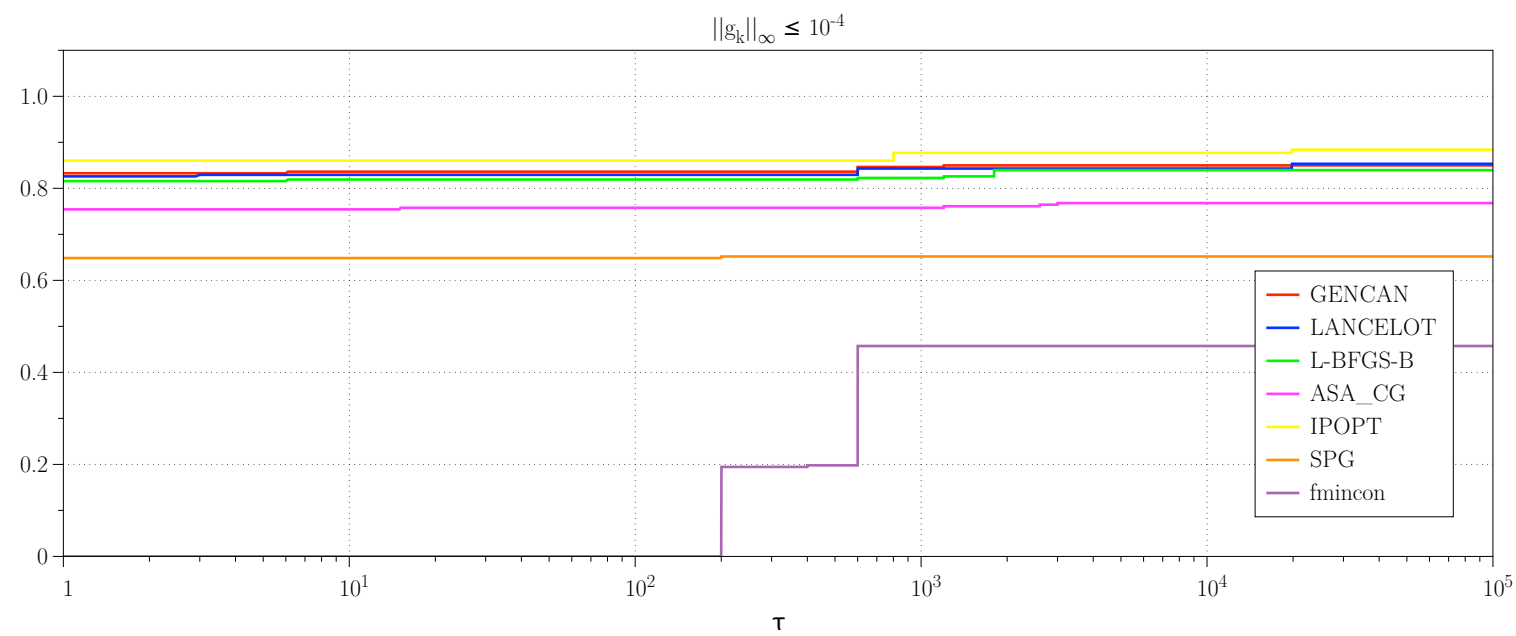

(a)

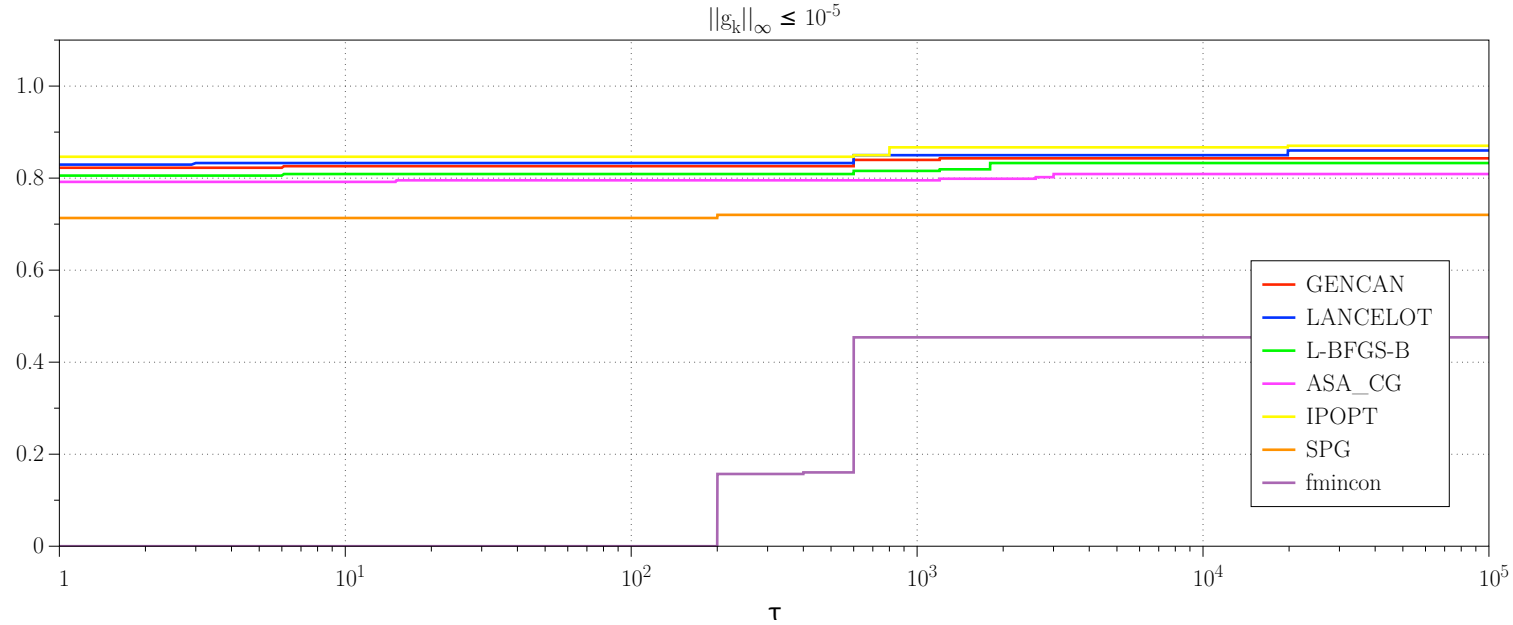

(b)

resultados inseridos a partir deste ponto foram obtidos tomando-se tolerâncias do critério de equivalência entre soluções iguais à precisão pedida sobre a norma infinito do gradiente projetado, isto é:

$$
\varepsilon=\epsilon
$$

Finalmente, são apresentados na Figura 6.5 gráficos de perfil de desempenho dos diversos métodos testados para cada um dos diferentes critérios de convergência. Quanto ao desempenho comparativo de GENCAN, é pertinente observar que figura tanto entre os mais eficientes quanto entre os mais robustos qualquer que seja a tolerância adotada para a norma infinito do gradiente projetado. Ademais, nos poucos casos em que curva que o descreve não domina todas as demais, é possível afirmar que essa diferença não 


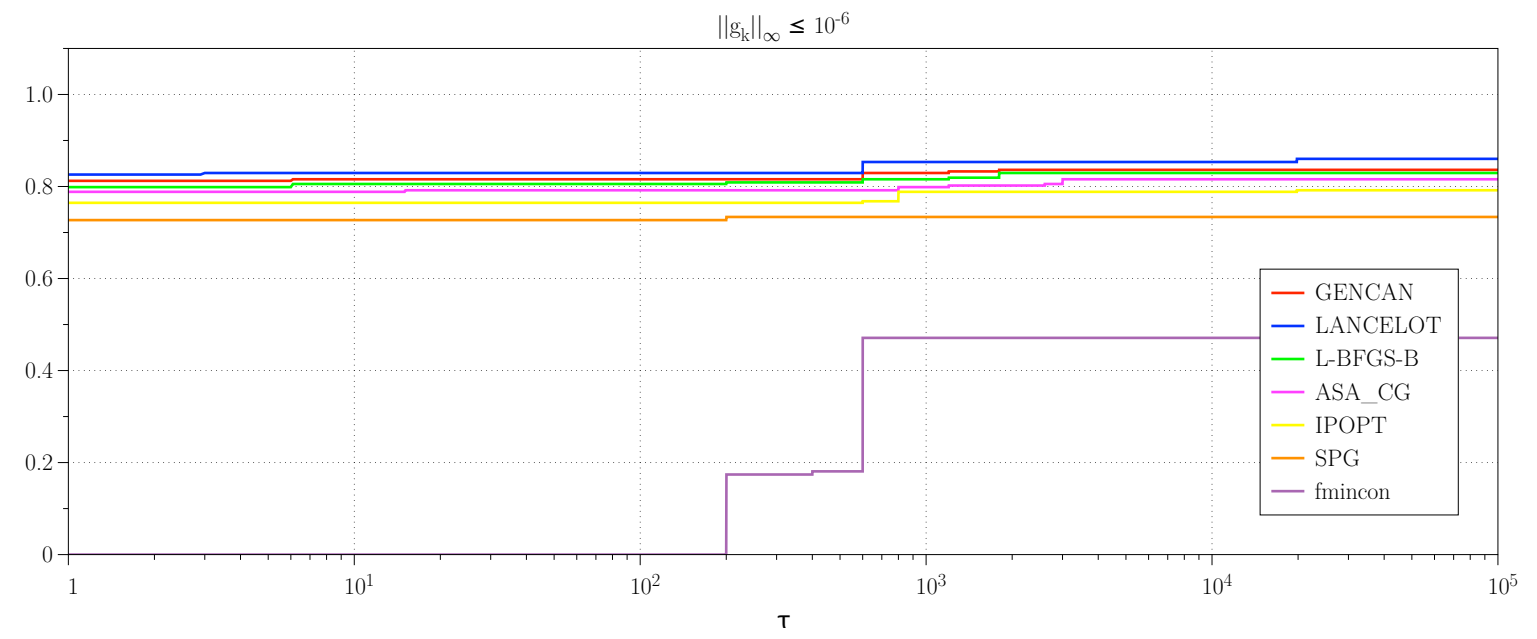

(c)

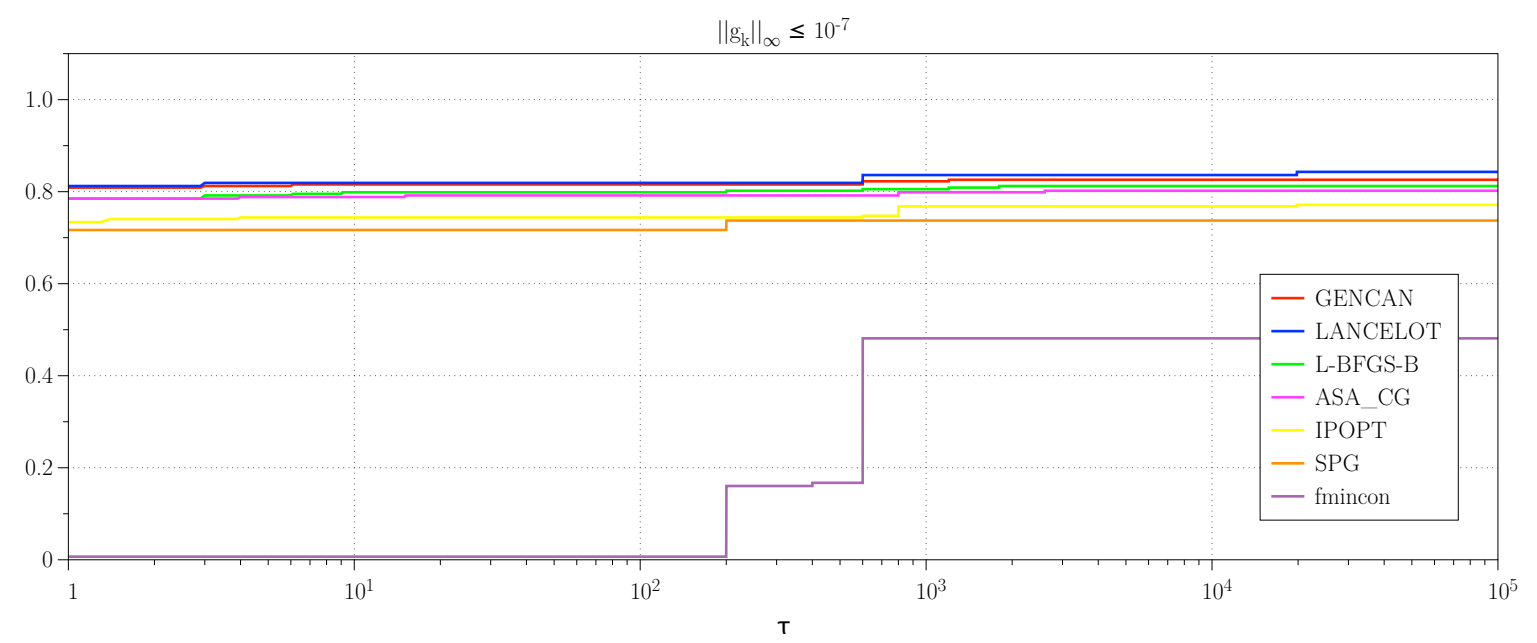

(d) 


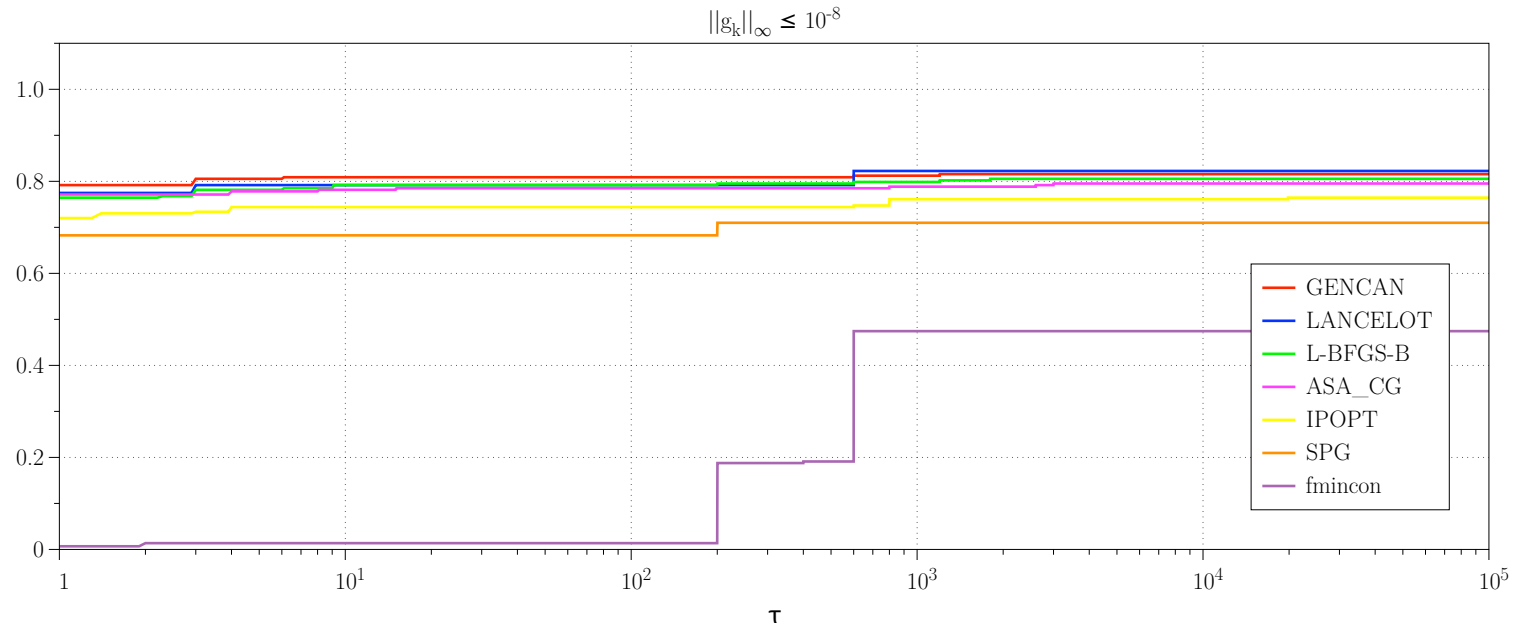

(e)

Figura 6.5: Gráficos de perfil de desempenho dos diversos métodos testados com o tempo de processamento consumido como medida de comparação empregada.

ultrapassa a marca de $2 \%$, colocando-o em posição de igualdade aos mais bem conceituados e estabelecidos métodos da atualidade. 


\section{Capítulo 7}

\section{Conclusão}

Sendo tanto ASA quanto GENCAN modernos métodos de restrições ativas para problemas de otimização em caixas que vêm passando por aprimoramentos constantes, este trabalho teve por objetivos estudá-los, compará-los e extrair conclusões que levassem à melhoria do segundo.

\subsection{Contribuições}

Entre as contribuições mais relevantes deste trabalho, estão:

- A elaboração de uma metodologia de testes que busca sanar alguns dos aspectos mais controversos no campo de medição de desempenho, tais como:

- aferição do tempo;

- critério de equivalência entre valores de função;

- forma de representação dos resultados.

- A incorporação de diversos aprimoramentos a GENCAN, com especial destaque dado a:

- disponibilização de novos algoritmos a serem empregados internamente às faces;

- concepção de uma estratégia de escolha automática entre eles;

- implementação de um novo critério de parada secundário;

- padronização do recurso de escalamento do sistema linear.

- Comprovação por meio da metodologia aqui introduzida do sensível ganho de desempenho acarretado em GENCAN após a realização das modificações propostas. 
- Disponibilização da nova versão de GENCAN na distribuição mais recente de Algencan, um moderno algoritmo de Lagrangianos Aumentados para minimização suave e restrita, introduzido em [1] e acessível por meio do Projeto TANGO [2]. 


\section{Referências Bibliográficas}

[1] R. Andreani, E. G. Birgin, J. M. Martínez, and M. L. Schuverdt, On Augmented Lagrangian methods with general lower-level constraints, SIAM Journal on Optimization 18 (2007), 1286-1309.

[2] E. G. Birgin and J. M. Martínez, Projeto TANGO (December 21, 2009), available at http://www. ime.usp.br/ egbirgin/tango.

[3] R. Andreani, E. G. Birgin, J. M. Martínez, and M. L. Schuverdt, Second-order negative-curvature methods for box-constrained and general constrained optimization, Computational Optimization and Applications (2009), por aparecer.

[4] M. Andretta, E. G. Birgin, and J. M. Martínez, Practical active-set Euclidian trust-region method with spectral projected gradients for bound-constrained minimization, Optimization 54 (2005), 305-325.

[5] M. Andretta, E. G. Birgin, and J. M. Martínez, Partial Spectral Projected Gradient Method with Active-Set Strategy for Linearly Constrained Optimization, Numerical Algorithms 53 (2010), 23-52.

[6] E. G. Birgin, R. Biloti, M. Tygel, and L. T. Santos, Restricted optimization: a clue to a fast and accurate implementation of the Common Reflection Surface method, Journal of Applied Geophysics 42 (1999), 143-155.

[7] E. G. Birgin, E. V. Castelani, A. L. M. Martinez, and J. M. Martínez, Outer Trust-Region method for Constrained Optimization (2009), submetido.

[8] E. G. Birgin, I. Chambouleyron, and J. M. Martínez, Estimation of the optical constants and the thickness of thin films using unconstrained optimization, Journal of Computational Physics $\mathbf{1 5 1}$ (1999), 862-880.

[9] E. G. Birgin and J. M. Martínez, A box-constrained optimization algorithm with negative curvature directions and spectral projected gradients, Computing [Suppl] 15 (2001), 49-60.

[10] E. G. Birgin and J. M. Martínez, Large-scale active-set box-constrained optimization method with spectral projected gradients, Computational Optimization and Applications 23 (2002), 101-125.

[11] E. G. Birgin, J. M. Martínez, and M. Raydan, Nonmonotone spectral projected gradient methods on convex sets, SIAM Journal on Optimization 10 (2000), 1196-1211.

[12] E. G. Birgin, J. M. Martínez, and M. Raydan, SPG: Software for convex-constrained optimization, ACM Transactions on Mathematical Software 27 (2001), 340-349.

[13] I. Bongartz, A. R. Conn, N. I. M. Gould, and Ph. L. Toint, CUTE: constrained and unconstrained testing environment, ACM Transactions on Mathematical Software 21 (1995), 123-160.

[14] O. Burdakov, J. M. Martínez, and E. A. Pilotta, A limited memory multipoint secant method for bound constrained optimization, Annals of Operations Research 117 (2002), 51-70.

[15] R. H. Byrd, P. Lu, J. Nocedal, and C. Zhu, A Limited Memory Algorithm for Bound Constrained Optimization, SIAM Journal on Scientific and Statistical Computing 16 (1995), 1190-1208.

[16] T. F. Coleman and Y. Li, An interior trust region approach for nonlinear minimization subject to bounds, SIAM Journal on Optimization 6 (1996), 418-445. 
[17] T. F. Coleman and Y. Li, A Subspace, Interior, and Conjugate Gradient Method for Large-Scale Bound-Constrained Minimization Problems, SIAM Journal on Scientific Computing 21 (1999), 1-23.

[18] A. R. Conn, N. I. M. Gould, and Ph. L. Toint, Global convergence of a class of trust region algorithms for optimization with simple bounds, SIAM Journal on Numerical Analysis 25 (1988), 433-460.

[19] A. R. Conn, N. I. M. Gould, and Ph. L. Toint, A globally convergent augmented Lagrangian algorithm for optimization with general constraints and simple bounds, SIAM Journal on Numerical Analysis 28 (1991), 545-572.

[20] A. R. Conn, N. I. M. Gould, and Ph. L. Toint, LANCELOT: a Fortran package for large-scale nonlinear optimization (Release A), Springer Series in Computational Mathematics, vol. 17, SpringerVerlag, New York, 1992.

[21] Y. H. Dai, W. W. Hager, K. Schittkowski, and H. Zhang, The cyclic Barzilai-Borwein method for unconstrained optimization, IMA Journal of Numerical Analysis 26 (2006), 604-627.

[22] R. S. Dembo and U. Tulowitzki, On the Minimization of Quadratic Functions Subject to Box Constraints, Yale University, New Haven, 1983.

[23] E. D. Dolan and J. J. Moré, Benchmarking optimization software with performance profiles, Mathematical Programming 91 (2002), 101-213.

[24] Z. Dostál, Box constrained quadratic programming with proportioning and projections, SIAM Journal on Optimization 7 (1997), 871-887.

[25] Z. Dostál, A proportioning based algorithm for bound constrained quadratic programming with the rate of convergence, Numerical Algorithms 34 (2003), 293-302.

[26] Z. Dostál, A. Friedlander, and S. A. Santos, Solution of coercive and semicoercive contact problems by FETI domain decomposition, Contemporary Mathematics 218 (1998), 82-93.

[27] Z. Dostál, A. Friedlander, and S. A. Santos, Augmented Lagrangians with adaptive precision control for quadratic programming with simple bounds and equality constraints, SIAM Journal on Optimization 13 (2003), 1120-1140.

[28] F. Facchinei and S. Lucidi, A class of penalty functions for optimization problems with bound constraints, Optimization 26 (1992), 239-259.

[29] A. Friedlander, J. M. Martínez, and S. A. Santos, A new trust region algorithm for bound constrained minimization, Applied Mathematics Optimization 30 (1994), 235-266.

[30] R. Glowinski, Numerical Methods for Nonlinear Variational Problems, Springer-Verlag, New York, 1984.

[31] W. Glunt, T. L. Hayden, and M. Raydan, Molecular conformations from distance matrices, Journal of Computational Chemistry 14 (1993), 114-120.

[32] CPU Time Inquiry, The GNU C Library Manual, GNU Project, May 20, 2009, available at http: //www.gnu.org/s/libc/manual/html_node/CPU-Time.html.

[33] W. W. Hager, Dual techniques for constrained optimization, Journal of Optimization Theory and Applications 55 (1987), 37-71.

[34] W. W. Hager, Analysis and implementation of a dual algorithm for constrained optimization, Journal of Optimization Theory and Applications 79 (1993), 427-462.

[35] W. W. Hager and H. Zhang, CG_DESCENT User's Guide, University of Florida, Gainesville, 2004.

[36] W. W. Hager and H. Zhang, A new conjugate gradient method with guaranteed descent and an efficient line search, SIAM Journal on Optimization 16 (2005), 170-192.

[37] W. W. Hager and H. Zhang, A survey of nonlinear conjugate gradient methods, Pacific Journal of Optimization 2 (2006), 35-58. 
[38] W. W. Hager and H. Zhang, Algorithm 851: CG_DESCENT, a conjugate gradient method with guaranteed descent, ACM Transactions on Mathematical Software 32 (2006), 113-137.

[39] W. W. Hager and H. Zhang, A new active set algorithm for box constrained optimization, SIAM Journal on Optimization 17 (2006), 526-557.

[40] HSL, A collection of Fortran codes for large scale scientific computation (2007), available at http: //www.numerical.rl.ac.uk/hsl.

[41] D. G. Luenberger, Linear and Nonlinear Programming, Addison-Wesley, Massachusetts, 2003.

[42] J. M. Martínez, BOX-QUACAN and the implementation of augmented Lagrangian algorithms for minimization with inequality constraints, Computation and Applied Mathematics 19 (2000), 31-56.

[43] J. J. Moré and G. Toraldo, On the solution of large quadratic programming problems with bound constraints, SIAM Journal on Optimization 1 (1991), 93-113.

[44] B. T. Polyak, The conjugate gradient method in extremal problems, USSR Computational Mathematics and Mathematical Physics 9 (1969), 94-112.

[45] A. Wächter and L. T. Biegler, On the Implementation of a Primal-Dual Interior Point Filter Line Search Algorithm for Large-Scale Nonlinear Programming, Mathematical Programming 106 (2006), $25-57$.

[46] S. J. Wright, Implementing proximal point methods for linear programming, Journal of Optimization Theory and Applications 65 (1990), 531-554.

[47] E. K. Yang and J. W. Tolle, A class of methods for solving large convex quadratic programs subject to box constraints, Mathematical Programming 51 (1991), 223-228.

[48] C. Zhu, R. H. Byrd, P. Lu, and J. Nocedal, Algorithm 778: L-BFGS-B, FORTRAN routines for large scale bound constrained optimization, ACM Transactions on Mathematical Software 23 (1997), $550-560$. 